\title{
Realizations of the Triple Point of Sulfur Hexafluoride in Transportable and Refillable Cells
}

\author{
Weston L. Tew ${ }^{1}$ and Klaus N. Quelhas ${ }^{1,2}$ \\ ${ }^{1}$ National Institute of Standards and Technology, \\ Gaithersburg, MD 20899, USA \\ ${ }^{2}$ National Institute of Metrology, Quality and Technology \\ Duque de Caxias, RJ 25250-020, Brazil
}

wtew@ nist.gov

knquelhas@inmetro.gov.br

\begin{abstract}
The Minamata Convention on Mercury has created a near-term need to develop alternative fixed points to replace the mercury triple point (Hg TP) for calibration of standard platinum resistance thermometers (SPRTs) on the International Temperature Scale of 1990 (ITS-90). The sulfur hexafluoride $\left(\mathrm{SF}_{6}\right) \mathrm{TP}$ is a good candidate to provide adequate "drop-in compatible" replacements for the lowest costs. We report our first results of $\mathrm{SF}_{6} \mathrm{TP}$ realizations performed at the National Institute of Standards and Technology (NIST) using a new series of transportable and refillable triple-point cells. The melting curves are presented at various melted fractions $F$ and compared to evaluate the reproducibility and overall uncertainty for the realizations. We obtained a TP temperature of 223.55587(33) K at $F=50 \%$ and 223.55607(35) K at $F=100 \%$ as a weighted average of realizations using two adiabatic-type cells and two immersion-type cells. (Unless otherwise stated, uncertainties are standard uncertainties corresponding to a $68 \%$ confidence level.) Temperatures were derived using a combination of five different SPRTs as calibrated at NIST on the ITS-90. The data were evaluated over a region of the melting plateau for melted fraction $F$ between $30 \% \leq F \leq 80 \%$ with a $0.2 \mathrm{mK}$ wide melting range. The results from the immersion-type cells were used to derive an experimental value for the $\mathrm{SF}_{6} \mathrm{TP}$ static head correction of $-11.6(1.7) \mathrm{mK} / \mathrm{m}$. This value implies an initial slope of the pressure-temperature $(p-T)$ equilibrium melting line of $1.55 \mathrm{MPa} / \mathrm{K}$, which is in agreement with the value predicted via the Clapeyron equation. The uncertainties of these initial $\mathrm{SF}_{6} \mathrm{TP}_{\text {realizations are limited }}$ by uncertainty in the realization of the ITS-90 $(0.25 \mathrm{mK})$ and, to a lesser extent, static pressure head effects and chemical impurities.
\end{abstract}

Key words: fixed point; ITS-90; mercury replacement; phase equilibria; sulfur hexafluoride; temperature standards; triple point.

Accepted: February 6, 2018

Published: July 2, 2018

https://doi.org/10.6028/jres.123.013

\section{Introduction}

The triple point of mercury $(\mathrm{Hg} \mathrm{TP})$ is a defining point $\left(T_{\mathrm{Hg} \text { TP }}=234.3156 \mathrm{~K}\right)$ on the International Temperature Scale of 1990 (ITS-90) [1]. Triple-point cells for use in calibrating standard platinum resistance thermometers (SPRTs) were first developed by Furukawa in the 1980s [2]. The current state-ofthe-art allows these to be used for TP realizations with reproducibilities at the level of $0.1 \mathrm{mK}$ [3]. Several national metrology institutes (NMIs) are capable of producing cells of this quality. A few (i.e., 2 or 3 
worldwide) commercial manufacturers also have the capability to produce high-quality cells, but practical, health, and regulatory issues represent significant impediments to their manufacture, sale, and distribution. Long-term stability considerations dictate the use of high-purity glass cells, while safety and shipping requirements necessitate the use of stainless steel, which compromises the long-term stability through dissolved base metal contamination. Stringent safeguards are put in place at every stage of production, which make Hg TP cells expensive to produce. The purification and filling procedures alone present sufficient risks to limit production of $\mathrm{Hg} \mathrm{TP}$ cells to only a few manufacturers worldwide. Furthermore, new regulations may soon to go into effect that would render commercial production of $\mathrm{Hg} \mathrm{TP}$ cells unviable.

The Mercury Export Ban Act of 2008 (MEBA) was passed by the U.S. Congress and signed into law in October 2008 [4]. Under the law: "Federal agencies are prohibited from conveying, selling or distributing elemental mercury that is under their control or jurisdiction"; and "Export of elemental mercury is prohibited from the United States beginning January 1, 2013." This act followed the actions by many state legislatures restricting or otherwise banning the sale of mercury or products containing significant amounts of mercury.

At the international level, the Minamata Convention on Mercury [5] was signed by approximately 40 countries, including the United States, in 2013. The terms of the full treaty have since taken effect with the required ratifications by 50 countries effective 16 August 2017. From this point forward, the international production and trade of products containing mercury are prohibited by those countries.

One consequence of the state laws already in effect within the United States has been the practical elimination of the market for mercury-in-glass (MIG) thermometers. Once widely used in science and industry, the MIG thermometer was already functionally obsolete as many practical and comparably accurate alternative thermometers have been available in the market for years. The market has already made adjustments for the MIG thermometer phase-outs, and standards specifying their use are likewise being revised or replaced [6].

The situation is completely different, however, for $\mathrm{Hg} \mathrm{TP}$ cells. There are currently no suitable substitute fixed points in production that could readily replace the $\mathrm{Hg} \mathrm{TP}$ as a calibration point for longstem SPRTs. While some NMIs such as the National Institute of Standards and Technology (NIST), which has a stockpile of high-purity mercury, could continue indefinitely to produce Hg TP cells for their own use, distribution by these institutes to other NMIs or commercial customers would be prohibited. While exceptions might be permitted for international comparisons under special temporary export licensing, dissemination would be severely constrained. Moreover, since commercial production of Hg TP cells will most likely cease, private calibration laboratories will be unable to realize the ITS-90 according to the current definition. This will in turn increase their costs of doing business as calibration requirements become more dependent on sending SPRTs out for calibration to NIST or one of the few other laboratories that maintain $\mathrm{Hg}$ TP cells. Eventually, the scarcity of the Hg TP cells will result in economic pressure to find some alternatives for calibration of SPRTs. The identification and development of such alternative fixed points are therefore imperative actions, and NIST can lead this effort by evaluating the technical feasibility for the most promising substitute fixed-point materials.

The general requirements for fixed-point materials are: (a) high chemical stability (i.e., nonreactive); (b) available in high-purity form or otherwise easily purified in the laboratory; and (c) manageable health and safety risks. Material costs can be another factor. In practice, the total cost of ownership for any standard-quality fixed-point cell is overwhelmingly dominated by the labor costs involved in operating and maintaining the related equipment. A fixed-point material that is suitable for packaging as a "drop-in replacement" to existing Hg TP cells, with only a minimal adjustment to bath temperature and heating rates, would result in a minimum replacement cost and the highest probability of market acceptance. A fixed-point material that exhibits narrow and reproducible melting plateaus (e.g., $0.1 \mathrm{mK}$ ), with only a modest degree of supercooling (i.e., $<\approx 1 \mathrm{~K}$ ), would result in the largest extent of scientific acceptance. 
The most readily adaptable fixed-point materials are those with triple points (TPs) between $200 \mathrm{~K}$ and $234 \mathrm{~K}$, allowing the use of conventional refrigerated ethanol/methanol bath technology. This lowtemperature melting condition restricts the potential materials to nonmetals, with $\mathrm{Hg}$ itself being a unique exception among all metals. The stable monoatomic noble gases all have TPs below $200 \mathrm{~K}$ and are thus ruled out for this application. A lower limit of $200 \mathrm{~K}$ also rules out the lighter and more volatile halocarbons. Some of the heavier halocarbons do fit the temperature range criterion; however, these are generally less chemically stable and not readily available in high-purity lots.

When all suitable and readily available substances are reviewed and compared, the two common candidates that stand out as potentially best suited for $\mathrm{Hg} \mathrm{TP}$ replacements are sulfur hexafluoride $\left(\mathrm{SF}_{6}\right)$ and carbon dioxide. Both are nearly chemically inert, readily available in high-purity form, and inexpensive, they have negligible risk to health, and they have TPs just below $(\Delta T=-10.8 \mathrm{~K}$ and $-17.7 \mathrm{~K}$, respectively) the $\mathrm{Hg} \mathrm{TP}$. Between these two candidates, the lower vapor pressures of $\mathrm{SF}_{6}$ present less of an engineering challenge. This work focuses solely on $\mathrm{SF}_{6}$, but studies of $\mathrm{CO}_{2}$ are planned for future work.

\section{Thermophysical Properties of $\mathrm{SF}_{6}$}

Sulfur hexafluoride is a synthesized industrial gas used extensively in the electrical power sector as a high-voltage insulating gas. It is chemically inert under most common conditions and is readily available in high purity at low costs. Guder and Wagner (GW) [7] reviewed the physical properties of $\mathrm{SF}_{6}$ as they pertain to the currently recommended equation of state $(\mathrm{EoS})$ in liquid and vapor phases. A collection of archival determinations of the TP temperature $T_{\mathrm{tp}}$ were tabulated by GW, and we have reproduced that listing here as a plot in Fig. 1. Prior to the 1993 determination of $T_{\mathrm{tp}}=223.554(5) \mathrm{K}$ by Blanke et al. [8], all temperatures reported in the literature were approximately $1 \mathrm{~K}$ colder than the more recent data. The 2002 determination by Funke et al. [9] is $T_{\mathrm{tp}}=223.555(3) \mathrm{K}$, and this value was adopted by $\mathrm{GW}$ for the purposes of their development of the EoS. More recently, Rourke [10] made a direct realization of the $\mathrm{SF}_{6} \mathrm{TP}$ of $T_{\mathrm{tp}}=223.55523(49) \mathrm{K}$ (also shown in Fig. 1), in close agreement with the value of Funke et al.

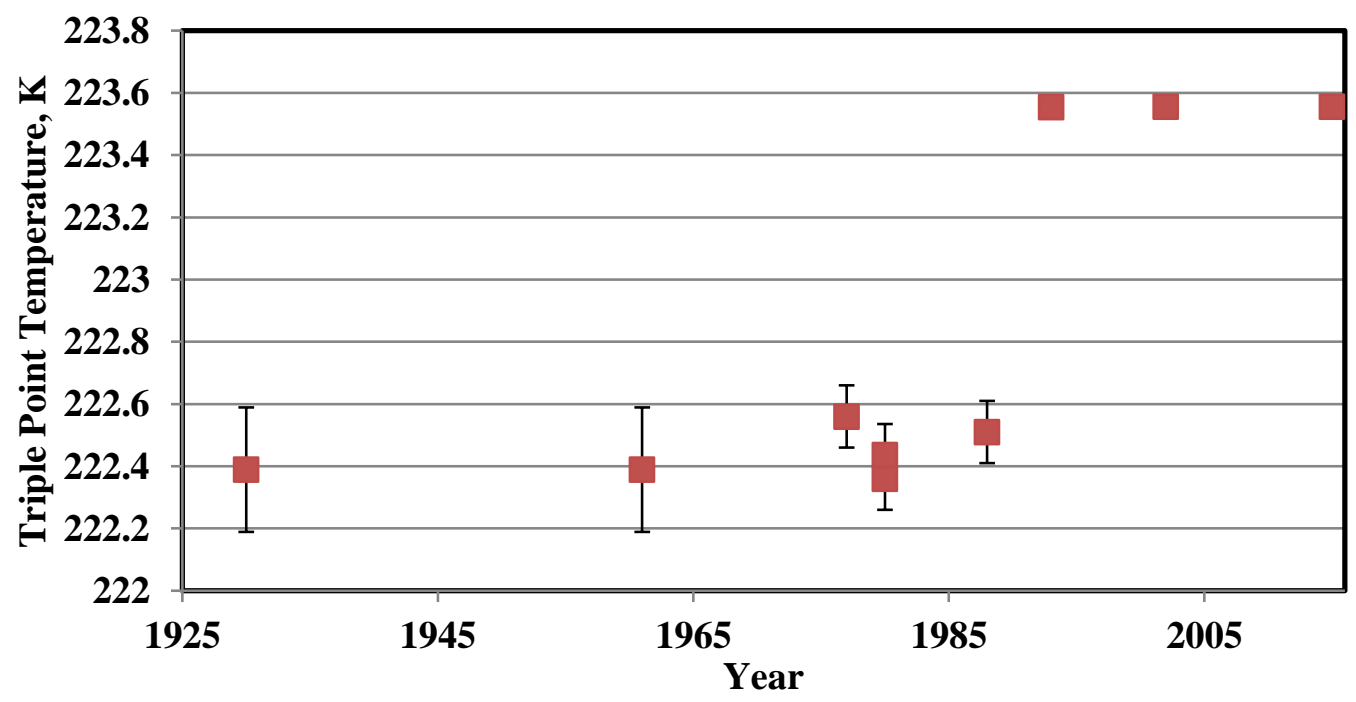

Fig. 1. Published values for the $\mathrm{SF}_{6} \mathrm{TP}$ from the literature as listed in GW [6]. Uncertainties for the data after 1990 are below $0.01 \mathrm{~K}$ and too small to be resolved on this scale. The value from Rourke (2016) [9] has been added.

Table 1 summarizes a few of the most important thermophysical properties of $\mathrm{SF}_{6}$ at its $\mathrm{TP}$ temperature and, for comparison, those of $\mathrm{Hg}$. The values listed for $\mathrm{Hg}$ are from Mangum and Furukawa [11] and Furukawa [2]. For $\mathrm{SF}_{6}$, the TP temperature $T_{\mathrm{tp}}$, pressure $p_{\mathrm{tp}}$, and liquid-phase density $\rho_{\mathrm{l}}$, were 
taken from GW [6]. The solid-phase density $\rho_{\mathrm{s}}$ was extrapolated from literature values as discussed in Sec. 2.2. The mass enthalpy of fusion $\Delta h_{\mathrm{f}}$ was taken from Rourke [10]. The slope of the melting line $\mathrm{d} p_{\mathrm{m}} / \mathrm{d} T$ is from Harvey [11], and it is discussed in detail in Sec. 2.3. Finally, $A^{-1}$ is the inverse of the first cryoscopic constant $A=\Delta h_{\mathrm{f}} / M R T^{2}$, where $M$ is the molar mass $\left(M_{\mathrm{SF} 6}=0.14606 \mathrm{~kg} / \mathrm{mol}\right)$ and $R$ is the molar gas constant $(R=8.3145 \mathrm{~J} / \mathrm{mol} \cdot \mathrm{K})$.

Table 1. Comparison of some thermodynamic properties of $\mathrm{SF}_{6}$ and $\mathrm{Hg}$ (see text for sources and discussion).

\begin{tabular}{|l|l|l|l|l|l|l|l|}
\hline & $T_{\mathrm{tp}}$ & $p_{\mathrm{tp}}$ & $\rho_{\mathrm{l}}$ & $\rho_{\mathrm{s}}$ & $\Delta h_{\mathrm{f}}$ & $\mathrm{d} p_{\mathrm{m}} / \mathrm{d} T$ & $A^{-1}$ \\
\hline & $(\mathrm{K})$ & $(\mathrm{MPa})$ & $\left(\mathrm{kg} / \mathrm{m}^{3}\right)$ & $\left(\mathrm{kg} / \mathrm{m}^{3}\right)$ & $(\mathrm{J} / \mathrm{kg})$ & $(\mathrm{MPa} / \mathrm{K})$ & $\left(\mu \mathrm{K} / \mathrm{ppm}^{\mathrm{a}}\right)$ \\
\hline $\mathrm{SF}_{6}$ & 223.555 & 0.231 & 1845 & 2279 & 36,150 & 1.56 & 78.7 \\
\hline $\mathrm{Hg}$ & 234.3156 & $1.7 \times 10^{-10}$ & 13,690 & 14,184 & 11,426 & 18.5 & 199 \\
\hline
\end{tabular}

While the molar mass of $\mathrm{Hg}$ is only 1.37 times that of $\mathrm{SF}_{6}$, the molar density is 5.3 times greater, so that the mass density is 7.3 times greater. When expressed as equal volumes of liquid, the enthalpy of fusion $\Delta h_{\mathrm{f}}$ of $\mathrm{SF}_{6}$ is only $43 \%$ of that of $\mathrm{Hg}$. So the available melting heat of $\mathrm{SF}_{6}$ is smaller for the same size cell compared to $\mathrm{Hg}$, but in practice, this is not a serious limitation.

The inverse cryoscopic constant $A^{-1}$ provides a rough estimate for the melting depression $\Delta T=x A^{-1}$ in kelvin due to impurities as expressed by a mole fraction $x$, in $\mu \mathrm{mol} \cdot \mathrm{mol}^{-1}$, provided that the impurity is soluble in the liquid and not the solid. While the lower value for $\mathrm{SF}_{6}$ of $A^{-1} \approx 79 \mu \mathrm{K} / \mu \mathrm{mol} \cdot \mathrm{mol}^{-1}$ compares favorably with $199 \mu \mathrm{K} / \mu \mathrm{mol} \cdot \mathrm{mol}^{-1}$ for $\mathrm{Hg}$, the fact that $\mathrm{Hg}$ can be easily distilled to ultrahigh purity [2] renders this difference unimportant.

In the historical context, the fact that older samples of $\mathrm{SF}_{6}$ yielded $\approx 1 \mathrm{~K}$ colder $\mathrm{TP}$ temperatures (see Fig. 1) could be due to larger concentrations of impurities in those old samples. However, a $1 \mathrm{~K}$ depression would imply a dissolved impurity concentration of $1.3 \%$, which seems surprising, particularly for samples from circa 1980 and later. While the existence of eutectic solid solutions is a plausible explanation, the origins of the large depressions in the pre-1993 $\mathrm{SF}_{6} \mathrm{TP}$ temperatures as reported in the literature are not well understood. The self-consistency of the modern data (starting in 1993), in contrast, is at the level of a few millikelvin. This implies that the modern methods for synthesis and purification of $\mathrm{SF}_{6}$ are sufficient to produce high-purity samples.

\subsection{Liquid and Vapor Phases}

Liquid $\mathrm{SF}_{6}$ coexists with its saturated vapor between the TP $223.555 \mathrm{~K}$ and the critical point $318.723 \mathrm{~K}$. The saturated vapor curve and a portion of the melting line are shown in Fig. 2. Also shown are four gas-phase isochores for temperatures above ambient. The two highest density isochores are for higher densities of $1030 \mathrm{~kg} \cdot \mathrm{m}^{-3}$ and $920 \mathrm{~kg} \cdot \mathrm{m}^{-3}$; the third isochore is exactly the critical density $\left(745.8 \mathrm{~kg} \cdot \mathrm{m}^{-3}\right)$; and the fourth isochore is for a lower density of $315 \mathrm{~kg} \cdot \mathrm{m}^{-3}$. These saturated pressures and isochores were calculated via the GW EoS as implemented using the NIST program REFPROP [12]. In practice, these isochores would normally not be accessible without overheating a given triple-point cell. They are, however, useful to understand, since a fixed-point cell has a fixed overall density, which determines these pressure-temperature $(p-T)$ gas equilibrium states. We discuss the related design and safety aspects for $\mathrm{SF}_{6}$ fixed-point cells in Sec. 3.

The densities of the saturated liquid and vapor phases for $\mathrm{SF}_{6}$ are shown in Fig. 3 between the TP and critical point. Calculations were again implemented via REFPROP [12]. At the TP, the densities are such that only $1 \%$ of the total mass of $\mathrm{SF}_{6}$ inside of a given cell would be in the vapor phase. Between the TP 


\section{Journal of Research of the National Institute of Standards and Technology}

and $300 \mathrm{~K}$, the liquid-phase volume will expand by a factor of approximately 1.4. Hence, there is a need for an expansion volume in $\mathrm{SF}_{6} \mathrm{TP}$ cells.

The transport properties of $\mathrm{SF}_{6}$ in the liquid and vapor phases are typical of most nonmetals under similar pressure and temperature conditions. These properties are significantly different from those of a liquid metal such as mercury. Table 2 lists selected transport properties: thermal conductivities, $\lambda_{1}, \lambda_{v}$; dynamic viscosities, $\eta_{1}, \eta_{v}$; thermal diffusivities, $\alpha_{1}, \alpha_{v}$; and Prandtl numbers, $\operatorname{Pr}_{1}, \operatorname{Pr}_{v}$. The factor of 80 higher thermal conductivity for liquid $\mathrm{Hg}$ implies $\mathrm{SF}_{6}$ would be expected to develop thermal gradients a factor of 80 larger than in $\mathrm{Hg}$ for the same external heat flux. Similarly, thermal diffusivity favors liquid $\mathrm{Hg}$ by a factor of 65 . This suggests that dynamical thermal response might be 65 times slower in $\mathrm{SF}_{6}$ compared to Hg. Finally, the factor of 100 in the Prandtl number is a clear separation between the dominant diffusive heat transport in $\mathrm{Hg}$ compared to a dominant convective transport in the case of liquid $\mathrm{SF}_{6}$.

Table 2. Comparison of some transport properties of liquid- and vapor-phase $\mathrm{SF}_{6}$ [12],[13], [14] and $\mathrm{Hg}$ [2], [15], [16] at their TP temperatures and pressures (see Table 1). The properties listed from left to right are liquid and vapor phase: thermal conductivity; dynamic viscosity; thermal diffusivity; and Prandtl number. Vapor-phase mercury properties are omitted since the very low pressure vapor makes a negligible contribution to heat transport.

\begin{tabular}{|l|l|l|l|l|l|l|l|l|}
\hline & $\lambda_{1}$ & $\lambda_{\mathrm{v}}$ & $\eta_{1}$ & $\eta_{\mathrm{v}}$ & $\alpha_{1}$ & $\alpha_{\mathrm{v}}$ & $\mathrm{Pr}_{1}$ & $\mathrm{Pr}_{\mathrm{v}}$ \\
\hline & $(\mathrm{mW} / \mathrm{m} \cdot \mathrm{K})$ & $(\mathrm{mW} / \mathrm{m} \cdot \mathrm{K})$ & $(\mu \mathrm{Pa} \cdot \mathrm{s})$ & $(\mu \mathrm{Pa} \cdot \mathrm{s})$ & $\left(\mathrm{cm}^{2} / \mathrm{s}\right)$ & $\left(\mathrm{cm}^{2} / \mathrm{s}\right)$ & & \\
\hline $\mathrm{SF}_{6}$ & 77.9 & 7.63 & 410 & 11.9 & 0.000504 & 0.00691 & 4.41 & 0.88 \\
\hline $\mathrm{Hg}$ & $6300[15]$ & - & $2033[16]$ & - & 0.0328 & - & 0.046 & - \\
\hline
\end{tabular}

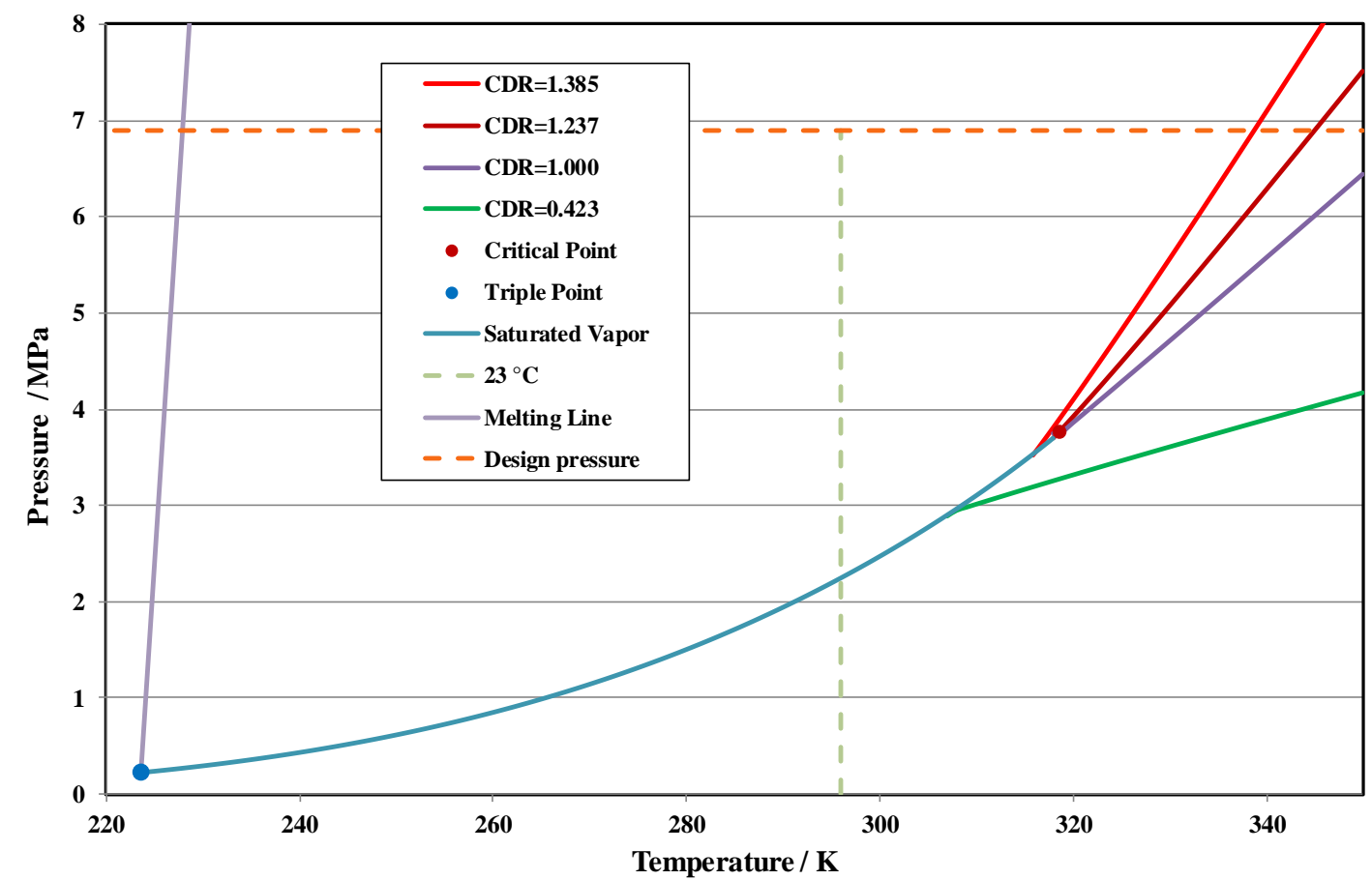

Fig. 2. The saturated vapor pressure curve, melting line, and four gas-phase isochores of $\mathrm{SF}_{6}$ from the TP to $350 \mathrm{~K}$. The densities of the isochores are expressed as a critical density ratio (CDR) of the cell density relative to the critical density. 


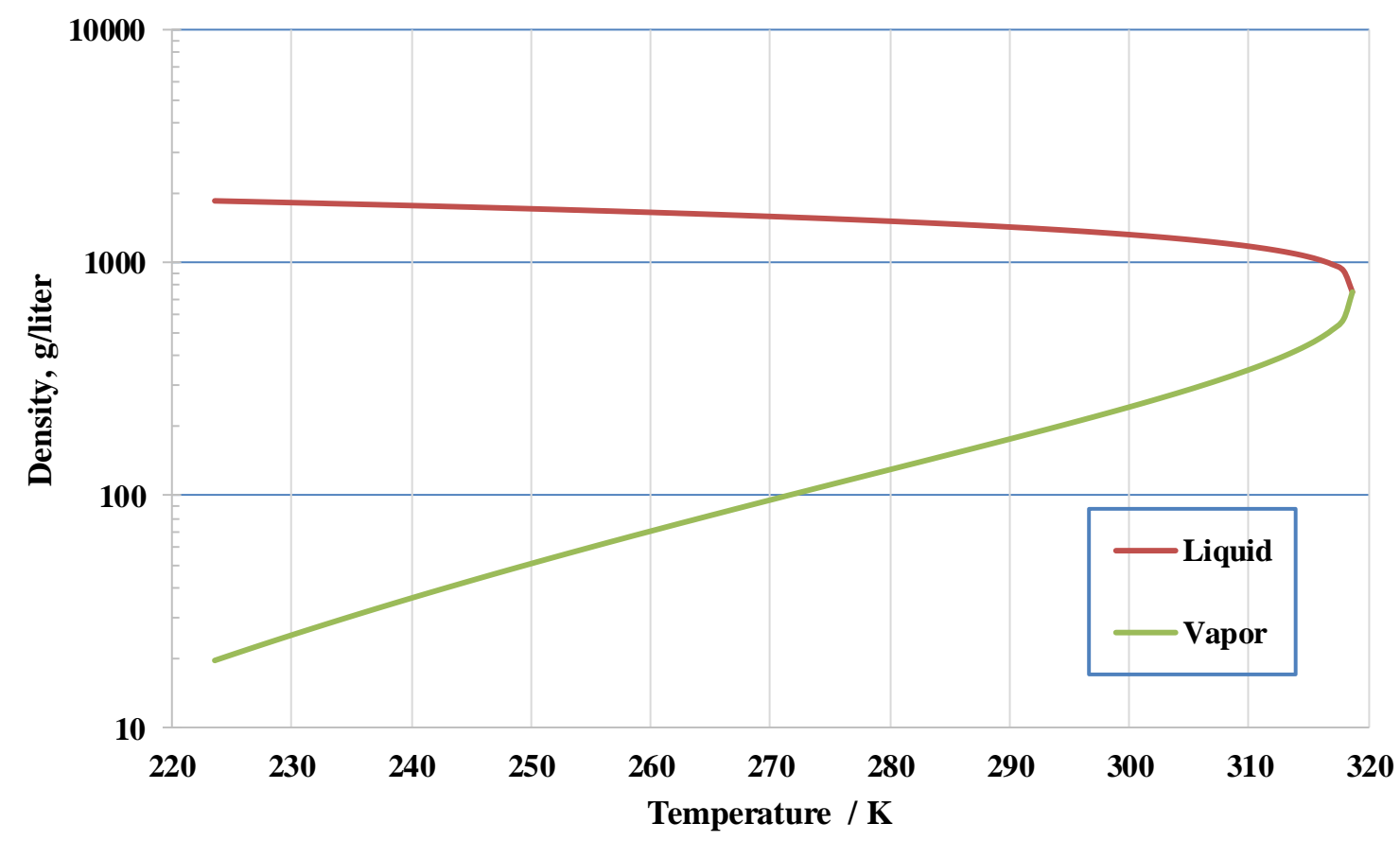

Fig. 3. The densities of the saturated liquid and vapor phases between the TP and critical point.

\subsection{Solid Phase}

In the region between $\approx 96 \mathrm{~K}$ and the melting line, solid-phase $\mathrm{SF}_{6}$ exists as a so-called "plastic" bodycentered cubic crystal [17]. This phase exhibits orientational disorder in the molecular axes, giving rise to the "plastic" phase description. We are unaware of any contemporary direct measurements of the density of this solid phase at the TP. There are, however, several measurements at lower temperatures, as well as various measurements of the lattice constants, which, when combined, allow a reliable extrapolation of those density values to the TP temperature. Kiefte et al. [18] reviewed the neutron and X-ray scattering data between $100 \mathrm{~K}$ and $200 \mathrm{~K}$ available prior to 1988 . They used a set of four lattice parameter determinations at four temperatures over that range to make a linear extrapolation of inferred crystal densities, which yields $\rho_{\mathrm{s}}=2280 \mathrm{~kg} \cdot \mathrm{m}^{-3}$ at $221 \mathrm{~K}$.

We reproduce the data as cited in Kiefte et al. [18] in Fig. 4, but we exclude the data below $180 \mathrm{~K}$. In addition, we include a set of three molar volume determinations from Konstaninov [19] at $188 \mathrm{~K}, 202 \mathrm{~K}$, and $212 \mathrm{~K}$. The result of a linear least-squares fit yields an extrapolated density of $\rho_{\mathrm{s}}=2282 \mathrm{~kg} \cdot \mathrm{m}^{-3}$ at $223.555 \mathrm{~K}$, as given in Table 1 . This density is equivalent to a molar volume of $64.0 \mathrm{~cm}^{3} \cdot \mathrm{mol}^{-1}$. Harvey [20] made a similar data extrapolation of the solid molar volume, based on a more extensive set of data, that yielded an equivalent value of $64.10(25) \mathrm{cm}^{3} \cdot \mathrm{mol}^{-1}$. We adopt this value for the purposes of calculations for static pressure head corrections discussed in Sec. 2.3.

It should be noted that the solid-phase density of $\rho_{\mathrm{s}}=2279 \mathrm{~kg} \cdot \mathrm{m}^{-3}$ implies a volume change from solid to liquid at the TP of $\left(V_{1}-V_{\mathrm{s}}\right) / V_{\mathrm{s}}=23.5 \%$ relative to the solid volume $V_{\mathrm{s}}(-19.0 \%$ on freezing relative to the liquid volume $V_{1}$ ). This is a much larger volume change than occurs for metals (e.g., $3.6 \%$ in $\mathrm{Hg}$ ), and it is also larger than that of many nonmetals, including all of the noble gases. 
In contrast to the liquid and vapor phases, there is no comprehensive review publication for solid-phase $\mathrm{SF}_{6}$ properties comparable to that of GW. Furthermore, we have not made a comprehensive review of the literature for solid $\mathrm{SF}_{6}$ properties, and so the data cited here should be considered incomplete.

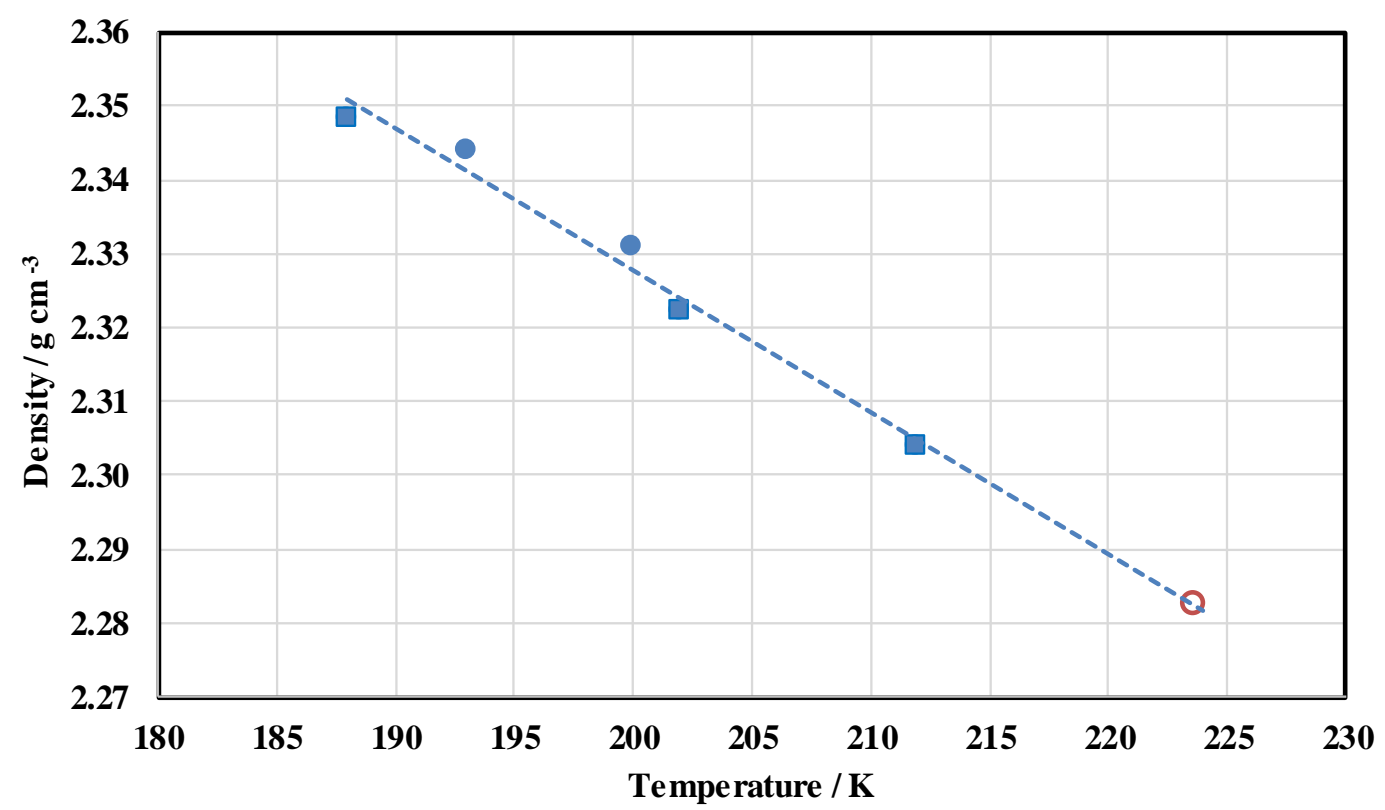

Fig. 4. The extrapolation of various determinations of solid-phase $\mathrm{SF}_{6}$ densities between $193 \mathrm{~K}$ and $212 \mathrm{~K}$ by neutron and $\mathrm{X}$-ray scattering and other methods to the TP temperature (red circle, see text).

\subsection{The Melting Line}

A revised melting-line equation was derived by Harvey [20] for use between the TP pressure of $0.231 \mathrm{MPa}$ and approximately $48 \mathrm{MPa}(253 \mathrm{~K})$. The slope of the melting line $\mathrm{d} p_{\mathrm{m}} / \mathrm{d} T$, as evaluated at the $\mathrm{TP}$, is a property of interest for immersion-type fixed-point cells, since the inverse slope governs the size of the static pressure head correction [11]. The revised melting-line equation takes into account the historical $1 \mathrm{~K}$ error in older melting data, where the TP temperature served as a reference. This revised equation also constrains the initial slope to agree with the Clapeyron prediction. An earlier melting-line equation used by GW [7] was not constrained to match any particular value for this initial slope. Taking the derivative of the Harvey's Eq. (2) [20] and evaluating it at $T=T_{\mathrm{tp}}$, we have

$$
\left.\frac{\mathrm{d} p_{\mathrm{m}}}{\mathrm{d} T}\right|_{T=T_{\text {tp }}}=\frac{a c}{T_{\mathrm{tp}}}=1.556 \mathrm{MPa} \cdot \mathrm{K}^{-1}
$$

where $a=223.7 \mathrm{MPa}$ and $c=1.555$. The slope as predicted by the Clapeyron equation is

$$
\begin{aligned}
\left.\frac{\mathrm{d} p_{\mathrm{mc}}}{\mathrm{d} T}\right|_{T=T_{\mathrm{tp}}} & =\frac{L_{\mathrm{tp}}}{T_{\mathrm{tp}} \Delta v_{\mathrm{tp}}}=\frac{36,150 \mathrm{~J} / \mathrm{kg}}{223.555 \mathrm{~K} \cdot(0.542-0.438) 10^{-3} \mathrm{~m}^{3} \cdot \mathrm{kg}^{-1}}, \\
& =1.557 \mathrm{MPa} \cdot \mathrm{K}^{-1}
\end{aligned}
$$

where the solid-phase molar volume $v_{\mathrm{s}}=0.438 \times 10^{-3} \mathrm{~m}^{3} / \mathrm{kg}$ is based on the extrapolated value from Harvey [20]. 
We used the Harvey melting line slope of $1.556 \mathrm{MPa} \cdot \mathrm{K}^{-1}$ to calculate a predicted pressure head correction coefficient for $\mathrm{SF}_{6}$ of

$$
\left.\frac{\mathrm{d} T}{\mathrm{~d} z}\right|_{T=T_{\mathrm{Tp}}}=\frac{-\rho g}{\left.\frac{\mathrm{d} p}{\mathrm{~d} T}\right|_{T=T_{\mathrm{Tp}}}}=-11.6 \mathrm{mK} \cdot \mathrm{m}^{-1},
$$

where the liquid density is assumed, and the negative sign accounts for increasing pressure with negative relative displacements below the free surface. This pressure head coefficient allows a correction to be calculated on the basis of the effective immersion depth $\Delta z$ from the thermometer element midpoint to the free surface of the liquid phase. This value exceeds (in magnitude) our earlier estimate [21] of $-10 \mathrm{mK} \cdot \mathrm{m}^{-1}$ based on the GW melting line slope by $16 \%$. The coefficient $-11.6 \mathrm{mK} \cdot \mathrm{m}^{-1}$ as predicted here is larger than that for any other ITS-90 fixed-point material, including that of $\mathrm{Hg}$ and $\mathrm{Au}$ [11].

\subsection{Solubility of Nitrogen}

Nitrogen is a common impurity in $\mathrm{SF}_{6}$ and is highly soluble in the liquid phase. The Bunsen absorption coefficient $\alpha(T)$ of $\mathrm{N}_{2}$ in liquid $\mathrm{SF}_{6}$ was measured by Miller et al. [22]. They found $\alpha(300 \mathrm{~K})=2 \mathrm{~atm}$ $(202 \mathrm{kPa})$, which, when converted to a Henry's law volatility constant, yields $K_{\mathrm{H}}(300 \mathrm{~K})=10 \mathrm{MPa}$ or $10 \mathrm{~Pa} \cdot\left(\mu \mathrm{mol} \mathrm{N} / \mathrm{mol} \mathrm{SF}_{6}\right)^{-1}$ when expressed as the partial pressure of $\mathrm{N}_{2}$ in the vapor phase divided by the mole fraction of $\mathrm{N}_{2}$ dissolved in the liquid phase at equilibrium. From this, we can calculate a vapor-liquid distribution coefficient $k_{\mathrm{v}, 1}$ for $\mathrm{N}_{2}$ impurities in $\mathrm{SF}_{6}$. At $300 \mathrm{~K}$ the saturated vapor pressure of $\mathrm{SF}_{6}$ is $p_{\mathrm{v}}=$ $2.4 \mathrm{MPa}$, so that $k_{\mathrm{v}, 1}(300 \mathrm{~K})=K_{\mathrm{H}}(300 \mathrm{~K}) / p_{\mathrm{v}} \cong 4$ (assuming a $\mathrm{N}_{2}$ fugacity of 1$)$. The temperature dependence of $k_{\mathrm{v}, 1}$ scales such that the product of $T \ln \left(k_{\mathrm{v}, 1}\right)$ is proportional to the liquid solvent density $\rho_{1}(T)$. Given that $\rho_{1}(223.555 \mathrm{~K}) / \rho_{1}(300 \mathrm{~K})=1.4$, we calculate $k_{\mathrm{v}, 1}(223.555 \mathrm{~K})=35$. This means that the mole fraction of $\mathrm{N}_{2}$ in the vapor phase is 35 times greater than the mole fraction of $\mathrm{N}_{2}$ dissolved in the liquid phase in equilibrium at the TP. However, a mitigating factor is the vapor density being only $1 \%$ of that of the liquid phase at the TP. Thus, if the vapor and liquid volumes are comparable, most of the $\mathrm{N}_{2}$ will still be dissolved in the limit of the liquidus point. This is an important factor for calculating the effective impurity fraction of $\mathrm{N}_{2}$ in the liquid phase for a known overall (all phases) fraction. Further specific details on this effect are given in Sec. 4.1.1.

\section{Experimental}

\subsection{Cell Design and Construction}

All fixed-point cells are subject to several constraints for realization of the fixed point at the highest level of reproducibility. The so-called immersion-type cell is specially designed to accommodate long-stem SPRTs at typical condensate-immersion depths of $15 \mathrm{~cm}$ to $18 \mathrm{~cm}$ [11]. This sets the size scale for all other cell dimensions, resulting in about $0.2 \mathrm{~L}$ of condensed $\mathrm{SF}_{6}$ surrounding a reentrant well and enclosed in an outer shell approximately $40 \mathrm{~cm}$ high and $5 \mathrm{~cm}$ in diameter. For all $\mathrm{SF}_{6} \mathrm{TP}$ cells with densities between the limits shown by the gas-phase isochores in Fig. 2, some liquid phase will continue to exist at ambient (e.g., $23{ }^{\circ} \mathrm{C}$ ) temperatures. The vapor pressure of $\mathrm{SF}_{6}$ at ambient temperature, $p(296 \mathrm{~K})=2.25 \mathrm{MPa}$, is low enough to permit safe containment provided that the cell has a liquid-phase expansion volume.

An important design criterion for the immersion cells is to keep the physical dimensions similar to those of a Hg TP cell, allowing the cell to be easily substituted into a refrigerated bath and readily transportable. Another criterion is to allow the sample to be changed when needed. This requires an integral valve of a sufficient pressure rating and suitable for high-purity gas service. The main benefit of the 
refillable design of the cell presented here is that the sample can be readily changed to a different source of $\mathrm{SF}_{6}$ with a different chemical assay, allowing sample-to-sample thermometric comparisons to be made with all other variables held constant.

Four TP cells were constructed and filled with $\mathrm{SF}_{6}$ for this study. Two of these (cell serial numbers 1202 and 801) were larger immersion cells and two others (cell serial numbers 302 and 401) were smaller "adiabatic"-type cells. The cell design parameters are summarized in Table 3 and identified by serial number $(\mathrm{s} / \mathrm{n})$. The cell volume, $V_{\text {cell }}$, represents the total internal volume of the cell. The $\mathrm{SF}_{6}$ mass, $m_{\mathrm{SF} 6}$, is the total mass of $\mathrm{SF}_{6}$ contained inside the cell. The cell density, $\rho_{\text {cell }}$, is the ratio of these values. The liquid and vapor volumes, $V_{1}$ and $V_{\mathrm{v}}$, were calculated for the liquidus condition (fraction melted $F=1$ ) at the TP temperature. The effective immersion, $\Delta z_{\text {eff }}$, is the depth of the thermometer element (at its midpoint) below the free surface of the condensed portion of $\mathrm{SF}_{6}$ at the TP temperature. The immersion depth is negligible for adiabatic cells. The thermowell is a reentrant cylindrical cavity matching the SPRT geometry and allows a thermometer to equilibrate with the sample within the cell. For the adiabatic cells, this is a triplewell configuration for capsule SPRTs under vacuum conditions. The two immersion cells, $\mathrm{s} / \mathrm{n} 801$ and s/n 1202, had single coaxial thermowells with inner diameters (IDs) of $8 \mathrm{~mm}$ and $12 \mathrm{~mm}$, respectively, and these required immersion corrections proportional to $\Delta z_{\text {eff. }}$. These cells allow the use of some combination of both long-stem and capsule-type SPRTs. Finally, the cell enthalpy was calculated by $\Delta H_{\mathrm{f}}=\Delta h_{\mathrm{f}} m_{\mathrm{SF}}$. We took the value of $M_{\mathrm{SF} 6} \Delta h_{\mathrm{f}}=5.28 \mathrm{~kJ} \cdot \mathrm{mol}^{-1}$ from Rourke [10] and assumed an uncertainty in both $\Delta H_{\mathrm{f}}$ and $\Delta h_{\mathrm{f}}$ of $1 \%$. The estimated uncertainties in the mass values were $0.1 \%$, and the estimated uncertainties in the volume and density values were $1 \%$.

Table 3. $\mathrm{SF}_{6}$ triple-point cell parameters as used in this study.

\begin{tabular}{|l|l|l|l|l|l|l|l|l|}
\hline Cell & $\begin{array}{l}\text { Volume, } \\
V_{\text {cell }}\end{array}$ & $\begin{array}{l}\mathrm{SF}_{6} \text { mass, } \\
m_{\mathrm{SF} 6}\end{array}$ & $\begin{array}{l}\text { Density, } \\
\rho_{\text {cell }}\end{array}$ & $\begin{array}{l}\text { Liquid, } \\
V_{1}\end{array}$ & $\begin{array}{l}\text { Vapor, } \\
V_{\mathrm{v}}\end{array}$ & $\begin{array}{l}\text { Immersion, } \\
\Delta z_{\text {eff }}\end{array}$ & $\begin{array}{l}\text { Thermowell inner } \\
\text { diameter }\end{array}$ & $\begin{array}{l}\text { Enthalpy, } \\
\Delta H_{\mathrm{f}}\end{array}$ \\
\hline $\mathrm{s} / \mathrm{n}$ & $\left(\mathrm{cm}^{3}\right)$ & $(\mathrm{g})$ & $\left(\mathrm{g} \cdot \mathrm{cm}^{-3}\right)$ & $\left(\mathrm{cm}^{3}\right)$ & $\left(\mathrm{cm}^{3}\right)$ & $(\mathrm{cm})$ & $(\mathrm{mm})$ & $(\mathrm{kJ})$ \\
\hline 302 & 42 & 12.9 & 0.307 & 6.6 & 35.4 & 0 & Three $\times 5.6$ & 0.47 \\
\hline 401 & 14 & 9.1 & 0.650 & 4.8 & 9.2 & 0 & Three $\times 5.6$ & 0.33 \\
\hline 801 & 580 & 590 & 1.017 & 317 & 263 & 17.1 & 8 & 21.3 \\
\hline 1202 & 550 & 470 & 0.855 & 252 & 298 & 13.4 & 12 & 17.0 \\
\hline
\end{tabular}

All the cells were made from type 316L stainless steel. In some cases, vacuum-arc remelt (VAR) bar stock and/or oxygen-free high-conductivity copper (OFHC) were used for certain parts. Electropolished 316L tubing was used for all cylindrical sections, and all joints were arc-welded using argon.

The stainless-steel tubing used in all cell construction was certified to meet the requirements of ASTM A269 and/or ASTM A270 specifications [23], [24]. Based on the as-tested certificate values for the ultimate tensile strength of the $50.8 \mathrm{~mm}$ diameter tubing used in the immersion cells, the nominal rated pressure exceeds $13.8 \mathrm{MPa}(\approx 2000 \mathrm{psig})$. Rated pressures in the smaller adiabatic cells are higher. For the cell with the highest density $\left(\mathrm{s} / \mathrm{n} 801,1.017 \mathrm{~g} \cdot \mathrm{cm}^{-3}\right)$, the volume would, in principle, have to be overheated to $382 \mathrm{~K}$ in order to reach that pressure. In practice, this pressure would not be sustainable (or even attainable) since the spring-loaded bellows valve would begin to leak through the valve seat at pressures exceeding $7 \mathrm{MPa}$.

\subsubsection{Cell 302}

The adiabatic cell serial number 302 is a special experimental prototype constructed from VAR stainless steel and OFHC copper as shown in Fig. 5a. The most unusual feature is an integral all-metal bellows valve in place of the more customary permanent welded tube seal. The valve is a modified version of the same commercial valves used on the immersion cells described below in Sec. 3.1.3 and Sec. 3.1.4. Unlike in those cells, however, in this case the valve body is isothermal with the cell body. The valve 
allows for changing the gas sample, but for this study, all data were obtained from melts using a single charge of $\mathrm{SF}_{6}$ from the source described in Sec. 3.3. This cell's internal volume was $42 \mathrm{~cm}^{3}$, and its overall dimensions were near the upper limits of what will fit in a typical calorimeter, which was a compromise necessary to accommodate the bellows valve. The main volume outer diameter (OD) was $32 \mathrm{~mm}$, with a $2.5 \mathrm{~mm}$ wall thickness. The horizontal axis of the valve body was $56 \mathrm{~mm}$, which defines the limiting radial dimension.

This cell incorporated a single removable copper block, which contained the three $5.6 \mathrm{~mm}$ diameter thermowells for mounting the capsule SPRTs. The block was threaded into a reentrant copper well that was welded into the bottom of the cell's stainless-steel containment wall. A single etched-foil-on-polyimide resistance heater was bonded onto the external cylindrical surface along with copper lead wire extensions for the SPRTs. All lead wires were terminated with gold-plated contact pins in a 14 contact (17 pin capacity) sub-D shell connector at the top of the cell. The tare mass of the cell with all components in place (except the SPRTs) was approximately $0.739 \mathrm{~kg}$.

\subsubsection{Cell 401}

The adiabatic cell serial number 401 was an all-stainless-steel cylindrical cell with a $25.4 \mathrm{~mm}$ OD, a $1.65 \mathrm{~mm}$ wall thickness, and an internal volume of $14 \mathrm{~cm}^{3}$. The internal block was welded in place with three oversized thermowells of $6.85 \mathrm{~mm}$ diameter. Individual copper sleeves were fitted into each thermowell to adapt to the smaller $5.5 \mathrm{~mm}$ diameters of the capsule SPRTs. Unlike the other cells described in this study, this cell did not have a valve and was permanently sealed with a stainless-steel tube weld. The cell was equipped with a single etched-foil-on-polyimide resistance heater bonded onto the external surface. The lead wire terminations and connector pins were made in the same way as already described above for cell $\mathrm{s} / \mathrm{n} 302$. A photo of the finished cell is shown in Fig. $5 \mathrm{~b}$. The tare mass of the cell with all components in place (except the SPRTs) was approximately $0.200 \mathrm{~kg}$.

\subsubsection{Cell 801}

The immersion cell 801 was constructed from type 316 welded stainless steel. The total internal volume was $580 \mathrm{~cm}^{3}$. The cell was made from a single $280 \mathrm{~mm}$ length of $50.8 \mathrm{~mm}$ OD tubing with a $2.8 \mathrm{~mm}$ wall thickness. The ID of this tubing was electropolished along with all other internally wetted parts prior to welding. Two $6.35 \mathrm{~mm}$ diameter tubes provided a gas fill line and another parallel gas line that was terminated in a high-purity Bourdon-type pressure gauge. The tubing connections were made using all-metal-gasketed fittings. A single central thermowell was made from a single piece of $8 \mathrm{~mm}$ ID $/ 12 \mathrm{~mm}$ OD stainless-steel tubing. The OD of the thermowell was reduced to $10 \mathrm{~mm}$ in the region above the pressurized cell volume to minimize axial heat transport through that cross-sectional area. The cell and some associated components and fittings are shown in Fig. 5c. The tare mass was $2.777 \mathrm{~kg}$ with the associated components as shown.

\subsubsection{Cell 1202}

The immersion cell s/n 1202 was essentially of identical construction to that of cell s/n 801, with the exception of the central thermowell, which in this case was made from $12 \mathrm{~mm} \mathrm{ID/16} \mathrm{mm} \mathrm{OD} \mathrm{stainless-}$ steel tubing. As a result of this difference, the cell volume was slightly smaller, having a total internal volume of $550 \mathrm{~cm}^{3}$. Unlike the $\mathrm{s} / \mathrm{n} 801 \mathrm{cell}$, the OD of the thermowell was not reduced above the cell volume, which resulted in a cross-sectional area that was 4.2 times larger in the s/n 1202 cell. The cell and some associated components and fittings are shown in Fig. 5d. The tare mass was $2.8485 \mathrm{~kg}$ with the associated components as shown. 

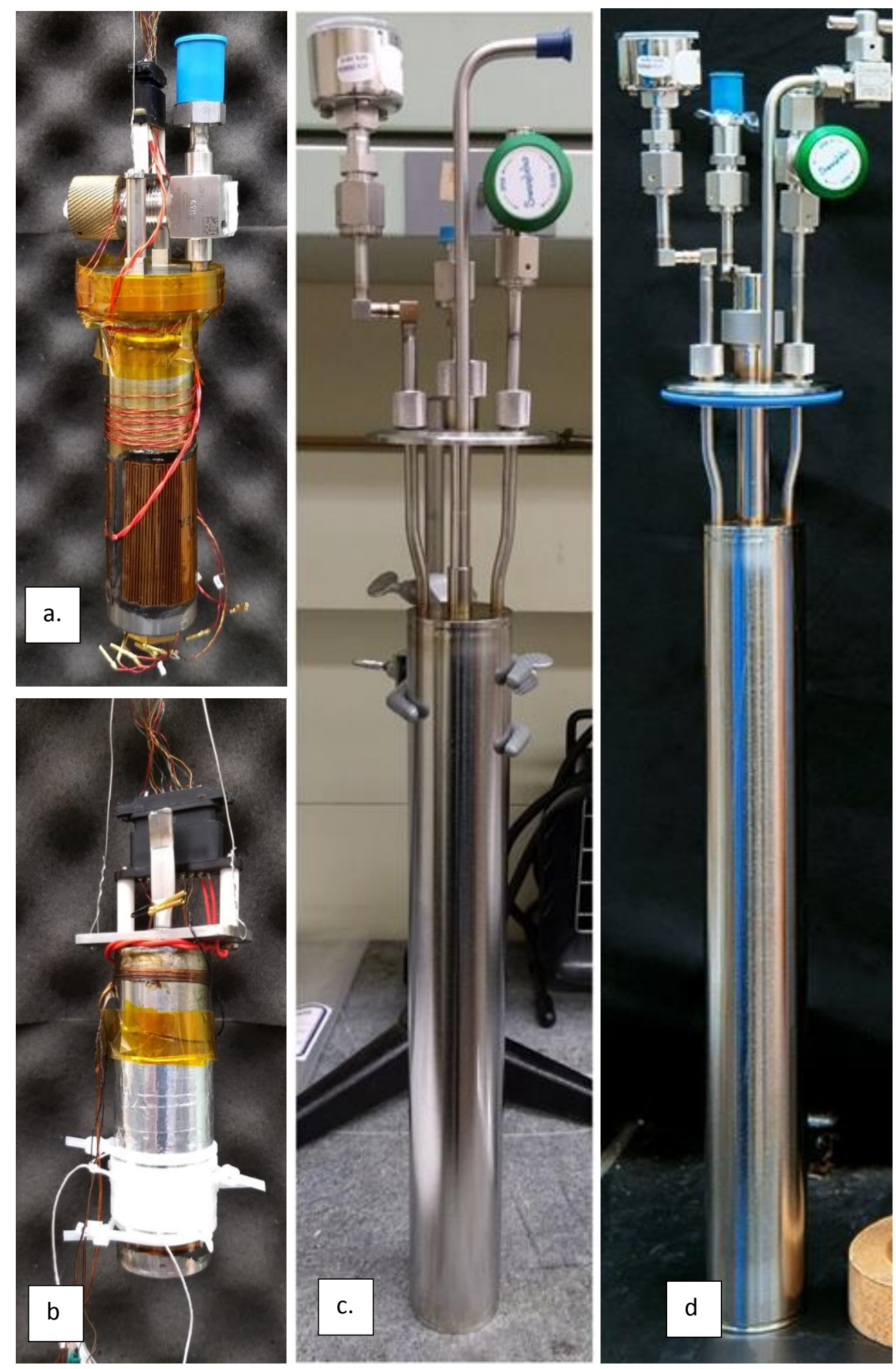

Fig. 5. The four cells as used in this study: (a) s/n 302; (b) s/n 401; (c) s/n 801; (d) s/n 1202. 


\subsection{Cell Testing}

Once the cell fabrication was completed, all cells were tested for leaks and pressure stress integrity. Leak testing was done using a helium leak detector with sensitivity at the $10^{-9} \mathrm{~cm}^{3} / \mathrm{s}$ level. The cells were then pressurized to a $6.9 \mathrm{MPa}(1000 \mathrm{psig}$ ) test pressure and afterward retested for leaks. The small cells were pressurized with nitrogen or argon gas, since the risks associated with stored compression energy in these small volumes are low [25]. The larger immersion-type cells were hydrostatically tested, however, since in those larger volumes, a containment failure does represent a moderate safety risk. Those cells undergoing hydrostatic testing were then subjected to a $200 \mathrm{~h}$ vacuum bake-out at $120{ }^{\circ} \mathrm{C}$ to $150{ }^{\circ} \mathrm{C}$ to remove residual water prior to the final helium leak test.

\subsection{Sample Preparation and Transfer}

All $\mathrm{SF}_{6}$ samples in this study were derived from the same commercial source ${ }^{1}$ [26]. A size D (7.4 L internal volume) gas cylinder was purchased containing $5 \mathrm{~kg}$ of SF 6 in 2014. The nominal purity grade specification of this "ultrahigh-purity" grade is equivalent to a $99.999 \%$ minimum purity on a volume basis. In addition, NIST requested that the $\mathrm{CF}_{4}$ content be below $1 \times 10^{-6}$ by volume fraction. The report of analysis supplied by the manufacturer is reproduced here in Table 4 . The analytical detection limits were not stated.

Table 4. Report of analysis for $\mathrm{SF}_{6}$ batch Lb-12 purchased in 2014 by NIST [26].

\begin{tabular}{|l|l|l|}
\hline Impurity & Test & Result \\
\hline \hline $\mathrm{H}_{2} \mathrm{O}$ & Unspecified & $<1 \mathrm{ppm}^{\mathrm{a}}$ by volume \\
\hline $\mathrm{H}_{2} \mathrm{O}$ & Dew point ASTM D2029 & $-78{ }^{\circ} \mathrm{C}$ \\
\hline $\mathrm{Air}\left(\mathrm{N}_{2}+\mathrm{O}_{2}\right)$ & Gas chromatography & $3.3 \mathrm{ppm}^{\mathrm{a}}$ by volume \\
\hline $\mathrm{CF}_{4}$ & Gas chromatography & $0.3 \mathrm{ppm}^{\mathrm{a}}$ by volume \\
\hline $\mathrm{SO}_{2}$ & Differential thermogram & None detected \\
\hline $\mathrm{CO}_{2}$ & Gas chromatography & None detected \\
\hline $\mathrm{R}-12\left(\mathrm{CCl}_{2} \mathrm{~F}_{2}\right)$ & Gas chromatography & None detected \\
\hline \multicolumn{2}{|l}{} \\
\hline
\end{tabular}

The cells were filled via condensation through a high-purity $\mathrm{SF}_{6}$ gas-handling manifold. A diagram of the filling system is shown in Fig. 6. Prior to filling the cells, they were repeatedly flushed with $\mathrm{SF}_{6}$ to about $10^{5} \mathrm{~Pa}$ and then reevacuated. This flush and purge cycle was repeated at least six times prior to the initiation of the filling process. The flow of $\mathrm{SF}_{6}$ proceeds from right to left via $7.75 \mathrm{~mm}$ ID electropolished stainless-steel tubing, which makes up most of the manifold. Separate sections of the manifold are connected via high-purity all-metal gasket fittings. The source cylinder remains at ambient temperature with its $2.3 \mathrm{MPa}$ output connected to a cross-purge fixture. From that point, the flow passes through a $2 \mu \mathrm{m}$ stainless-steel filter, which is heated to approximately $40{ }^{\circ} \mathrm{C}$ to prevent condensation of the $\mathrm{SF}_{6}$ stream. This filter protects a high-purity two-stage pressure regulator from stray particle damage. The regulator steps the pressure down to approximately $0.3 \mathrm{MPa}$, which corresponds to a condensation temperature of approximately $230 \mathrm{~K}$.

\footnotetext{
${ }^{1}$ Certain commercial equipment, instruments, or materials are identified in this paper to foster understanding. Such identification does not imply recommendation or endorsement by the National Institute of Standards and Technology, nor does it imply that the materials or equipment identified are necessarily the best available for the purpose.
} 


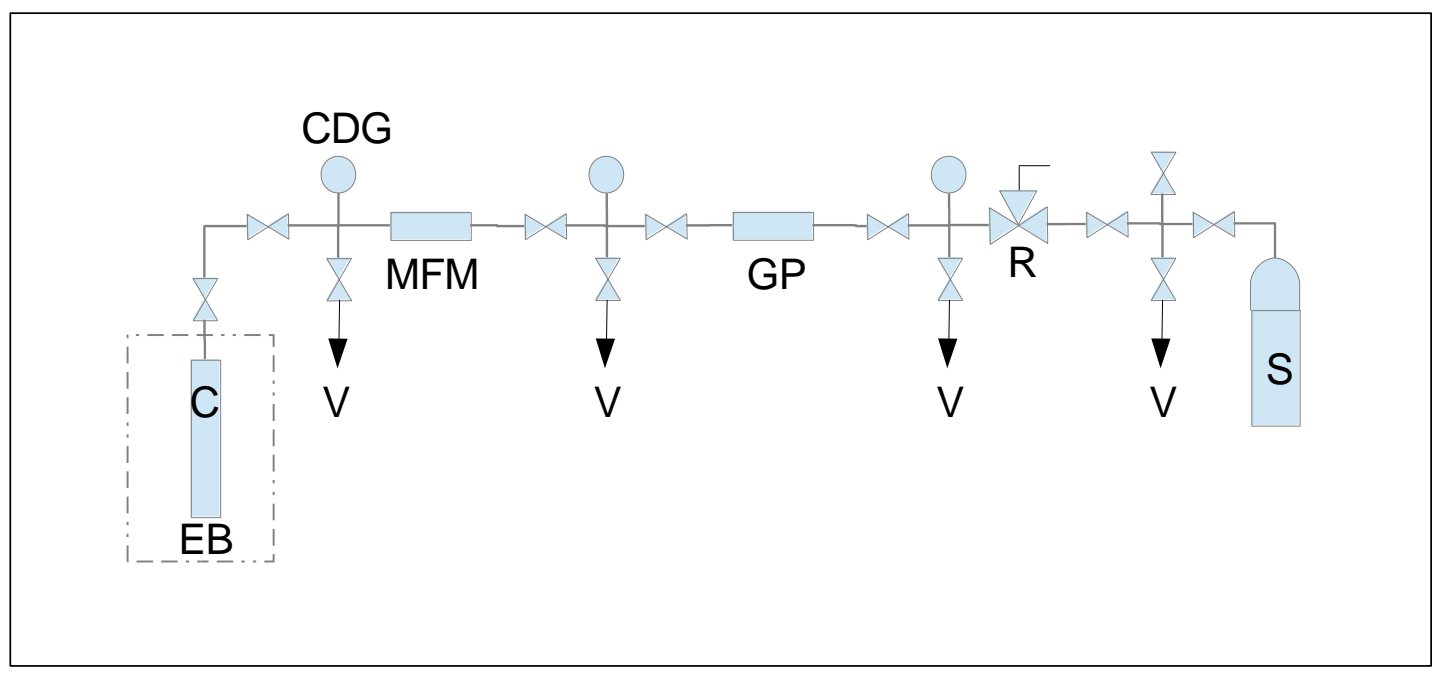

Fig. 6. The gas-handling manifold used for filling $\mathrm{SF}_{6}$ cells. From right to left: $\mathrm{SF}_{6}$ source cylinder $\mathrm{S}$; vacuum lines V; pressure regulator R; gas purifier GP; mass flow meter MFM; capacitance diaphragm gauge CDG; triple-point cell C; ethanol bath EB.

Once leaving the regulator, the $\mathrm{SF}_{6}$ stream enters an in-line gas purifier containing a reactive getter material [27] designed to remove impurities of $\mathrm{H}_{2} \mathrm{O}, \mathrm{CO}, \mathrm{CO}_{2}, \mathrm{O}_{2}$, and metal vapors to below $1 \times 10^{-9}$ volume fraction. The getter material should also remove $\mathrm{SO}_{2}$ in trace quantities, but the efficacy for that particular impurity is not well known. The stream exits the purifier and enters a mass flow meter that has an upper limit of $260 \mathrm{~cm}^{3} \cdot \mathrm{min}^{-1}$ when corrected for $\mathrm{SF}_{6}$. Once past the flow meter, the stream exits the main section of the manifold, where a capacitance diaphragm gauge monitors the condensation pressure at the point connecting the manifold with a $45 \mathrm{~cm}$ long section of tubing that terminates at the cell volume. The cell is cooled to $230 \mathrm{~K}$ inside a stirred ethanol bath during the condensation filling process.

The flow rate during the filling process was monitored and pressures were occasionally adjusted in order to keep the flow constant at $250 \mathrm{~cm}^{3} \cdot \mathrm{min}^{-1}$. Once a sufficient time had elapsed to condense the required mass of $\mathrm{SF}_{6}$, all valves were closed to stop the flow, and the cell and ethanol bath were allowed to gradually warm to ambient temperature. Once the cell equilibrated to room temperature, it was weighed, and that gross weight was compared to a known tare weight for the empty cell as taken prior to the filling operation. The net weights of $\mathrm{SF}_{6}$ samples in all four cells are listed in Table 3.

An additional processing step was added during the preparation of cell s/n 1202 to check for the presence of volatile impurities. In particular, the in-line gas purifier was not expected to remove the known $\mathrm{N}_{2}$ impurities, so we added a degassing step after the cell was filled by cooling the cell to approximately $100 \mathrm{~K}$ and pumping away any remaining volatile impurities. The pressure of $\mathrm{SF}_{6}$ at $100 \mathrm{~K}$ was calculated to be $2.7 \times 10^{-2} \mathrm{~Pa}$ based on the GW sublimation pressure equation [6]. The presence of volatile impurities (e.g., $\mathrm{N}_{2}$ ) would exert an additional partial pressure proportional to the concentration. During this process, we were unable to detect any partial pressure due to volatile $\mathrm{N}_{2}$ or similar weight impurities over the frozen $\mathrm{SF}_{6}$ at $100 \mathrm{~K}$ greater than the $10 \mathrm{~Pa}$ resolution of our $\mathrm{CDG}$, even before any pumping was initiated. A $10 \mathrm{~Pa}$ partial pressure would correspond to an ideal gas density of $0.012 \mathrm{~mol} / \mathrm{m}^{3}$ at $100 \mathrm{~K}$. A rough estimate for the available volume would be about $350 \mathrm{~cm}^{3}$, implying a possible presence of about $4.2 \mu \mathrm{mol}$ of $\mathrm{N}_{2}$, or a mole fraction of about $1.3 \mu \mathrm{mol} \cdot \mathrm{mol}^{-1}$ relative to the $\mathrm{SF}_{6}$ content. The absence of accurate low-pressure gauging, however, leaves some ambiguity about how much of that residual $\mathrm{N}_{2}$ gas may have been pumped away. 


\subsection{Thermometers}

Five capsule-type SPRTs were used in this study as listed in Table 5. Capsule-type SPRTs can easily be adapted for use in immersion-type cells, provided that the ID of the thermowell is adequate. The inverse statement is not true for long-stem SPRTs, for which the use is limited to immersion-type cells only. Given the requirement for making direct comparisons of all four cells used in this study, we exclusively used capsule-type SPRTs.

The capsule SPRTs were adapted for use in the immersion thermowells via borosilicate glass adapter tubes as described elsewhere [28], [29]. Of the capsule SPRTs listed in Table 5, the first three are more traditional in design, with a limiting OD of about $8.5 \mathrm{~mm}$. This necessitates using glass adapter tubes of $11 \mathrm{~mm}$ OD, and this limits their use to the immersion cell s/n 1202 with a $12 \mathrm{~mm}$ diameter thermowell. The last two capsule SPRTs in Table 5 are of a newer design with a limiting diameter of only about $5.6 \mathrm{~mm}$, so in this case, the glass adapter tubes are smaller, with an OD of $7.5 \mathrm{~mm}$, allowing their use in the $8 \mathrm{~mm}$ thermowell of the immersion cell $\mathrm{s} / \mathrm{n}$ 801. It should be noted that the immersion characteristics of our $11 \mathrm{~mm}$ adapter tubes are somewhat inferior to that of conventional long-stem SPRTs, while the characteristics of the $7.5 \mathrm{~mm}$ tubes are comparable to those of long-stem SPRTs.

All SPRTs were calibrated on subrange $4(83.8 \mathrm{~K}$ to $273.16 \mathrm{~K})$ of the ITS-90 from realizations of the $\mathrm{Hg}$ TP, Ar TP, and water triple point (WTP) at NIST [28], [30]. The temperatures $T_{90}$ were obtained via measurement of the resistance ratio $W\left(T_{90}\right)=R\left(T_{90}\right) / R\left(T_{\text {wtp }}\right)$, where $T_{\text {wtp }}$ is the WTP temperature $(273.16 \mathrm{~K})$, and the ITS-90 subrange 4 interpolation is defined by the deviation equation,

$$
\Delta W=W\left(T_{90}\right)-W_{\text {ref }}=a_{4}(W-1)+b_{4}(W-1) \ln (W) .
$$

The $1 \mathrm{~mA}$ calibration data for these SPRTs are shown in Table 5. The interpolation characteristics of four of the SPRTs listed in the table were studied by Meyer and Tew [31]. Some additional calibration history for 1774092 and 1842385 is provided in the NIST SP250-91 calibration document [28].

Table 5. Summary of SPRTs used with the $\mathrm{SF}_{6}$ cells at a current of $1 \mathrm{~mA}$.

\begin{tabular}{|l|l|l|l|l|l|}
\hline SPRT $\mathrm{s} / \mathrm{n}$ & $\mathrm{SF}_{6}$ cells & $W(\mathrm{Ar} \mathrm{TP})$ & $W(\mathrm{Hg} \mathrm{TP})$ & $a_{4}$ & $b_{4}$ \\
\hline \hline 1774092 & 1202,401 & 0.21587763 & 0.84414790 & $-3.590 \times 10^{-5}$ & $-1.773 \times 10^{-5}$ \\
\hline 1774096 & 302,401 & 0.21585420 & 0.84414047 & $1.099 \times 10^{-5}$ & $2.550 \times 10^{-6}$ \\
\hline 1842385 & 1202 & 0.21589819 & 0.84415016 & $-5.194 \times 10^{-5}$ & $-1.905 \times 10^{-6}$ \\
\hline $162 \mathrm{D} 3363$ & 801 & 0.21618024 & 0.84420321 & $-3.901 \times 10^{-4}$ & $1.228 \times 10^{-5}$ \\
\hline 56860103 & 801,401 & 0.21596604 & 0.84416306 & $-1.343 \times 10^{-4}$ & $8.506 \times 10^{-7}$ \\
\hline
\end{tabular}

The measured resistances were all approximately $20.4 \Omega$ at $223.555 \mathrm{~K}$. The SPRT resistances were measured using a digital substitution bridge (DSB) [32] at $1 \mathrm{~mA}$ using a $25 \Omega$ reference resistor or, in the case of the 2016 data, a $100 \Omega$ reference resistor. The self-heating was occasionally checked at $2 \mathrm{~mA}$, but all temperatures were derived from the $1 \mathrm{~mA}$ data.

\subsection{Experimental Setup for Adiabatic Cells}

The adiabatic cells 302 and 401 were installed inside a $63.5 \mathrm{~mm}$ diameter cylindrical vacuum chamber configured as a simplified calorimeter, as shown in Fig. 7. The chamber was then immersed into a refrigerated ethanol bath with single-shaft, dual-impeller-driven stirring and precision temperature control. The ethanol bath was a customized version of a standard commercial model with a larger working volume depth that can accommodate cells of larger vertical dimensions than standard versions. The vertical dimension of the vacuum chamber was approximately $0.5 \mathrm{~m}$, including various service and access fittings on the top flange (ISO-63). 
The cells were suspended inside the chamber by a $250 \mu \mathrm{m}$ diameter nickel-chrome alloy wire, and all lead wires going into the chamber were thermally anchored to the top flange interior surface. The calorimeter was designed to balance small external heat leaks by controlling the temperature of an internal stage directly above the cell that was weakly coupled to the bath. In practice, this was not achievable, since external heat leaks were found to be too large to keep the internal stage temperature sufficiently stable. Consequently, all of the melts performed with the s/n 302 cell (March 2016) showed irreproducible behavior above melted fractions of $F=75 \%$ (see Sec. 4.1). These effects were mitigated by wiring modifications in August 2017, which allowed better balance of residual heat leaks and a closer approximation to adiabatic conditions for the series of melts using cell $\mathrm{s} / \mathrm{n} 401$.

All TP realizations using the adiabatic-type cells were performed in step-melting mode. The procedure for obtaining melting data began with freezing the $\mathrm{SF}_{6}$ by filling the vacuum can with a small pressure of heat exchange gas (either $\mathrm{N}_{2}$ or $\mathrm{He}$ ) and lowering the bath temperature to approximately $-52^{\circ} \mathrm{C}$. Supercooling was normally observed prior to freezing by amounts varying from $-0.1{ }^{\circ} \mathrm{C}$ to $-0.25{ }^{\circ} \mathrm{C}$. On one occasion, prior to a slow freeze cycle using cell $\mathrm{s} / \mathrm{n} 302$, a supercooling of $-1.15^{\circ} \mathrm{C}$ was observed.

Once the cell temperature reequilibrated to the bath temperature, indicating isothermal solidification was complete, the heat exchange gas was evacuated, and the cell reequilibrated to some variable initial condition, typically between $-0.5{ }^{\circ} \mathrm{C}$ and $-0.1{ }^{\circ} \mathrm{C}$ below the melting point. The initial state for each melt varied depending on the bath temperature set point, the degree of heat-leak-induced drift in the cell temperature, and the initial amount of heat added to the cell. The bath temperature was adjusted to empirically balance the calorimeter to minimize the inferred heat leak to/from the cell. This was done by fitting the observed cell temperature drift rates below and above the melting temperature and extrapolating the linear fit to the nominal TP temperature. This usually resulted in a bath temperature between $-0.1{ }^{\circ} \mathrm{C}$ and $-0.05^{\circ} \mathrm{C}$ below the nominal TP temperature. A calibrated check SPRT (shown as 'B' in Fig. 7), chosen from the set listed in Table 5, was always used to measure the bath temperature. The spatial uniformity in the interior regions of the bath was found to be within $\pm 1 \mathrm{mK}$ for small displacements.

Step melting was initiated according to an automated sequence of regular heat pulses $Q_{i}$ applied via the cell heater. The melted fraction $F$ at a given point within a melt was calculated as the ratio of the cumulative applied heat to the cell enthalpy of fusion or $F=\Sigma Q_{\mathrm{i}} / \Delta H_{\mathrm{f}}$. For all of the adiabatic cell melts reported here, the heater power was fixed during a given experimental melt at either $0.5 \mathrm{~W}$ or $1 \mathrm{~W}$, with pulse dwell times set to a fixed value between $30 \mathrm{~s}$ and $50 \mathrm{~s}$. These settings yielded fixed heat pulse values in the range $15 \leq Q_{i} / \mathrm{J} \leq 50$. The pulse period (time between pulses) was set to $5600 \mathrm{~s}$ or higher in all but one case. In this way, most melts were divided into approximately 10 segments or in some cases 16 segments. The total number of applied heat pulses was set to a limit between 15 and 26, allowing some heating to occur in the all-liquid phase after the melting was completed. Depending on the exact chosen melting parameters, a melt sequence took place over a period of $15 \mathrm{~h}$ to $30 \mathrm{~h}$. Once the sample was completely melted, a new freeze was initiated by repeating that process. 


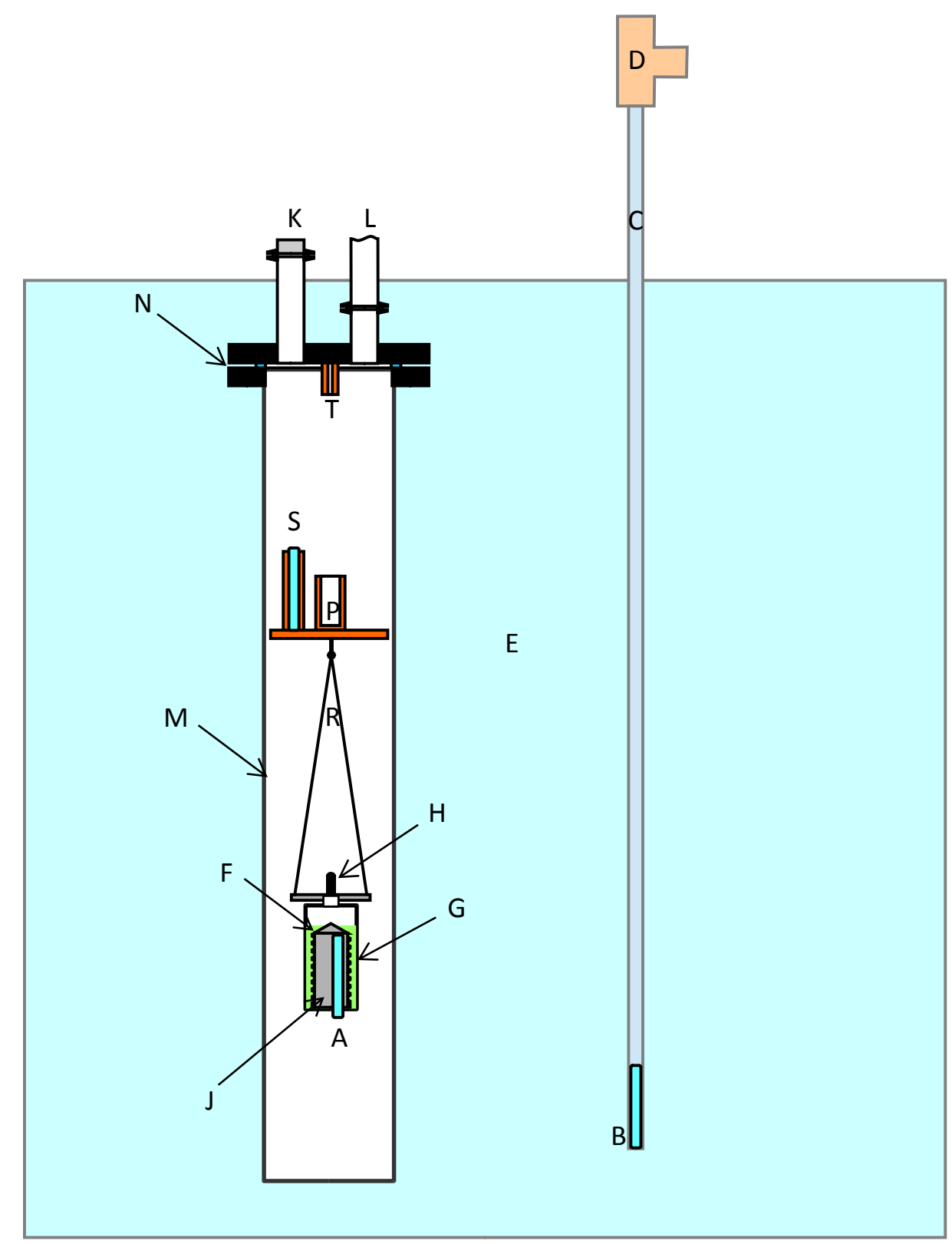

Fig. 7. Experimental setup for adiabatic-type $\mathrm{SF}_{6} \mathrm{TP}$ cells shown as a cross-sectional diagram of cell s/n 401: (A) capsule-type SPRT to measure the cell temperature; (B) capsule-type SPRT to measure the bath temperature; (C) borosilicate glass adapter tube; (D) nylon gas-tight fittings/header; (E) $50 \mathrm{~L}$ ethanol bath volume; (F) condensed (shown in green) portion of $\mathrm{SF}_{6}$ (shown as bulk liquid phase); (G) pressure wall of cell volume; (H) welded fill-line pinch-off; (J) internal block and thermowells (one of three shown); (K) electrical feedthrough; (L) vacuum line; (M) vacuum chamber; (N) ISO-63 C-clamp-style vacuum flange with fluorosilicone O-ring seal; (P) internal control stage (copper); (R) wire suspension; (S) control stage SPRT; and (T) wiring heat sink (one of two shown). 


\subsection{Experimental Setup for Immersion Cells}

The immersion cells, serial numbers 1202 and 801, were maintained inside the same refrigerated ethanol bath as already described in Sec. 3.5. These cells were also installed inside vacuum chambers of similar dimensions to those used for the adiabatic cells. In this case, however, the chambers were filled with either nitrogen or argon gas at pressures of (10 to 20) $\mathrm{kPa}$ to provide a moderate degree of heat exchange with the bath. The setup is shown in Fig. 8.

As in the case of the adiabatic cells, all TP realizations were performed in melting mode. The same basic procedure was used for freezing the $\mathrm{SF}_{6}$, utilizing a small partial pressure of heat exchange gas (either $\mathrm{N}_{2}$, Ar, or $\mathrm{He}$ ) and lowering the bath temperature to approximately $-52{ }^{\circ} \mathrm{C}$. Some supercooling was normally observed prior to freezing, varying from $-0.1{ }^{\circ} \mathrm{C}$ to $-0.2{ }^{\circ} \mathrm{C}$.

Once freezing was completed, the heat exchange gas was pumped out and replaced with argon by pumping and flushing the chamber. In a few cases, the heat exchange gas was nitrogen or helium and was allowed to remain during the melt phase. Prior to the melt cycle, a 'pre-melt' phase was initiated by raising the bath temperature to approximately $-0.1{ }^{\circ} \mathrm{C}$ below the TP temperature for several hours until the cell reached equilibrium with the bath. In the same manner as described above for the adiabatic set up, a calibrated SPRT (shown as 'B' in Fig. 8) was used to measure the bath temperature.

We then raised the temperature of the bath again to a positive bath-cell differential in order to initiate the melt. We always utilized a calibrated capsule-type SPRT immersed in the bath to an equivalent depth to the cell SPRT to determine the bath-cell differential. Once the cell temperature approached the initial plateau value, we initiated an inner melt. The inner melt was created using an immersion heater set to a power of $2 \mathrm{~W}$, removing the cell SPRT, and slowly inserting the immersion heater into the thermowell. The immersion heater was left in place for a period of approximately $30 \mathrm{~min}$, creating a liquid zone surrounding the thermowell, normally reaching a nominal $20 \%$ initial melted fraction. In a few cases, some inner melts were performed for shorter and longer durations, yielding initial melted fractions as low as $10 \%$ and as high as $30 \%$. Once the inner melt was created at the target initial melted fraction, the immersion heater was switched off and removed. The cell SPRT was then taken from a temporary location within the bath, reinserted into the cell, and allowed to reequilibrate.

In our initial experiments, a continuous melting mode was attempted with very limited success. In these experiments, the procedure was to continuously melt the sample by raising the bath temperature from $+0.04 \mathrm{~K}$ to $+0.10 \mathrm{~K}$ above the nominal $\mathrm{SF}_{6}$ melting point $(223.555 \mathrm{~K})$ and $\log$ data continuously. The nominal heating rates under these conditions were estimated to be between $10 \mathrm{~mW}$ and $25 \mathrm{~mW}$ for cell s/n 1202 , and slightly lower for cell $\mathrm{s} / \mathrm{n} 801$. Under continuous melting conditions, even these relatively low heating rates did not produce stable plateaus for melted fractions above approximately $25 \%$. The observed instabilities on the melting plateaus occurred earlier in the melt (lower $F$ ) when higher heating rates were applied.

After our initial trials, we established a new experimental procedure for the immersion cells that was similar to the adiabatic approach described in Sec. 3.5. This procedure approximated a step melting approach by alternating between a continuous-melt mode and a quasi-adiabatic mode. The continuous-melt mode was $16 \mathrm{~h}$ to $20 \mathrm{~h}$ (usually overnight) with nominally fixed heating rates for a given melt. The normal bath heating rates were about $10 \mathrm{~mW}$. The immersion heater was always used to create inner melts of between $10 \%$ and $30 \%$ melted fractions initiating each melt cycle.

The melting rate was then decreased by factors between 10 and 100 by decreasing the bath set point temperature to within $1 \mathrm{mK}$ to $5 \mathrm{mK}$ above the nominal $\mathrm{SF}_{6}$ melting point $(223.555 \mathrm{~K})$. This procedure was sufficient to establish a quasi-adiabatic condition where the estimated residual heat leak into or out of the cell was approximately $200 \mu \mathrm{W} \pm 100 \mu \mathrm{W}$. Under these conditions, a negligible increment (i.e., $\Delta F<$ $0.02 \%$ ) of melting would occur in a $4 \mathrm{~h}$ interval. Within these quasi-adiabatic conditions, the plateaus remained stable and immune to small changes in the bath temperature with the thermometer at full 
immersion and $F<80 \%$. All of the data for the immersion cells reported here were obtained under these conditions. Figure 9 illustrates the effect of switching between continuous melting and quasi-adiabatic mode when melting the 1202 cell.

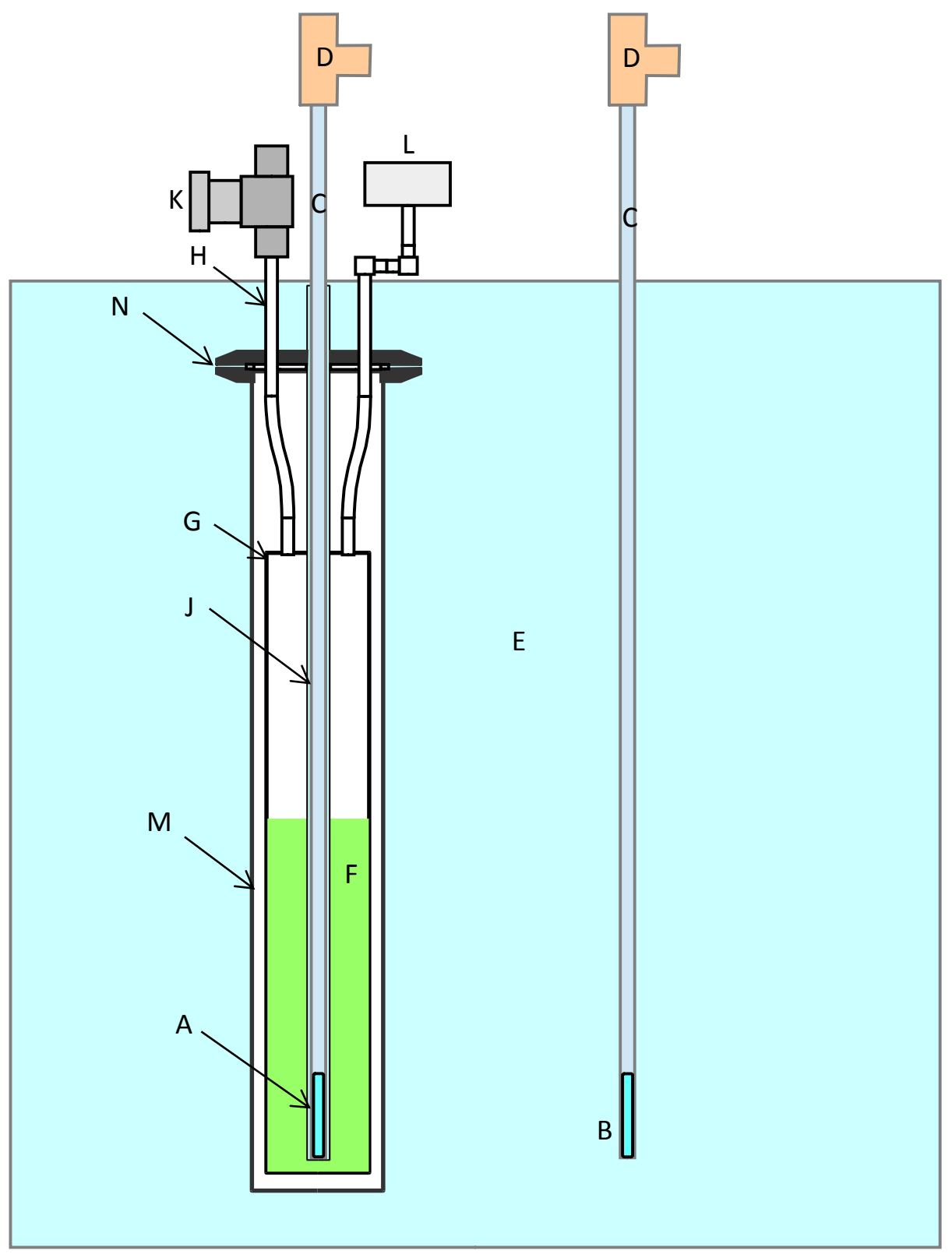

Fig. 8. Experimental setup for immersion-type $\mathrm{SF}_{6} \mathrm{TP}$ cells shown as a cross-sectional diagram: (A) capsule-type SPRT to measure the cell temperature; (B) capsule-type SPRT to measure the bath temperature; (C) borosilicate glass adapter tubes; (D) nylon gas-tight fittings/headers; (E) $50 \mathrm{~L}$ ethanol bath volume; (F) condensed (shown in green) portion of $\mathrm{SF}_{6}$ (shown as bulk liquid phase); (G) pressure wall of cell volume; $(\mathrm{H}) \mathrm{SF}_{6}$ fill line; $(\mathrm{J})$ central thermowell; $(\mathrm{K})$ bellows valve; (L) pressure gauge; (M) vacuum chamber; and (N) ISO-63 chain-clamp-style vacuum flange with aluminum gasket. 


\section{Journal of Research of the National Institute of Standards and Technology}

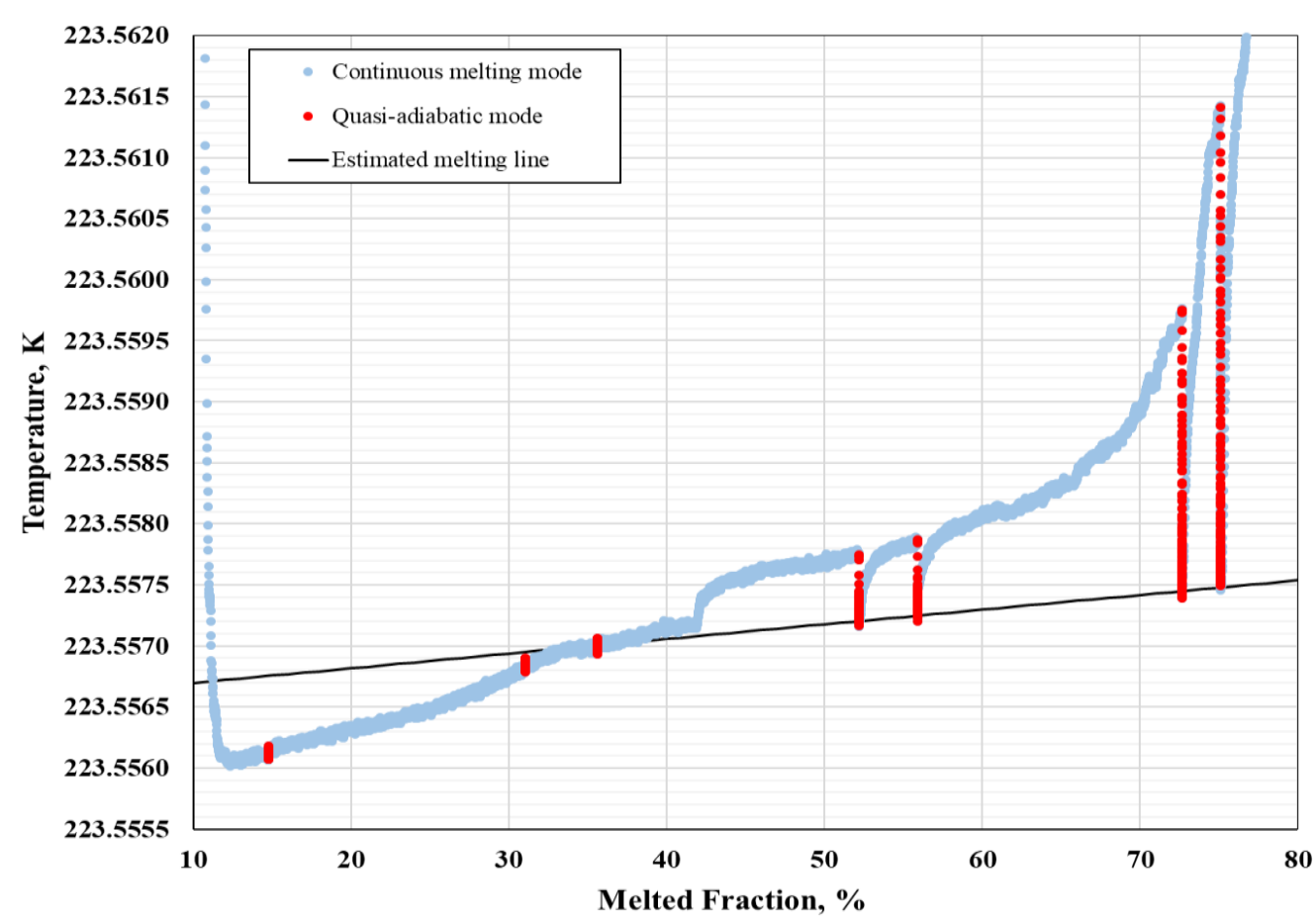

Fig. 9. Effect of switching between continuous melt and quasi-adiabatic modes. The estimated melting line (assuming a linear model in $F$ ) was fitted using data within the range $30 \%<F<80 \%$.

Figure 9 has a small, step increase in the temperature around $42 \%$ of melted fraction. Similar abrupt changes were seen in previous melts at even lower melted fractions, depending on the heating rate and the initial melted fraction. Before this spontaneous step increase, the measurements made with both continuous and adiabatic modes agreed well, while after the step, the differences between the measurements performed with the two modes increased with the melted fraction. This suggests that the step was due to a sudden degradation in the immersion conditions, leading to an increasing heat leak along the thermowell. Our hypothesis for this effect is the partial disintegration of the solid mantle as it melted, causing portions of the solid mantle to collapse and fall to the bottom of the cell.

\subsubsection{Immersion Profiles}

The immersion characteristics of the cells and thermometers taken together were observed in the customary way by obtaining an immersion profile of temperature changes $\Delta T$ versus elevation of the thermometer above the full immersion point by axial displacements $\Delta z$. This was initiated by elevating the thermometer by $7 \mathrm{~cm}$ above the full insertion depth and then lowering the thermometer in $1 \mathrm{~cm}$ steps, allowing equilibration at every step. The time required for equilibration within $0.1 \mathrm{mK}$ was about $30 \mathrm{~min}$.

The first profile with the 1202 cell was obtained with the top of the reentrant well outside the bath fluid and with the bath set to a temperature about $50 \mathrm{mK}$ above the $\mathrm{SF}_{6} \mathrm{TP}$. These conditions caused a poor immersion profile, with the temperature at higher positions about $1 \mathrm{mK}$ to $5 \mathrm{mK}$ hotter than the expected immersion line, evidencing a significant heat leak through the thermowell. The cell was then repositioned to allow the bath fluid to completely cover the cell, and the test was repeated, with better results, even though some heat leak was noticeable. 
As discussed previously in Sec. 3.6, the quasi-adiabatic mode, with the bath's set point about $1 \mathrm{mK}$ to $5 \mathrm{mK}$ above the TP, reduced the heat leaks to a minimum level. Therefore, all the subsequent immersion profiles were performed under quasi-adiabatic conditions. Figure 10 illustrates the results of the immersion profiles under three conditions and compares them with the theoretical line [11].

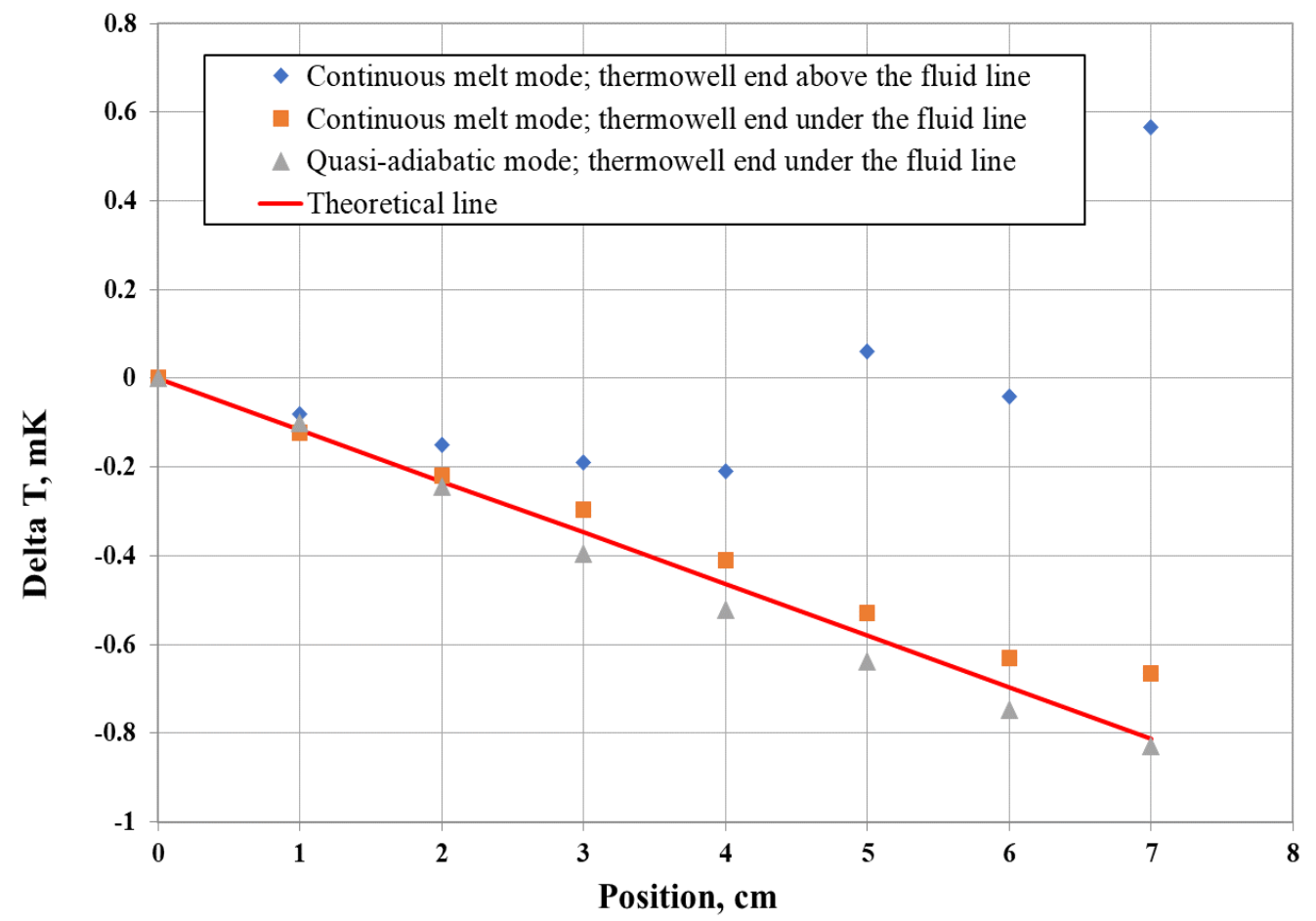

Fig. 10. Results of immersion profiles under different conditions.

\section{Results}

\subsection{TP Realizations Using Adiabatic Cells}

Our first realizations of the $\mathrm{SF}_{6} \mathrm{TP}$ were with cell s/n 302 in March 2016. Five melts were performed under a range of bath settings yielding relatively poor adiabatic conditions. The main problem was from ambient heat leaks, $P_{\mathrm{e}}$, due to inadequate immersion of the vacuum chamber. We attempted to compensate for these heat leaks by setting the bath well below the nominal plateau temperature. This led to net negative, but variable, heat leaks in the range $-150 \mu \mathrm{W} \geq P_{\mathrm{e}} \geq-420 \mu \mathrm{W}$ during these melts. The data from the first of those melts were unusable, but melts 2 through 5 yielded acceptable results for $F<\approx 75 \%$ and are included in the analysis in Sec. 4.3.

After working exclusively on the immersion cells, we turned to the adiabatic setup in August 2017 to perform a short series of TP realizations using cell $\mathrm{s} / \mathrm{n} 401$. The improved experimental configuration of the vacuum chamber allowed full immersion for this series of realizations, and concurrent improvements to the wiring reduced the parasitic joule heating inside of the chamber. These changes resulted in a much closer approximation to adiabatic conditions, in some cases achieving heat leaks $\left|P_{\mathrm{e}}\right| \leq 20 \mu \mathrm{W}$. Melts 1 to 4 all yielded highly reproducible temperatures over the entire extent of the melt plateau, even above $75 \%$. Melt 5 was slightly distorted at the higher melted fractions, however, due to an accidental imbalance in the bath set-point temperature, which resulted in $P_{\mathrm{e}} \approx 200 \mu \mathrm{W}$. The results from all five melts are included in the analysis in Sec. 4.3. 


\subsection{TP Realizations Using Immersion Cells}

The initial trials starting in April of 2016 were all performed in a continuous melting mode. As already mentioned in Sec. 3.6, we observed spontaneous instabilities in the melt plateau temperature in the continuous heating mode using immersion cells. These instabilities manifested as relatively abrupt step increases in the cell temperature, on the order of $1 \mathrm{mK}$ or larger, depending on the heating rate and the fraction melted. These instabilities precluded obtaining any reproducible data much above $F \approx 25 \%$. Similar instabilities have been reported by Dedyulin [33], [34] in $\mathrm{SF}_{6} \mathrm{TP}$ realizations at the National Research Council of Canada.

The step melting approach as described in Sec. 3.6 was initiated later in April of 2017 and yielded reproducible plateau temperatures provided that the heat transfer coefficient, as mediated by the heatexchange gas, was reasonably constant during the course of a given melt. When this assumption was satisfied, the amount of heat absorbed by the cell was proportional to the cell-bath temperature difference and the duration of a heating step. This allowed us to calculate the fraction melted as a function of time during the melt process. Data taken during a quasi-adiabatic interval between the melt steps were then assigned to that value of $F$.

The heat-transfer coefficient between the cell and the bath is primarily determined by the heatexchange gas inside the vacuum chamber. The composition of this gas was nominally either pure argon or pure nitrogen as supplied by regulated gas cylinders. Some contamination of the exchange gas would occur when leaks were present, and this was often a problem during use of the immersion cells due to ineffective elastomer seals. The $6.35 \mathrm{~mm}$ ID O-ring seals in the fittings that sealed the fill-line tubing to the ISO-63 vacuum flange would always leak to some extent, allowing a combination of ethanol, water, and air to enter the vacuum chamber and mix with the otherwise pure exchange gas. The vapor pressures of both ethanol and water at $-49.6{ }^{\circ} \mathrm{C}$ are sufficiently low that those contaminants make a negligible contribution to the gas-phase heat exchange. Any air leaks, however, would have increased the effective thermal conductivity of the heat-exchange gas when argon was used as the prime constituent. These effects increase the uncertainty in our knowledge of $F$ for most of the immersion cell melts.

Table 6 summarizes all of the immersion cell melts, including those used for the final data compilation presented in Sec. 4.3. Two melts were made using cell $\mathrm{s} / \mathrm{n} 801$, and nine melts were made using cell $\mathrm{s} / \mathrm{n}$ 1202 under varying experimental conditions. However, only some of those melts were made using the step melting approach, and not all melts included immersion profiles. For the purposes of making accurate pressure head corrections, only those melts where immersion profiles were performed under quasi-adiabatic conditions or otherwise low melted fractions (i.e., stable plateaus) at a known $F$ value are included in the final data compilation.

Table 6. Immersion cell melt data summary. Those immersion profiles included in the determination of the pressure head coefficient are shown as underlined.

\begin{tabular}{|c|c|c|c|c|}
\hline Cell & Melt No. & Dates & Immersion Profiles, $F(\%)$ & Exchange Gas \\
\hline 1202 & 1 & 31-Mar-17 to 4-Apr-17 & 35.9 & Air \\
\hline 1202 & 2 & 7-Apr-17 to $10-A p r-17$ & none & Air \\
\hline 1202 & 3 & 14-Apr-17 to 18 -Apr-17 & $\underline{38.6}$ & $\mathrm{Ar}$ \\
\hline 1202 & 4 & 19-Apr-17 to $25-\mathrm{Apr}-17$ & $11.7 ; 16.2 ; \underline{31.9} ; \underline{37.0}$ & $\mathrm{Ar}$ \\
\hline 1202 & 5 & $26-A p r-17$ to $27-A p r-17$ & none & $\mathrm{He}$ \\
\hline 1202 & 6 & 28-Apr-17 to 2-May-17 & $22.2 ; 35.2 ; 54.5$ & $\mathrm{Ar}$ \\
\hline 1202 & 7 & 3-May-17 to 4-May-17 & none & $\mathrm{Ar}$ \\
\hline 1202 & 8 & 4-May-17 to 8-May-17 & $40.4 ; \underline{54.3}$ & $\mathrm{Ar}$ \\
\hline 1202 & 9 & 9-May-17 to $12-$ May-17 & $14.8 ; \underline{35.7} ; \underline{55.9} ; 75.1 ;$ & $\mathrm{Ar}$ \\
\hline 801 & 1 & 26-Jun-17 to $18-J u l-17$ & $\begin{array}{l}18.9 ; 21.3 ; 23.3 ; 25.4 ; 27.4 ; \underline{36.1} \\
41.6 ; \underline{44.0} ; \underline{46.0} ; \underline{54.8} ; \underline{57.0} ; 59.2 ; \\
65.1 ; 74.0 ; 86.6\end{array}$ & $\mathrm{~N}_{2}$ \\
\hline 801 & 2 & 20-Jul-17 to 1 -Aug-17 & $\begin{array}{l}21.4 ; \underline{32.0} ; 39.4 ; \underline{45.1} ; \underline{51.8} ; \underline{57.1} ;\end{array}$ & $\mathrm{Ar}$ \\
\hline
\end{tabular}




\subsubsection{Determination of the pressure head correction coefficient}

In order to test the assumptions described in Sec. 2.3, as well as to evaluate the heat-flux effect while measuring the two immersion cells, both were subjected to immersion testing. The tests consisted of measuring the SPRT while inserting it into the cells' thermometric well in $1 \mathrm{~cm}$ steps, starting from $7 \mathrm{~cm}$ above the full insertion depth (i.e bottom of thermowell) and moving downward, all while keeping the cell on a stable portion of the melt plateau under quasi-adiabatic conditions. These measurements were used to estimate the pressure head correction coefficient for the $\mathrm{SF}_{6}$.

As discussed in Sec. 2.3, the temperature of the $\mathrm{SF}_{6} \mathrm{TP}$ is linearly dependent on the immersion depth due to the static pressure effect. Thus, the measured data on each test were used to estimate the line (slope) that best described the temperature/depth relation $\mathrm{d} T / \mathrm{d} z$. A slope selection criterion was developed to treat the effects of heat-flux distortions as illustrated in Fig. 11.

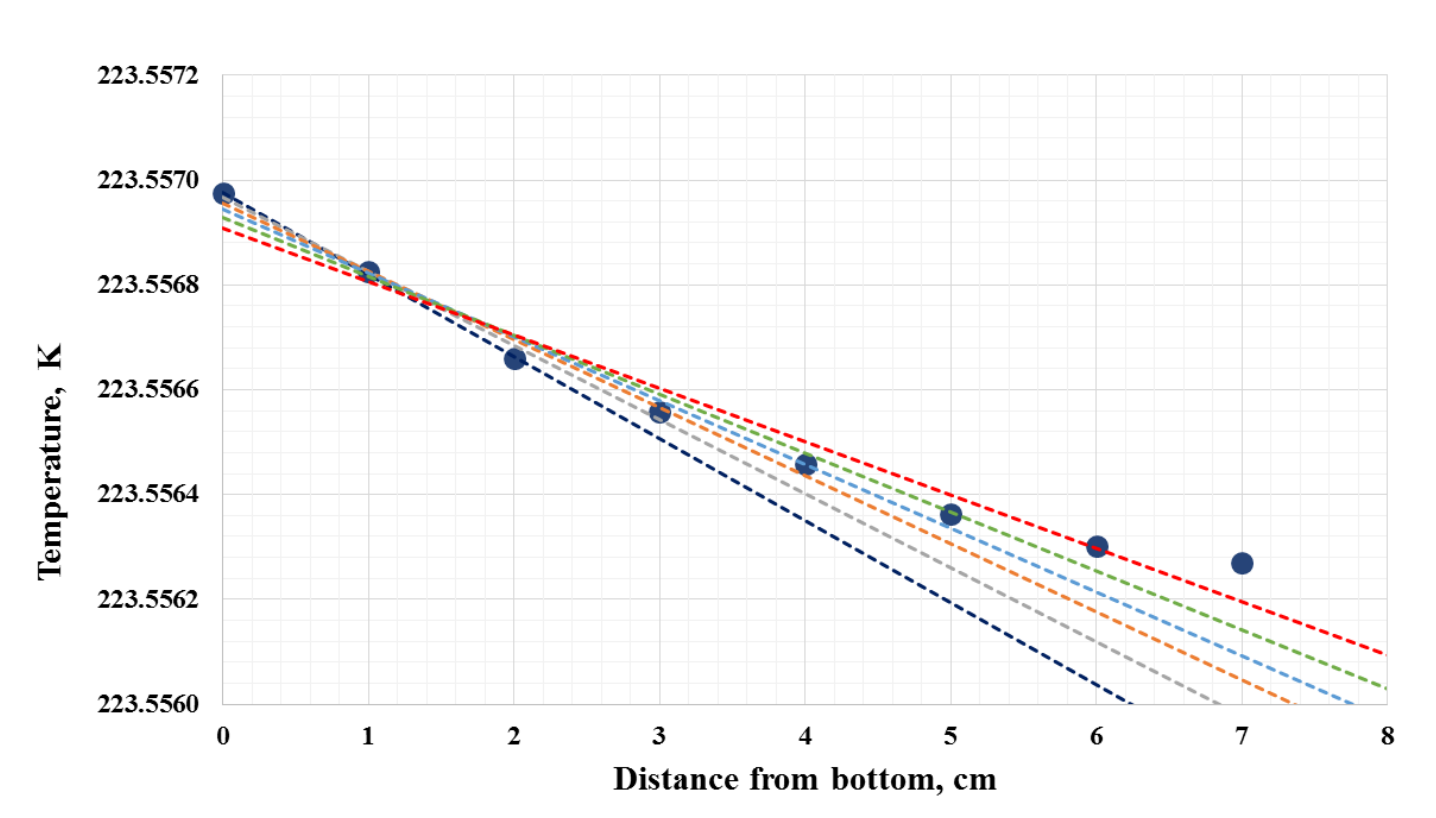

Fig. 11. Example of an immersion profile measurement with a moderate degree of distortion. Each different line was obtained from a different number of points. Data set was deliberately selected to illustrate the heat-flux effect at higher positions.

For each immersion profile measurement, up to 11 straight lines were fitted using least-squares, employing a different number of points, starting from the bottom and also from $1 \mathrm{~cm}$ above it, in such a way that all lines fitted from three to eight points, ensuring at least one degree of freedom.

To select the best estimate of the slope, we considered two major effects that contribute to the misalignment of the data: (1) imperfect vertical positioning, and (2) heat flux, especially at high melted fractions (as described in Sec. 3.6). Both effects may produce errors, but the latter is primarily a systematic effect (as shown in Fig. 11). For the selection of the best slope $m_{\mathrm{i}}$, we chose a statistical criterion that is a compromise between a minimum variance and maximal degrees of freedom for all linear fits within these particular profile data. We chose the slopes $m_{i}$ that maximized the ratio

$$
w_{i}=\frac{v_{i}}{\sigma_{i}^{2}}
$$


for each profile data set $i$, where $\sigma_{i}$ and $v_{i}$ are the uncertainty of the slope $m_{i}$ and the number of degrees of freedom of the fitted line, respectively. (Throughout this paper, we report the statistical, standard uncertainty corresponding to a $68 \%$ confidence level.) This choice favored somewhat larger $v_{i}$ (i.e., larger $\Delta z_{\max }$ cutoffs) in the data, allowing the inclusion of longer vertical excursions in the immersion data sets than would otherwise be included by a simple minimal variance criterion. All fittings provided triplets $\left\{m_{i}\right.$; $\left.\sigma_{i} ; v_{i}\right\}$, which were used to determine the best result for a particular profile. The profile measurements were performed with both immersion cells (s/n 1202 and s/n 801), and the results were restricted to those between $30 \%$ and $80 \%$ of melted fraction, amounting to 20 independent immersion profile data sets. Figure 12 illustrates the distribution of a restricted set of experimental slopes (hereafter referred to as "pressure head coefficients") over the range of melted fraction $F$.

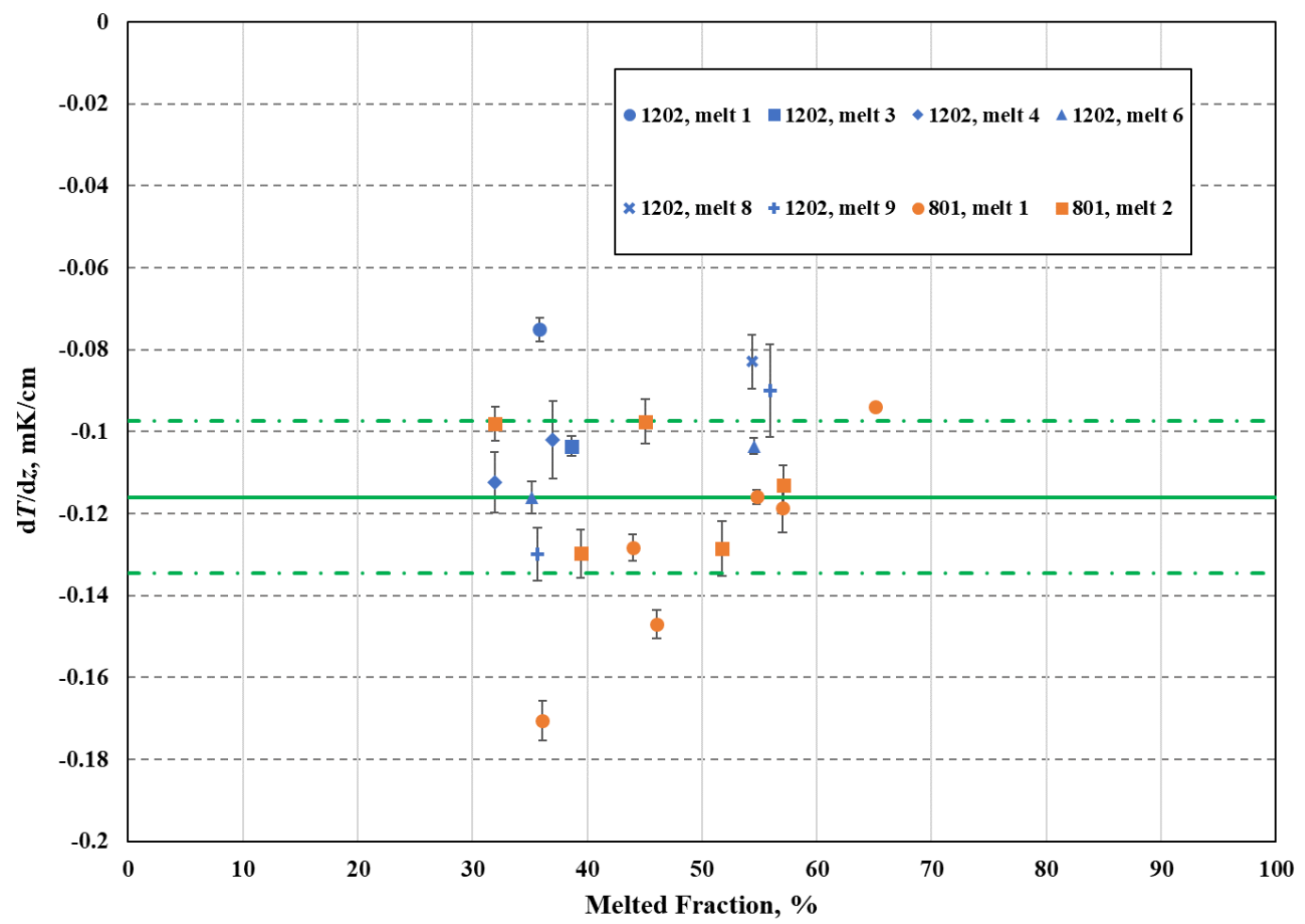

Fig. 12. Immersion profile results showing the restricted set of pressure head coefficients for $30 \% \leq F \leq 80 \%$ with uncertainties $\sigma_{i}$ The weighted average pressure head coefficient is shown by the solid green line, and its uncertainty limits are shown by the dashed green lines.

For averaging the results, the values of degrees of freedom were taken as weights instead of $w_{i}$. The resulting weighted average value of the pressure head coefficient was $\mathrm{d} T / \mathrm{d} z=-0.116(17) \mathrm{mK} / \mathrm{cm}$ (the value in parentheses is the standard uncertainty for the last two digits). This agreement with the value calculated in Sec. 2.3 is entirely fortuitous given the $15 \%$ uncertainty of the measurements. We investigated other weighting schemes, such as using $w_{\mathrm{i}}$ to combine the data. However, in that case, the resulting distributions were highly skewed due to the disproportionate influence of a small number of lowuncertainty results. 
As a systematic check, we also evaluated the slope data for each cell separately, again using the same weighted averaging procedure. This resulted in different values of $\mathrm{d} T / \mathrm{d} z=-0.102(14) \mathrm{mK} / \mathrm{cm}$ for cell $\mathrm{s} / \mathrm{n}$ 1202 and $\mathrm{d} T / \mathrm{d} z=-0.125(12) \mathrm{mK} / \mathrm{cm}$ for cell $\mathrm{s} / \mathrm{n} 801$. Both individual cell coefficients are within the $15 \%$ $(k=1)$ bounds for uncertainty associated with the weighted mean of $-0.116(17) \mathrm{mK} / \mathrm{cm}$ for the combined cell distribution.

\subsection{Determination of the $\mathrm{SF}_{6}$ Triple-Point Temperature}

The TP temperatures, $T_{\mathrm{tp}}(F)$, were derived for each cell as a function of $F$. In the case of the two immersion-type cells, a static pressure head correction $\Delta T_{\mathrm{z}}$ was applied according to

$$
\left.T_{\mathrm{tp}}=T_{\mathrm{m}}(0)=T_{\mathrm{m}}\left(z_{\mathrm{eff}}\right)+\Delta T_{z}=T_{\mathrm{m}}\left(z_{\mathrm{eff}}\right)+\frac{d T}{d z}\right] \Delta z_{\mathrm{eff}}
$$

where $T_{\mathrm{m}}\left(z_{\text {eff }}\right)$ is the temperature of a point on the melting line at a pressure $p_{\mathrm{tp}}+\rho g \Delta z_{\text {eff }}$, and $\Delta z_{\text {eff }}$ is a displacement below the free surface at $z_{\text {eff }}=0$ (see Sec. 2.3). We used the value $\mathrm{d} T / \mathrm{d} z=-0.116 \mathrm{mK} / \mathrm{cm} \mathrm{for}$ the static head coefficient (Sec. 2.3) and the values for $\Delta z_{\text {eff }}$ given in Table 3. No correction was applied for $T_{\text {tp }}$ using the adiabatic cells, since $\Delta z_{\text {eff }} \approx 0 \mathrm{~cm}$ for those cells, but a related uncertainty is still applicable (see Sec. 4.4.5).

The values of $\Delta z_{\text {eff }}$ for the two immersion cells were calculated based on the known interior cell dimensions, the measured net mass of $\mathrm{SF}_{6}$, and the liquid-phase density. A correction to the calculated liquid column $h_{\mathrm{SF} 6}$ was then applied to account for the volume contraction of the solid using the factor $h_{\text {sol }} / h_{\text {liq }}=\left(\rho_{\text {liq }} / \rho_{\text {sol }}\right)^{1 / 3}=0.9315$. The assumption here is that the inner melt creates a column of liquid along the exterior of the thermowell that is the same height as that of the solid.

In total, 17 separate melts distributed among the four cells were analyzed for the range $2.3 \% \leq F \leq$ $97.0 \%$. The combined results are shown in Fig. 13 on a linear $F$ scale. The observed plateau for melt temperatures has three distinct regions. For $F \leq 30 \%$, there is a steep portion of the melting plateau where the temperatures are noticeably depressed. In the midsection of the plateau, $30 \% \leq F \leq 80 \%$, the $F$ dependence becomes significantly weaker and is approximately linear. The fitted linear slopes ("fit A") for each cell's combined data in this region vary between $0.35 \mathrm{mK}$ and $0.6 \mathrm{mK}$ over that $\Delta F=50 \%$ wide range. The linear fits as shown in Fig. 13 all agree at $F=50 \%$ to within $<0.2 \mathrm{mK}$. The third region of the plateau for $F>80 \%$ is observed to be much less reproducible where the presumed effects of heat leaks become more pronounced and produce scatter in the data. The fit A extrapolations to $F=1$ agree to within $<0.22 \mathrm{mK}$; however, we do not assign any physical significance to extrapolations that are linear in $F$. 


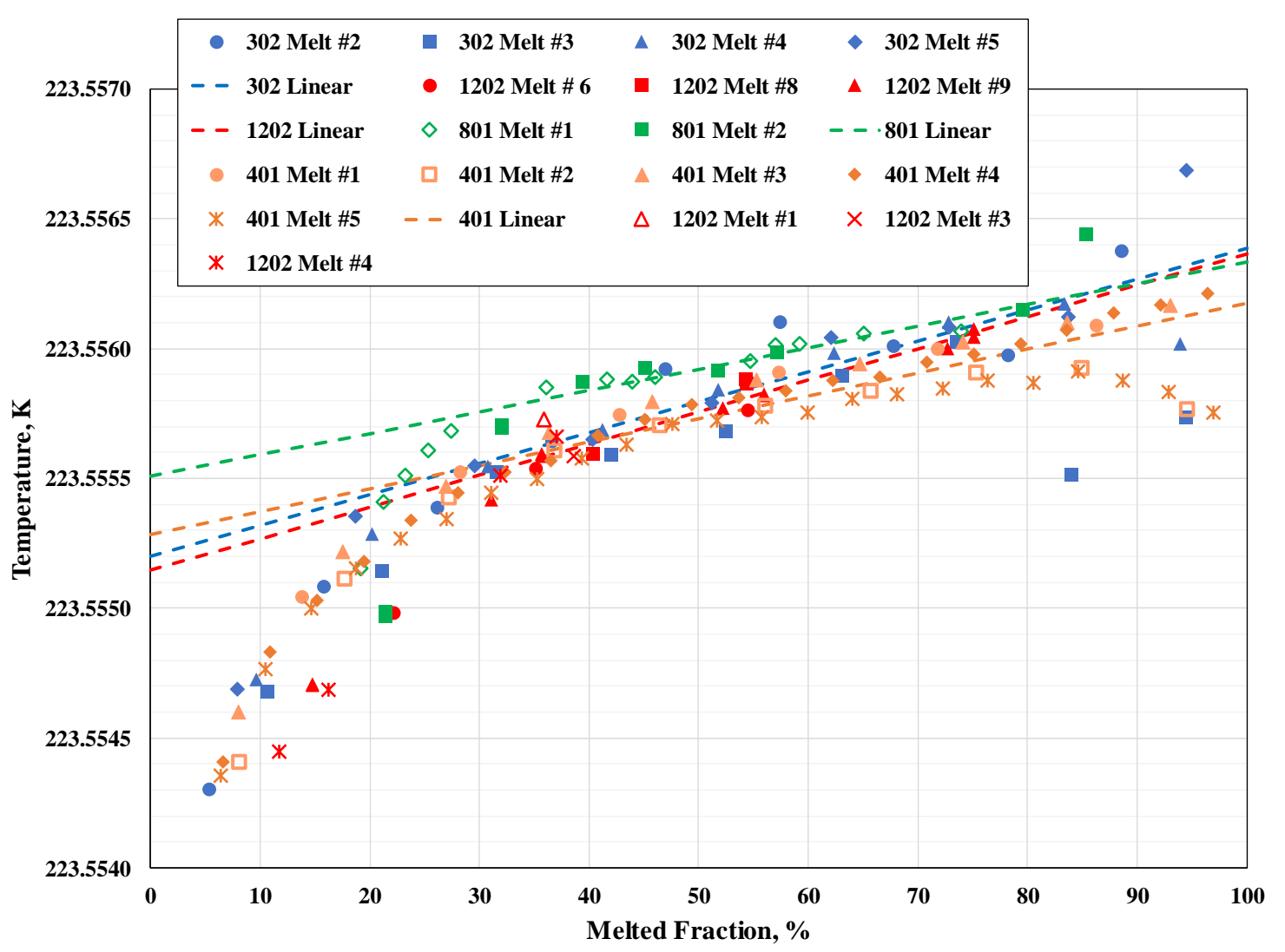

Fig. 13. The combined results for all melts using all four $\mathrm{SF}_{6}$ cells, including immersion corrections. Random uncertainties in temperature are $<\sim 0.1 \mathrm{mK}$, so error bars have been omitted for clarity. The linear fits (fit A) for the combined results of each cell were derived from the restricted range $30 \% \leq F \leq 80 \%$ but are shown extrapolated beyond those limits.

These same data are aggregated for each of the four cells and plotted versus a log scale in $F^{-1}$ in Fig. 14. A new set of fits is shown for the four cells ("fit B") that are linear in $F^{-1}$. The log scale induces an apparent curvature. The use of $F^{-1}$ as the independent variable is preferable to $F$ for three reasons. First, it allows a better representation of the melt curve at low melted fractions, and the series 'B' fits in $F^{-1}$ are thus extended below the $F=30 \%$ limit of the series A fits. Second, there is a physico-chemical basis for $1 / F$ dependence in melting curves from the standpoint of liquid-phase impurities [34]. Third, the fit $\mathrm{B}$ statistical uncertainties for the $F=1$ extrapolated temperatures are all lower than those from fit $\mathrm{A}$, and the agreement between the four cells is within $0.23 \mathrm{mK}$. 


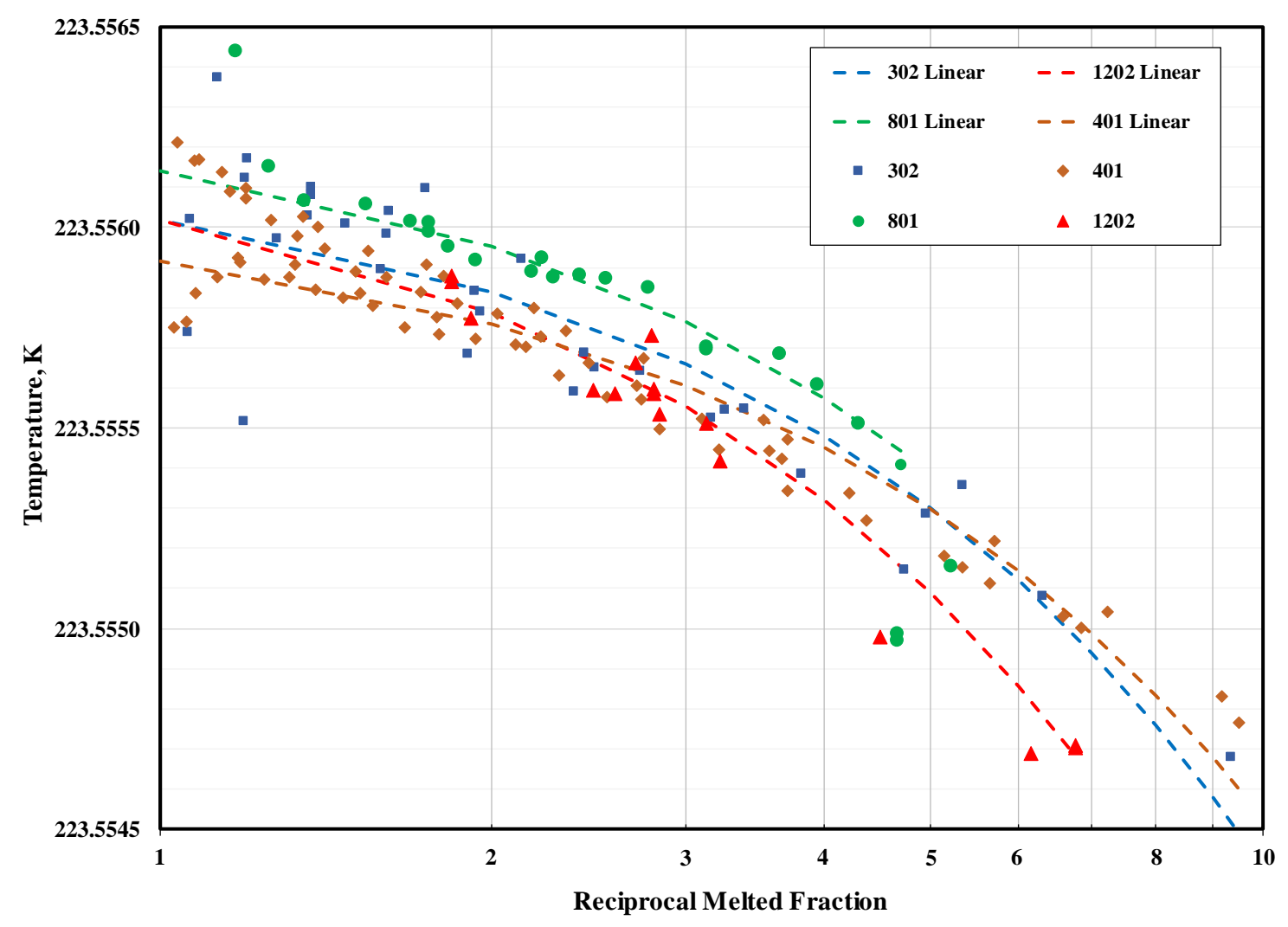

Fig. 14. The combined results for all melts for each of the four $\mathrm{SF}_{6}$ cells, including pressure head corrections, plotted versus the reciprocal of the melted fraction $F^{-1}$. Random uncertainties in temperature are < 0.1 mK, so again error bars have been omitted for clarity. The four linear fits in $F^{-1}$ (fit B) for each cell were derived from restricted ranges between lower limits of $F=0.1(\mathrm{~s} / \mathrm{n} 302$ and $\mathrm{s} / \mathrm{n} 401), F=0.22(\mathrm{~s} / \mathrm{n} 801)$, and $F=0.15$ (s/n 1202) and in all cases an upper limit of $F \leq 0.8$ but are all shown extrapolated to $F=1$.

Other functional forms for $T(F)$ are also possible, some of which can yield lower statistical fitting uncertainties as well as better agreement in the liquidus point $T(1)$ between the four samples. A more general form is $T(F)=T_{0}+c F^{-y}$, where $0 \leq y \leq 1$. Such melting curves would be consistent with effects due to impurities soluble in the solid phase with solid/liquid distribution coefficients $1 \geq k_{\mathrm{s}, 1} \geq 0$, where $-y=$ $k_{\mathrm{s}, 1}-1$ [35]. We investigated fitting functions of this form ("fit C") and found that fits with $0.5 \leq y \leq 0.8$ do yield slightly better fit statistics than those of fit B (the special case of $y=1$ ). In particular, $y=0.8$ also results in lower dispersion in the liquidus points for three out of the four cells. The liquidus temperature for cell $\mathrm{s} / \mathrm{n} 401$ is not as well aligned with the other three cells unless a lower value exponent (i.e., $y=0.6$ ) is chosen for that fit $\mathrm{C}$ curve. The fit $\mathrm{C}$ curves for all four cells are shown in Fig. 15 in a plot that is otherwise identical to Fig. 14. The fitting ranges in $F$ for the fit $\mathrm{B}$ and fit $\mathrm{C}$ curves are the same, and the fit parameters are listed in Table 7 for all four cells. The fit statistic $S=\left[\Sigma\left(T_{i}-T\left(F_{i}\right)\right)^{2} /(n-2)\right]^{1 / 2}$ is listed for each of the eight curves.

Table 7. Summary of fit B $(y=1)$ and fit C parameters (and standard statistical uncertainties), for the four cells.

\begin{tabular}{|l|l|l|l||l|l|l|l|}
\hline Cell & $T_{0}$, fit B $(\mathrm{K})$ & $c$, fit B $(\mathrm{K})$ & $S$, fit B $(\mathrm{mK})$ & $T_{0}$, fit C $(\mathrm{K})$ & $c$, fit C $(\mathrm{K})$ & $S$, fit C $(\mathrm{mK})$ & $y$, fit C \\
\hline 302 & $223.556199(43)$ & $-1.80(12) \times 10^{-4}$ & 0.118 & $223.556363(47)$ & $-3.00(18) \times 10^{-4}$ & 0.106 & 0.8 \\
\hline 401 & $223.556069(31)$ & $-1.54(5) \times 10^{-4}$ & 0.094 & $223.556443(37)$ & $-4.52(13) \times 10^{-4}$ & 0.080 & 0.6 \\
\hline 801 & $223.556330(22)$ & $-1.89(9) \times 10^{-4}$ & 0.032 & $223.556447(26)$ & $-2.86(12) \times 10^{-4}$ & 0.030 & 0.8 \\
\hline 1202 & $223.556252(37)$ & $-2.33(10) \times 10^{-4}$ & 0.084 & $223.556466(39)$ & $-3.88(14) \times 10^{-4}$ & 0.062 & 0.8 \\
\hline
\end{tabular}




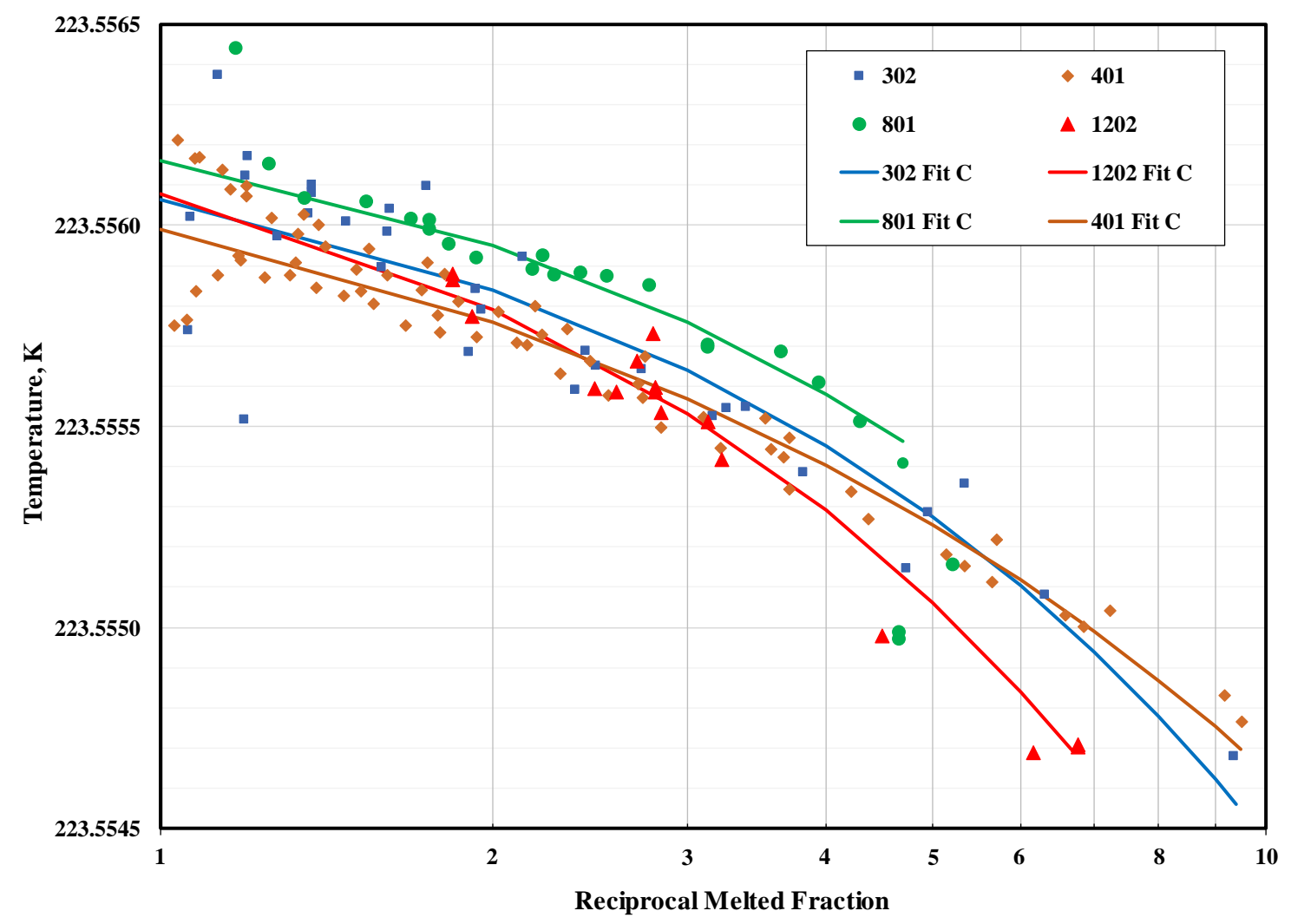

Fig. 15. The combined results for all melts for each of the four $\mathrm{SF}_{6}$ cells, as duplicated in Fig. 14, and fit $\mathrm{C}$ curves plotted versus the reciprocal of the melted fraction $F^{-1}$. The four fits (fit C) are proportional to $F^{-\mathrm{y}}$ (see Table 7) and are derived from the same restricted ranges between lower limits of $F=0.1(\mathrm{~s} / \mathrm{n} 302$ and s/n 401), $F=0.22(\mathrm{~s} / \mathrm{n} 801)$ and $F=0.15(\mathrm{~s} / \mathrm{n} 1202)$ and in all cases an upper limit of $F \leq 0.8$ but are all shown as extrapolated to $F=1$.

In Table 8, we have listed the TP temperatures for each of the four cells as determined by all three sets of fits at $F=50 \%$ and as extrapolated to $F=100 \%$ (liquidus point) for fits B and C, with their respective statistical uncertainties. These temperatures are tabulated with the statistical uncertainties as calculated according to the conventional least-squares methods.

We combined these TP temperatures and uncertainties for all four cells to yield weighted mean values $\overline{T_{\mathrm{tp}}}$ as shown in the bottom row of Table 8 . The weighted mean values for fit $\mathrm{B}$ and fit $\mathrm{C}$ differ by only $0.031 \mathrm{mK}$. We used the fit $\mathrm{C}$ (linear in $F^{-\mathrm{y}}$ ) weighted mean temperatures as shown in Table 8 for our best estimated triple-point temperatures, $T_{\mathrm{tp}}(0.5)=223.55587(1) \mathrm{K}$ and $T_{\mathrm{tp}}(1.0)=223.55607(1) \mathrm{K}$. The uncertainties quoted here are purely statistical and unrealistically small, since the dispersion in the temperatures among the four cells is much larger (the fit $\mathrm{C}$ values for $T_{\mathrm{tp}}(0.5)$ differ by $0.19 \mathrm{mK}$ across all four cells). The fit $\mathrm{C}$ uncertainties for the adiabatic cells were combined to yield $s_{\mathrm{ad}}(0.5)=0.016 \mathrm{mK}$ and $s_{\mathrm{ad}}(1)=0.024 \mathrm{mK}$. Similarly, we have $s_{\mathrm{im}}(0.5)=0.014 \mathrm{mK}$ and $s_{\mathrm{im}}(1)=0.021 \mathrm{mK}$ for the immersion cells. The normal least-squares standard error calculations assume all the data are Gaussian. In contrast, the distribution of the cell's triple-point temperatures is dominated by systematic effects and is not Gaussian. In Sec. 4.4, we calculate several type-B uncertainty components that are 10 to 20 times larger than these statistical uncertainties. 
Table 8. Summary of TP realization temperatures (and statistical uncertainties), in kelvin. The realization temperatures are shown for $F=50 \%$ and $F=100 \%$ as determined by a linear fit in $F$ (fit A), and a linear fit in $F^{-1}$ (fit B).

\begin{tabular}{|l|l||l|l||l|l|}
\hline Cell & $\begin{array}{l}T_{\text {tp }}(0.5), \text { fit A } \\
(\mathrm{K})\end{array}$ & $\begin{array}{l}T_{\mathrm{t}}(0.5), \text { fit B } \\
(\mathrm{K})\end{array}$ & $\begin{array}{l}T_{\text {tp }}(1), \text { fit B } \\
(\mathrm{K})\end{array}$ & $\begin{array}{l}T_{\text {tp }}(0.5), \text { fit C } \\
(\mathrm{K})\end{array}$ & $\begin{array}{l}T_{\text {tp }}(1), \text { fit C } \\
(\mathrm{K})\end{array}$ \\
\hline 302 & $223.55579(2)$ & $223.55584(3)$ & $223.55602(3)$ & $223.55584(2)$ & $223.55606(3)$ \\
\hline 401 & $223.55573(1)$ & $223.55576(1)$ & $223.55591(2)$ & $223.55576(1)$ & $223.55599(1)$ \\
\hline 801 & $223.55592(1)$ & $223.55595(1)$ & $223.55614(1)$ & $223.55595(1)$ & $223.55616(1)$ \\
\hline 1202 & $223.55576(1)$ & $223.55579(2)$ & $223.55602(3)$ & $223.55579(2)$ & $223.55608(3)$ \\
\hline$\overline{T_{\text {tp }}}$ & $223.55582(1)$ & $223.55589(1)$ & $223.55604(1)$ & $223.55587(1)$ & $223.55607(1)$ \\
\hline
\end{tabular}

\subsection{Uncertainties}

We independently evaluated all known sources of uncertainty that were not purely statistical in origin (i.e., "type B") following the general principles outlined in the Guide to (the Expression of) Uncertainty in Measurement (GUM) [36]. The uncertainties are summarized in Table 9. The estimated standard uncertainties were separately evaluated for adiabatic and immersion-type realizations and, in some cases, further divided for $F=0.5$ and $F=1.0$ melted fractions. The statistical uncertainties were taken from the type $\mathrm{C}$ fits $\left(s_{\mathrm{ad}}(F)\right.$ and $\left.s_{\mathrm{im}}(F)\right)$ as described in the previous section. All other uncertainties in Table 9 are estimates of systematic effects, otherwise known as "type B" uncertainties. These type B uncertainties are labeled $u_{i}$ for $i=1$ to 10 according to the subsection in which they are described below.

Table 9. Summary of standard uncertainties for the realization of the TP temperatures using adiabatic and immersion-type cells, in units of $\mathrm{mK}$.

\begin{tabular}{|c|c|c|c|c|c|c|}
\hline & \multicolumn{2}{|c|}{ Adiabatic } & \multicolumn{2}{|c|}{ Immersion } & \multirow[t]{2}{*}{ Distribution } & \multirow[t]{2}{*}{ Notes } \\
\hline Component & $F=0.5$ & $F=1.0$ & $F=0.5$ & $F=1.0$ & & \\
\hline "Statistical & 0.016 & 0.024 & 0.014 & 0.021 & Gaussian & 4.3 \\
\hline Chemical impurities & \multicolumn{2}{|l|}{0.138} & \multicolumn{2}{|l|}{0.138} & Rectangular & 4.4 .1 \\
\hline Plateau specification & 0.003 & 0.002 & 0.021 & 0.011 & Combination & 4.4 .2 \\
\hline Heat leaks & \multicolumn{2}{|l|}{0.065} & \multicolumn{2}{|l|}{-} & Rectangular & 4.4 .3 \\
\hline Immersion errors & \multicolumn{2}{|c|}{-} & \multicolumn{2}{|l|}{0.050} & Gaussian & 4.4 .4 \\
\hline Head correction & \multicolumn{2}{|l|}{0.11} & \multicolumn{2}{|l|}{0.12} & Combination & 4.4 .5 \\
\hline Extrapolation error & - & 0.106 & - & 0.106 & Gaussian & 4.4 .6 \\
\hline ITS-90 realization & \multicolumn{2}{|l|}{0.25} & \multicolumn{2}{|l|}{0.25} & Combination & 4.4 .7 \\
\hline WTP propagation & \multicolumn{2}{|l|}{0.078} & \multicolumn{2}{|l|}{0.078} & Gaussian & 4.4 .8 \\
\hline SPRT self-heating & \multicolumn{2}{|l|}{0.058} & \multicolumn{2}{|l|}{0.058} & Rectangular & 4.4 .9 \\
\hline Bridge uncertainty & \multicolumn{2}{|l|}{0.032} & \multicolumn{2}{|l|}{0.032} & Gaussian & 4.4 .10 \\
\hline "Total combined & 0.33 & 0.35 & 0.33 & 0.35 & & \\
\hline
\end{tabular}

\subsubsection{Chemical Impurities}

Our source of $\mathrm{SF}_{6}$ as described in Sec. 3.3 has a known air impurity content of $3.3 \times 10^{-6}$ by volume, which we assume is equivalent to a mole fraction impurity. We expect that the $\mathrm{O}_{2}$ component is completely removed by our gas purifier, but the $\mathrm{N}_{2}$ content is not removed. Assuming the composition ratios are those of the sea-level atmosphere, the only remaining volatile impurity of any consequence is $\mathrm{N}_{2}$ in the amount fraction of $X_{\mathrm{N} 2} \approx 2.6 \times 10^{-6}$. In Raoult's law approximation (i.e., fit B), this would depress the melting point at $F=1$ by an amount $X_{\mathrm{N} 2} A^{-1}=0.2 \mathrm{mK}$ and would also produce a slope to the melting curve, expressed as temperature change over the final $\Delta F=50 \%$ (i.e., $T(1)-T(0.5)$ ) melted fraction of $0.2 \mathrm{mK}$ when plotted against $1 / F$. However, this is a simplification that ignores partitioning of the impurity between the vapor and liquid phases. 
In practice, we expect the amount of $\mathrm{N}_{2}$ dissolved in the liquid phase to be lower than the total amount present in a given cell due to the finite value of the vapor-liquid distribution coefficient, $k_{\mathrm{v}, 1}\left(T_{\mathrm{tp}}\right)=X_{\mathrm{N} 2 \mathrm{v}} / X_{\mathrm{N} 2 \mathrm{l}}$ $=35$, as calculated in Sec. 2.4 and expressed as a mole fraction ratio. Given the total molar $\mathrm{N}_{2}$ impurity content of a cell $n_{\mathrm{N} 2}=X_{\mathrm{N} 2} n_{\mathrm{SF} 6}$ and $n_{\mathrm{N} 2}=n_{\mathrm{N} 2 \mathrm{v}}+n_{\mathrm{N} 21}$, it is straightforward to show that the mole fraction $X_{\mathrm{N} 21}$ of dissolved $\mathrm{N}_{2}$ is given by

$$
X_{\mathrm{N} 21}=\frac{n_{\mathrm{N} 2}}{n_{\mathrm{SF} 61}}\left(1+k_{\mathrm{v}, 1} \frac{V_{\mathrm{SF} 6 \mathrm{v}} \rho_{\mathrm{v}}}{V_{\mathrm{SF} 61} \rho_{1}}\right)^{-1},
$$

where the volumes $V_{\mathrm{SF} 6 \mathrm{v}}$ and $V_{\mathrm{SF} 61}$ refer to the vapor and liquid phases of the $\mathrm{SF}_{6}$ solvent, the densities $\rho_{\mathrm{v}}$ and $\rho_{1}$ refer to the vapor and liquid phases, and $n_{\mathrm{SF} 61}$ is the moles of liquid $\mathrm{SF}_{6}$. Equation (7) predicts a variable liquid-phase impurity fraction at the liquidus condition for each cell depending on the volume ratio of vapor to liquid $\mathrm{SF}_{6}$ present. The actual dissolved $\mathrm{N}_{2}$ fraction will always be lower than $X_{\mathrm{N} 2}$ due to the partitioning of the impurity between the vapor and liquid phases as long as some vapor is present. The predicted slopes in Raoult's law approximation are thus lower than those calculated above when partitioning was ignored. The cell-specific vapor-liquid parameters and Raoult-predicted slopes $\Delta T_{\mathrm{R}}$ for our four cells are listed in Table 10 based on Eq. (7), the cell data from Table 3, the assumed total impurity mole fraction $X_{\mathrm{N} 2} \approx 2.6 \times 10^{-6}$, and the known GW EoS densities shown in Fig. 3. The observed slopes $\Delta T_{\mathrm{B}}$ $=T(1)-T(0.5)$ for the fit B melting curves are larger than these predictions by factors of 1.2 to 2.4 with no obvious correlation to the $X_{\mathrm{N} 21}$ values.

There are, however, other nonideal behaviors that alter the shape of the melting curve, but physical interpretations of the melting curves can be ambiguous [35]. In particular, $\mathrm{N}_{2}$ is known to form eutectic mixtures in binary combinations with $\mathrm{Ar}, \mathrm{O}_{2}$, and $\mathrm{CH}_{4}$ [33], [37]. The net effect of a possible associated solid solution of $\mathrm{SF}_{6}$ and $\mathrm{N}_{2}$ would be to increase the effective sensitivity of the melting curve to the impurity in the dilute limit. If the $\mathrm{N}_{2}$ impurities were soluble in the solid phase of $\mathrm{SF}_{6}$, we could expect finite solid-liquid distribution coefficients $k_{\mathrm{s}, 1} \equiv X_{\mathrm{N} 2 \mathrm{~s}} / X_{\mathrm{N} 21} \neq 0$. Our fit C analysis is an attempt to make allowances for effects of solid-phase impurities, and an exponent of $y=0.8$ implies a distribution coefficient of $k_{\mathrm{s}, 1}=0.2$. In this case we can't necessarily make an $a b$ initio prediction for the extent of the temperature depressions, but we note that the slopes, $\Delta T_{\mathrm{C}}=T(1)-T(0.5)=-0.74 \mathrm{c}$, range from $0.21 \mathrm{mK}$ to $0.29 \mathrm{mK}$ (see Table 10) given the fit parameters in Table 7. The fit $\mathrm{C}$ slopes are also uncorrelated with the $X_{\mathrm{N} 21}$ values. A comparison of fit B and fit $\mathrm{C}$ extrapolations to the liquidus point yields differences less than $0.06 \mathrm{mK}$ for three of the four cells and less than $0.08 \mathrm{mK}$ for cell $\mathrm{s} / \mathrm{n} 401$. The fact that the s/n 401 cell sample is more consistent with a distribution coefficient of $k_{\mathrm{s}, 1}=0.4$ (i.e., $y=0.6$, and $\Delta T_{\mathrm{C}}=-0.52 c$ ) suggests that an impurity other than $\mathrm{N}_{2}$ may be present in that case. Problems that occurred during the arcwelding operation to seal off this cell make argon contamination a plausible explanation. Other known volatile impurities such as $\mathrm{CF}_{4}$ could, in principle, also have some influence on all of the samples, but the nominal $\mathrm{CF}_{4}$ mole fraction (Table 4) is a factor of ten lower than that of $\mathrm{N}_{2}$.

Table 10. $\mathrm{SF}_{6} \mathrm{TP}$ cell vapor-liquid parameters as used for $\mathrm{N}_{2}$ impurity calculations.

\begin{tabular}{|l|l|l|l|l|l|l|l|l|l|}
\hline Cell & $\begin{array}{l}\text { Total } \\
n_{\mathrm{SF} 6}\end{array}$ & $\begin{array}{l}\text { Liquid } \\
n_{\mathrm{SF61}}\end{array}$ & $\begin{array}{l}\text { Vapor } \\
n_{\mathrm{SF} 6 \mathrm{v}}\end{array}$ & $\begin{array}{l}\text { Total } \mathrm{N}_{2}, \\
n_{\mathrm{N} 2}\end{array}$ & $\begin{array}{l}\mathrm{N}_{2} \text { in Liquid, } \\
X_{\mathrm{N} 21}\end{array}$ & $\begin{array}{l}\mathrm{N}_{2} \text { in Vapor, } \\
X_{\mathrm{N} 2 \mathrm{v}}\end{array}$ & $\begin{array}{l}\text { Predicted Slope, } \\
\Delta T_{\mathrm{R}}\end{array}$ & $\begin{array}{l}\text { Slope, } \\
\Delta T_{\mathrm{B}}\end{array}$ & $\begin{array}{l}\text { Slope, } \\
\Delta T_{\mathrm{C}}\end{array}$ \\
\hline $\mathrm{s} / \mathrm{n}$ & $(\mathrm{mol})$ & $(\mathrm{mol})$ & $(\mathrm{mol})$ & $(\mu \mathrm{mol})$ & $\left(\mu \mathrm{mol} \cdot \mathrm{mol}^{-1}\right)$ & $\left(\mu \mathrm{mol} \cdot \mathrm{mol}^{-1}\right)$ & $(\mathrm{mK})$ & $(\mathrm{mK})$ & $(\mathrm{mK})$ \\
\hline 302 & 0.088 & 0.0836 & 0.0047 & 0.233 & 0.935 & 32.7 & 0.074 & 0.18 & 0.22 \\
\hline 401 & 0.062 & 0.0611 & 0.0012 & 0.164 & 1.58 & 55.3 & 0.124 & 0.15 & 0.23 \\
\hline 801 & 4.04 & 4.004 & 0.035 & 10.7 & 2.04 & 71.3 & 0.160 & 0.19 & 0.21 \\
\hline 1202 & 3.22 & 3.178 & 0.040 & 8.50 & 1.86 & 65.0 & 0.146 & 0.23 & 0.29 \\
\hline
\end{tabular}


The problem of determining the actual value of the overall $\mathrm{N}_{2}$ impurity content $X_{\mathrm{N} 2}$ in a given cell is further complicated by the impurity partitioning that should take place in the $\mathrm{SF}_{6}$ source cylinder at $300 \mathrm{~K}$. Equation (7) should still govern the equilibrium partitioning of impurities, but in this case, the $300 \mathrm{~K}$ value of $k_{\mathrm{v}, \mathrm{l}}=43$ would apply, and the effects are enhanced, since the vapor-liquid density ratio is nearly $16 \%$, compared to the $1 \%$ value at the TP. The cells are filled from the $\mathrm{SF}_{6}$ in vapor phase, which has a much higher mole fraction of the volatile $\mathrm{N}_{2}$ impurities. However, transferring the gas is a dynamical process that removes the impurity-rich vapor from the cylinder at first, while it is continuously replaced by impuritydepleted vapor boiling out of the liquid phase. The lower partial pressure of the $\mathrm{N}_{2}$ gas will eventually drive more $\mathrm{N}_{2}$ out of solution and into the vapor to reequilibrate the partitioning, but this diffusion-limited process may not be able to occur as fast as required during a cell transfer. Moreover, cells that are filled from a full cylinder may contain higher $\mathrm{N}_{2}$ impurities compared to cells that are filled later when the cylinder has less $\mathrm{SF}_{6}$. Our data do exhibit some degree of correlation with filling order, in the sense that temperatures derived from the cell $\mathrm{s} / \mathrm{n} 801$ (having been the last one to be filled) were slightly higher with a somewhat flatter plateau than the others.

Given these complications, and without cell-specific chemical assays, we are unable to make reliable estimates of the actual $\mathrm{N}_{2}$ impurity content inside of any given cell. We make an estimate here based on only the simplest assumptions consistent with some nominal assumed $\mathrm{N}_{2}$ impurity and an observed average melting curve slope of $\Delta T_{\mathrm{C}}=0.24 \mathrm{mK}$ as determined via fit $\mathrm{C}$. We estimate the standard uncertainty from this impurity as $u_{1}=\Delta T_{\mathrm{C}} / 3^{1 / 2}$, which is basically equivalent to the method of overall maximum estimate [35]. This yields $u_{1}=0.138 \mathrm{mK}$, which we assign to all cells. We recognize the fact that the actual $\mathrm{N}_{2}$ impurity fractions are very likely somewhat different across the four cells, but we do not have enough information to take this into account in any meaningful way.

\subsubsection{Plateau Specification}

We specified our TP temperatures at both $F=0.5$ and $F=1.0$, but these $F$ values were experimentally determined with an $F$-dependent uncertainty $u_{F}(F)$. In addition, the observed slope in the plateaus $\mathrm{d} T / \mathrm{d} F$ will produce a corresponding uncertainty in temperature given by $u_{2}(F)=u_{F}(F) \cdot \mathrm{d} T / \mathrm{d} F$. For the $F^{-1}$ representation, $\mathrm{d} T / \mathrm{d} F=\Delta T_{1,0.5}$ at $F=1$ and $\mathrm{d} T / \mathrm{d} F=4 \Delta T_{1,0.5}$ at $F=0.5$, where $\Delta T_{1,0.5} \equiv T(1)-T(0.5) \approx$ $0.2 \mathrm{mK}$.

For the adiabatic cells, the step melting approach results in precise measures of both the step heat inputs and the total heat input. In addition, the effects of the heat leaks on the calorimetry are known, and corrections are straightforward. We estimated our standard uncertainty in $F$ to be $u_{F}(F=0.5)=0.005$ (i.e., $0.5 \%)$ and $u_{F}(F=1)=0.01$ (i.e., $1 \%$ ) for the adiabatic setup as described in Sec. 3.5. This results in the estimated uncertainties of $u_{2}(0.5)=0.003 \mathrm{mK}$ and $u_{2}(1)=0.002 \mathrm{mK}$, which are completely negligible.

In contrast, for the immersion-type cells, the step melting approach is only crudely implemented via the bath set-point temperature and an assumed constant for the heat-transfer coefficient (see related discussions in Sec. 3.6 and Sec. 4.2). Therefore, the corresponding uncertainties for $u_{F}(F)$ are much larger in this case. We estimated our standard uncertainty in $F$ to be $u_{F}(F=0.5)=0.025$ (i.e., $\left.2.5 \%\right)$ and $u_{F}(F=1)$ $=0.05$ (i.e., $5 \%$ ) for the immersion-type cell setup. This results in the estimated uncertainties of $u_{2}(0.5)=$ $0.022 \mathrm{mK}$ and $u_{2}(1)=0.011 \mathrm{mK}$ for the immersion cells.

\subsubsection{Heat Leaks}

The heat-leak uncertainty category is specific to adiabatic realizations and represents the distortions and offsets in the plateaus resulting from imperfect adiabatic conditions. Heat-leak errors may be modeled according to static $\Delta T_{\text {stat }}$ and dynamic $\Delta T_{\text {dyn }}$ temperature measurement error parameterizations [38]. The internal thermal resistance $R_{\mathrm{cs}}$ was estimated for the two adiabatic type cells for $F \approx 50 \%$ based on the observed changes in equilibrium temperatures under known variable heat leaks $P_{\mathrm{e}}$. We estimated $R_{\mathrm{cs}} \approx$ 
$0.2 \mathrm{~K} / \mathrm{W}$ for cell s/n 302 and $R_{\mathrm{cs}} \approx 0.6 \mathrm{~K} / \mathrm{W}$ for cell s/n 401 for $F \approx 50 \%$. This resulted in predicted offsets in the plateau temperatures in the range $-0.085 \mathrm{mK} \leq \Delta T_{\text {stat }} \leq-0.030 \mathrm{mK}$ for cell $\mathrm{s} / \mathrm{n} 302$. There is only a weak correlation between these estimates and the observed variation in plateau temperatures over the four melts, numbers 2 through 5 . The range of predicted offsets for cell $\mathrm{s} / \mathrm{n} 401$ is $-0.120 \mathrm{mK} \leq \Delta T_{\text {stat }} \leq+0.008 \mathrm{mK}$, and these values are strongly correlated with the observed variations in plateau temperatures for that cell's melt numbers 1 through 5 . The effect of averaging the various melts yields mean static error estimates of $\Delta T_{\text {stat }} \approx-0.065 \mathrm{mK}$ and $\Delta T_{\text {stat }} \approx-0.06 \mathrm{mK}$ for the two adiabatic cells, respectively.

The dynamic errors are caused by incomplete equilibration after an applied heat pulse. Typical overheating of $10 \mathrm{mK}$ to $15 \mathrm{mK}$ was observed during heating of these cells for $F \approx 50 \%$, and these values were about ten times higher for $F \approx 85 \%$. To a first approximation, the cell thermal relaxation time is $\tau_{\mathrm{RC}}$ $=C_{\text {cell }} R_{\mathrm{cs}}$, where $C_{\text {cell }}$ is the heat capacity of the cell at the triple-point temperature. We measured the heat capacities of the two adiabatic type cells and found $C_{302} \approx 300 \mathrm{~J} / \mathrm{K}$ and $C_{401} \approx 100 \mathrm{~J} / \mathrm{K}$, so we estimate $\tau_{\mathrm{RC}}=$ $60 \mathrm{~s}$ for both cells for $F \approx 50 \%$. Therefore, a wait interval of $5600 \mathrm{~s}$ corresponds to about 93 time constants, which would reduce any residual equilibration error to a negligible level for these conditions. In practice, more complex relaxation mechanisms are likely present, but we found no evidence that resolvable changes (i.e., $<\approx 0.01 \mathrm{mK}$ ) would take place for wait times beyond $5000 \mathrm{~s}$ for $F<85 \%$. Given that the static errors are dominant, we estimate an uncertainty due to heat leaks of $u_{3}=0.065 \mathrm{mK}$.

\subsubsection{Immersion Errors}

The immersion error uncertainty category is specific to the immersion-type cell realizations and is analogous to the heat-leak category for the adiabatic cells. This uncertainty represents the influence of ambient temperature on the plateaus resulting from imperfect immersion of SPRTs. The effects are mainly due to a loss of effective immersion depth at high melted fractions as measured by the immersion profiles. The profiles are distorted when an excess amount of heat is leaking into the thermowell. As long as the entire cell remains completely submerged in the ethanol bath, the primary source of those heat leaks into the thermowell is the conducted heat from the copper alloy lead wires inside the SPRT adapter tubes. The effective immersion depth is determined by a number of factors, not least of which is the height of the column of solid $\mathrm{SF}_{6}$ coaxial with the thermowell. Our observations of immersion profiles are consistent with the gradual and/or abrupt disintegration of this solid mantle as the melt proceeds.

We estimated the magnitude of these errors by analyzing our immersion profile data using the $\mathrm{d} T / \mathrm{d} z$ value as calculated from GW [7] density and the Harvey [20] melting line (see Sec. 4.2). We determined a dispersion of the data for each immersion test performed with the cells $\mathrm{s} / \mathrm{n} 1202$ and $\mathrm{s} / \mathrm{n} 801$ within the range $30 \% \leq F \leq 80 \%$. The dispersion was obtained using immersion data between $0 \mathrm{~cm}$ and $5 \mathrm{~cm}$ from the bottom of the thermowells, in comparison to the theoretical line (Eq. (3) and Eq. (6)), by

$$
u_{\mathrm{imm}}=\left\{\frac{1}{N-1} \sum_{i=1}^{N}\left[T_{i}-T_{0}-\frac{\mathrm{d} T}{\mathrm{~d} z}\left(z_{i}-z_{0}\right)\right]^{2}\right\}^{1 / 2},
$$

where $T_{0}$ and $T_{i}$ are the temperatures measured at the bottom of the cell $\left(z_{0}=0\right)$ and at the position $z_{i}$. The rightmost term inside the brackets refers to the theoretical line. The dispersion was calculated for 17 of the 20 immersion tests performed to estimate the $\mathrm{d} T / \mathrm{d} z$ in Sec. 4.2, which kept an approximately linear behavior at higher positions (up to $5 \mathrm{~cm}$ ). The data for this estimated uncertainty are shown in Fig. 16. We calculated an average (without weights) value for the immersion error uncertainty component $u_{4}=u_{\mathrm{imm}}=$ $0.05 \mathrm{mK}$. 


\section{Journal of Research of the National Institute of Standards and Technology}

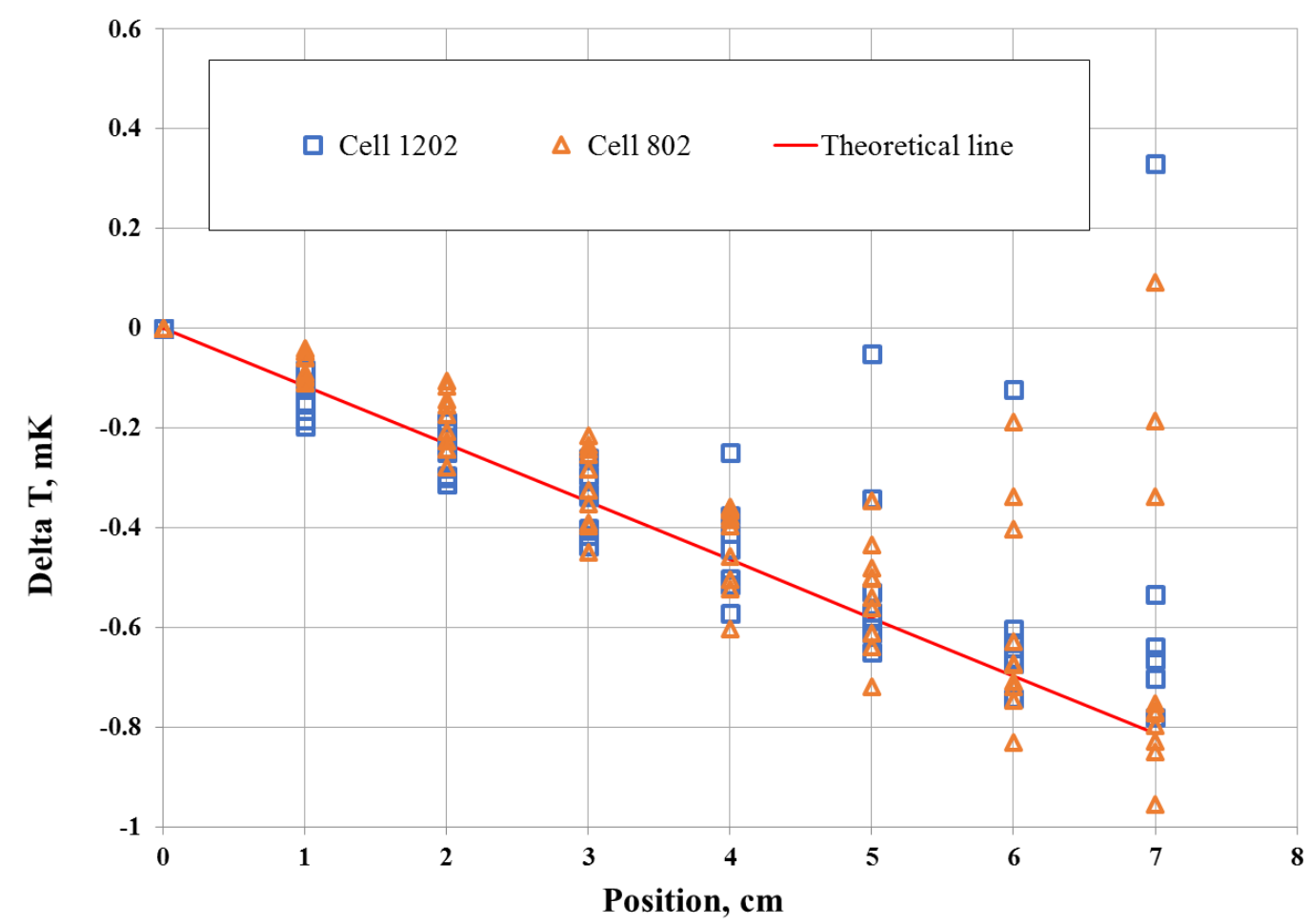

Fig. 16. Results for the 17 immersion profiles included in the immersion error uncertainty estimate.

\subsubsection{Pressure Head Corrections}

The pressure head corrections were applied to the immersion cells only, and these carried a finite uncertainty due to both uncertainties in the head coefficient and in the effective immersion depth, $\Delta z_{\text {eff. }}$. The adiabatic cells were not corrected but were still subject to a smaller uncertainty due to an uncertainty in the effective depth, which is nominally $0 \mathrm{~cm}$. In both cases, we assigned $u^{2}\left(\Delta z_{\text {eff }}\right)=\left(l_{\mathrm{Pt}}\right)^{2} / 12+u^{2}\left(h_{\mathrm{SF} 6}\right)$, where $l_{\mathrm{Pt}}$ $=3 \mathrm{~cm}$ is the active length of the SPRT platinum sensing coil, and $u\left(h_{\mathrm{SF} 6}\right)=0.5 \mathrm{~cm}$ is the uncertainty in height of the free surface of condensed $\mathrm{SF}_{6}$. Starting from Eq. (6), it is straightforward to show that

$$
u_{5}=\left[\left(\frac{d T}{d z} \cdot u\left(\Delta z_{\mathrm{eff}}\right)\right)^{2}+\left(u\left(\frac{d T}{d z}\right) \cdot \Delta z_{\mathrm{eff}}\right)^{2}\right]^{1 / 2}
$$

where $\mathrm{d} T / \mathrm{d} z=-0.116 \mathrm{mK} / \mathrm{cm}, u(\mathrm{~d} T / \mathrm{d} z)=0.017 \mathrm{mK} / \mathrm{cm}$, and $\Delta z_{\text {eff }}$ are given in Table 3. Given these values, we calculated: $u_{5}=0.116 \mathrm{mK}$ for the adiabatic cells; $u_{5}=0.25 \mathrm{mK}$ for cell 1202 ; and $0.30 \mathrm{mK}$ for cell 801 . These uncertainties would be the dominant contributions overall, which is due to the unusually large head correction and the $15 \%$ relative uncertainty in its experimental value.

If instead we assume that Eq. (2) and Eq. (3) are both correct and applicable to our cells within the melting range $(0.3 \leq F \leq 0.8)$, then according to GW [7] and Harvey [20], the relative standard uncertainties in $\rho_{l}$ and $\mathrm{d} p / \mathrm{d} T$ are $0.01 \%$ and $1.6 \%$, respectively. The relative uncertainty from the calculated value of $\mathrm{d} T / \mathrm{d} z$ would then be only about $1.6 \%$, or $u(\mathrm{~d} T / \mathrm{d} z)=0.00186 \mathrm{mK} / \mathrm{cm}$. In this case, we obtain $u_{5}=$ $0.118 \mathrm{mK}$ for cell 1202, and $0.120 \mathrm{mK}$ for cell 801 . We therefore used the recommended GW EoS and Harvey melting line uncertainties for evaluating $u_{5}$. 


\subsubsection{Extrapolation Error}

There is uncertainty for the $F=1$ extrapolation, and possibly the $F=0.5$ interpolation, due to uncertainty in the functional form of the fit. We chose the $F^{-y}$ models to fit the data with $y=0.8$ and $y=$ 0.6 , but the range of statistically reasonable values of the exponent would be $0.5 \leq y \leq 1$. Given the quality of our data, it is not possible to rule out other values of $y$ over the limited melting range of $0.2<F<0.8$. We made a comparison between our linear $F^{-1}$ fits $(y=1$, fit B) and another series of fits where $y=0.5$. The results of this fit comparison yielded only small changes in the $T_{\mathrm{tp}}(F=0.5)$ interpolated values that are well within the statistical uncertainties for the $F^{-y}$ model fits. The fit comparisons for the $F=1$ extrapolations, however, did yield significant differences, with an average difference of $0.106 \mathrm{mK}$. In contrast, the differences in the $F=1$ extrapolations between the fit $\mathrm{B}$ and fit $\mathrm{C}$ curves are less than half of that. We therefore estimate $u_{6}(1)=0.106 \mathrm{mK}$ for all four of the $\mathrm{SF}_{6}$ cells.

\subsubsection{ITS-90 Realization}

The uncertainty in the ITS-90 realization via the SPRTs is dominated by the uncertainty contributions of the two fixed points, Ar TP and Hg TP, defining the subrange. The two fixed-point uncertainties were propagated over the subrange 4 according to the deviation equation, Eq. (4). For the capsule-type SPRTs used here, we assigned $u(\mathrm{Ar} \mathrm{TP})=0.093 \mathrm{mK}$ and $u(\mathrm{Hg} \mathrm{TP})=0.2 \mathrm{mK}$. Figure 17 illustrates how these uncertainties were propagated to $T_{90}=223.555 \mathrm{~K}$ and combined as an uncorrelated quadrature summation (i.e., root-sum-squared); the result is $u_{90}(223.555 \mathrm{~K})=0.245 \mathrm{mK}$. Other contributions to the total uncertainty in ITS-90 are from type-3 nonuniqueness [39], where $u_{\mathrm{NU}-3}(223.555 \mathrm{~K})=0.053 \mathrm{mK}$. The combined uncertainty for realization of the ITS-90 is then $u_{7}=0.251 \mathrm{mK}$.

We made both direct and indirect comparisons at the $\mathrm{SF}_{6} \mathrm{TP}$ temperature between our five SPRTs to support our ITS-90 uncertainty estimate. As shown in Table 5, realizations using the two immersion cells were performed using two SPRTs each. One was primarily used in the cell, while the other was primarily used to determine the bath temperature. Each pair of SPRTs were also occasionally interchanged under otherwise static conditions to compare their interpolated temperatures. In these indirect comparisons, indicated temperature differences of approximately $0.2 \mathrm{mK}$ were observed. In the case of the adiabatic cell $\mathrm{s} / \mathrm{n} 401$, a direct comparison among three SPRTs was possible during the realizations, and again differences as large as $0.2 \mathrm{mK}$ were observed. In the case of two specific SPRTs, 1774092 and 56860103, however, the relative agreement was much better, with differences less than $0.04 \mathrm{mK}$. Given our $\mathrm{Hg}$ TP uncertainty estimates here, we find these differences in interpolated temperature to be unremarkable. 


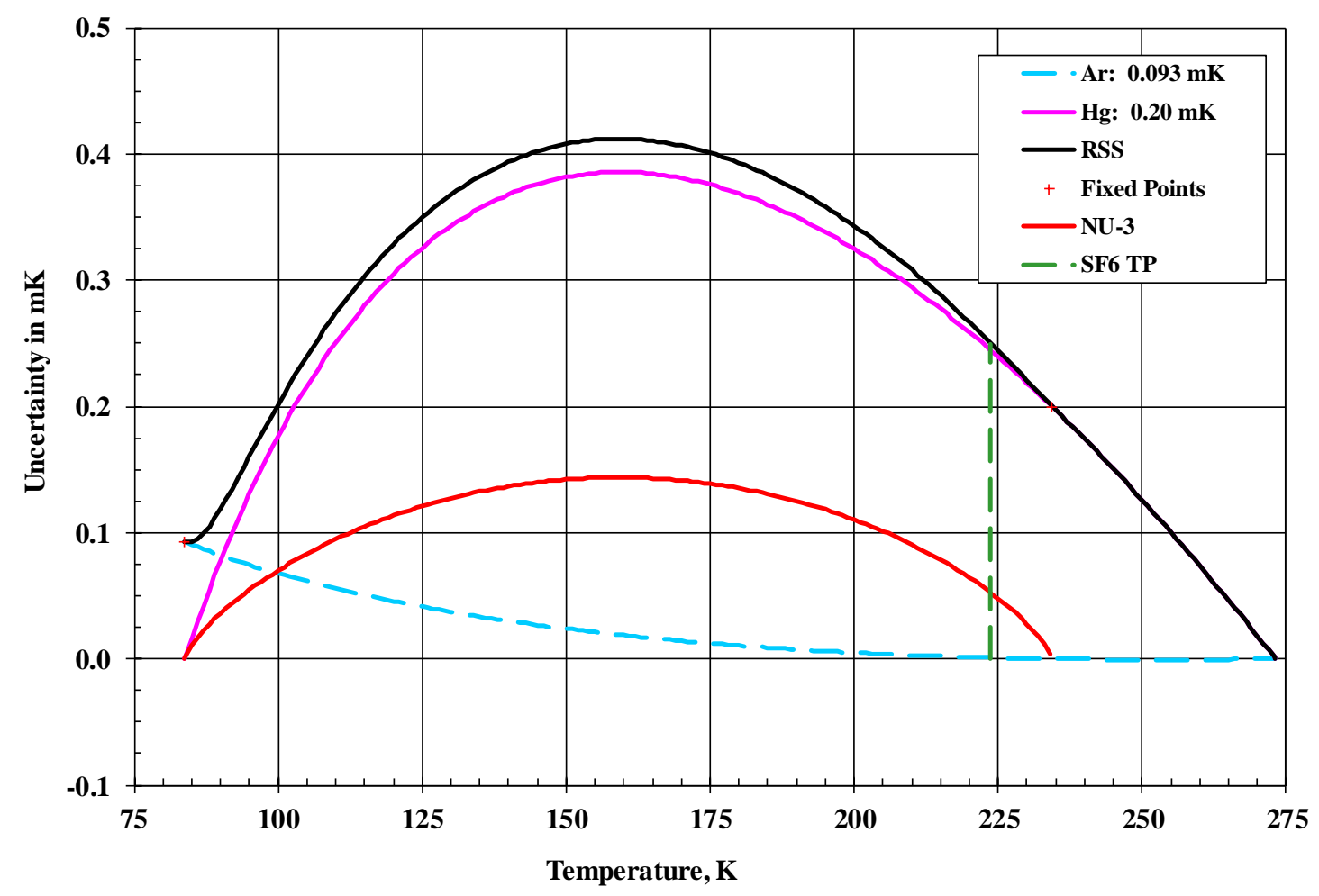

Fig. 17. The ITS-90 fixed-point uncertainties and non-uniqueness uncertainties as propagated over the subrange 4 from $273.16 \mathrm{~K}$ to 83.8058 K. The various components are combined as a root-sum-square (RSS) uncertainty to form the black curve as shown.

\subsubsection{Water Triple Point Propagated Uncertainty}

The WTP is treated separately from the other ITS-90-specific uncertainty components. Like the other fixed-point uncertainties, its realization uncertainty propagates over the subrange according to a particular functional form. Unlike the other fixed points, however, the exact form of the uncertainty propagation depends on certain details of how the WTP data are utilized in the course of SPRT interpolations [40]. In the case of the capsule SPRTs utilized in our laboratory, the SPRT calibration data were generated at earlier times, often with different measurement systems or within other facilities [28] at NIST. We made regular checks of the WTP resistances for our SPRTs during the course of these $\mathrm{SF}_{6} \mathrm{TP}$ realizations, and all the thermometers exhibited stability $<0.1 \mathrm{mK}$. In only one case, we made a small adjustment in the WTP resistance value for SPRT 56860103 as used for interpolation. Given this situation, the WTP uncertainty propagation most closely corresponds to the "case 1" example as detailed in the article by Meyer and Ripple [40]. When the linear form of the propagated uncertainty is evaluated at $223.555 \mathrm{~K}$, the result is a factor of 0.8 times the WTP realization uncertainty. The WTP uncertainty for routine calibration purposes in our laboratory is $0.097 \mathrm{mK}$ [28], so its uncertainty contribution when propagated to $223.555 \mathrm{~K}$ is $u_{8}=0.8 \times 0.097 \mathrm{mK}=0.078 \mathrm{mK}$.

\subsubsection{Self-Heating Effects}

The SPRTs were calibrated using constant current data with $i=1 \mathrm{~mA}$ from the $\mathrm{Hg} \mathrm{TP}, \mathrm{Ar} \mathrm{TP}$, and WTP. The quiescent power dissipation at the $\mathrm{SF}_{6} \mathrm{TP}$ is $P \approx 20.4 \mu \mathrm{W}$ for an SPRT. Consequently, we used the SPRTs at an excitation current of $1 \mathrm{~mA}$ to measure the $\mathrm{SF}_{6} \mathrm{TP}$ temperatures. This practice works well when the interpolation temperature and the fixed-point calibration temperature are reasonably close and the 
external self-heating is small [28]. As a systematic check, we also made occasional measurements of the SPRT self-heating while on the melt plateaus. The observed self-heating $\Delta T_{\text {osh }}$ was a combination of external, $\Delta T_{\text {esh }}=\eta_{\text {ext }} P$, and internal, $\Delta T_{\text {ish }}=\eta_{\text {int }} P$, contributions, each with its own coefficient $\eta$, such that $\Delta T_{\text {osh }}=\Delta T_{\text {ish }}+\Delta T_{\text {esh. }}$. The internal self-heating coefficient $\eta_{\text {int }}$ (a property of the capsule SPRT), as mediated by helium exchange gas, will scale with temperature $\propto T^{-0.67}$ [41], so that the ratio of self-heating coefficients would be $\eta_{\text {int }}\left(\mathrm{SF}_{6} \mathrm{TP}\right) / \eta_{\text {int }}(\mathrm{Hg} \mathrm{TP})=1.032$. However, the observed internal self-heating was $\Delta T_{\mathrm{sh}}(T)=\eta_{\text {int }} i^{2} R(T)$, so that the ratio of self-heating will be $\Delta T_{\mathrm{sh}}\left(\mathrm{SF}_{6} \mathrm{TP}\right) / \Delta T_{\mathrm{sh}}(\mathrm{Hg} \mathrm{TP}) \approx 1.032 \times\left\{W_{\text {ref }}\left(\mathrm{SF}_{6}\right.\right.$ $\left.\mathrm{TP}) / W_{\text {ref }}(\mathrm{Hg} \mathrm{TP})\right\} \approx 0.979$. So neglecting external self-heating contributions, the expected error in assuming a constant self-heating between the $\mathrm{Hg} \mathrm{TP}$ and $\mathrm{SF}_{6} \mathrm{TP}$ will be approximately $2 \%$ of the observed selfheating at the Hg TP.

Since the internal self-heating errors are small, the dominant source of error is that produced when the external self-heating in the $\mathrm{Hg} \mathrm{TP}$ cell is different from that in a given $\mathrm{SF}_{6} \mathrm{TP}$ cell. It is more difficult to estimate the external self-heating, however, since this is installation dependent and less reproducible. For four out of the five SPRTs in this study, $\Delta T_{\mathrm{osh}} \approx 0.5 \mathrm{mK}$ at the $\mathrm{SF}_{6} \mathrm{TP}$ for $1 \mathrm{~mA}$. Our experience using these capsules indicates that $\Delta T_{\text {esh }} \approx 0.1 \mathrm{mK}$, and that this would never exceed $0.2 \mathrm{mK}$ when properly installed. We therefore assigned a rectangular distribution of half-width $0.1 \mathrm{mK}$ (i.e., $20 \%$ of $\Delta T_{\text {osh }}$ ) to the selfheating error uncertainty so that $u_{9}=0.058 \mathrm{mK}$.

\subsubsection{Resistance Measurement Uncertainties}

The SPRT resistance measurements were performed using the DSB [32] and one of two external resistance standards with nominal values of $100 \Omega$ and $25 \Omega$. This particular model of DSB has a ratio uncertainty specification of $0.07 \mu \Omega / \Omega$, and the random noise component is comparable to this specification. Experience at NIST [42] using many DSBs with Hamon-type resistance calibrators [43] has confirmed this basic performance specification. In practice, we used this same bridge and same two reference resistors for both the $\mathrm{SF}_{6}$ measurements and the WTP measurements, so the absolute calibration in ohms does not enter into the uncertainty budget. The short-term stability (i.e., $\leq 1 \mathrm{month}$ ) of the reference resistors does contribute, but this was usually below $0.05 \mu \Omega / \Omega$. For the purposes of this work, we assumed a combined uncertainty for the resistance measurements of $0.1 \mu \Omega / \Omega$, which corresponds to an equivalent temperature uncertainty of $u_{10}=0.032 \mathrm{mK}$.

\subsubsection{Total Combined Standard Uncertainty}

As shown in Table 9, the combined total standard uncertainties for the adiabatic and immersion cells are comparable, ranging from $u_{\mathrm{c}}=0.33 \mathrm{mK}$ for adiabatic cells at $F=0.5$ to $u_{\mathrm{c}}=0.35 \mathrm{mK}$ for immersion cells at $F=1$. We assume any correlations between the various uncertainty components are negligible, so the combined uncertainties are simply a root-sum-square calculation.

\section{Discussion}

Our results may be compared with other published realizations of the $\mathrm{SF}_{6} \mathrm{TP}$, but now with more detail than that already presented in Sec. 2. We limit a detailed comparison to those results published from 1993 forward, omitting those earlier results where apparently unknown chemical impurities were dominant. The comparison is summarized in Table 11 for TP temperatures and the reported standard uncertainties. 
Table 11. A summary of modern realizations of the $\mathrm{SF}_{6} \mathrm{TP}$.

\begin{tabular}{|l|l|l|l|}
\hline Year & Citation & $T_{\mathrm{tp}}(\mathrm{K})$ & Notes \\
\hline 1993 & Blanke et al. $[8]$ & $223.555(5)$ & \\
\hline 2001 & Funke et al. $[9]$ & $223.555(3)$ & \\
\hline 2016 & Rourke [10] & $223.55523(49)$ & $F=1,1$ adiabatic cell \\
\hline 2017 & This work & $223.55607(35)$ & $F=1$, weighted avg. of 4 cells \\
\hline
\end{tabular}

Our results are generally consistent with these and other contemporary results [44] for the $\mathrm{SF}_{6} \mathrm{TP}$, given that the differences are all within twice the combined uncertainties. In particular, our results differ from those of Rourke [10] by $0.84 \mathrm{mK}$, which is 1.4 times the combined standard uncertainty of $0.60 \mathrm{mK}$. The source of $\mathrm{SF}_{6}$ as used by Rourke was from the same commercial supplier as used in this work, but it was from a different batch with higher chemical impurities than that of our $\mathrm{SF}_{6}$. The sample used by Rourke was reported to contain an impurity fraction of $9 \times 10^{-6}$ of air, and it was not subjected to any additional purification steps. The higher impurity fractions would be expected to produce a lower TP temperature, as observed.

The question of achieving sufficient chemical purity is complicated. From a simple Raoult's law approximation, the observed melting range of $0.2 \mathrm{mK}$ over a $50 \%$ span of melted fraction would correspond to an impurity concentration of $2.6 \mu \mathrm{mol} / \mathrm{mol}$, which happens to be the same nominal fraction of $\mathrm{N}_{2}$ impurity one would expect to be present based on the chemical assay from our supplier (Table 4). Our analysis of the impurity partitioning effects described in Sec. 4.1 .1 casts some doubt on this simplified explanation. On the one hand, the partitioning that takes place between vapor and liquid phases within a cell would have the effect of decreasing the dissolved $\mathrm{N}_{2}$ in the liquid phase. On the other hand, the partitioning that takes place inside the $\mathrm{SF}_{6}$ source cylinder during the gas transfer process would have the effect of enhancing the overall $\mathrm{N}_{2}$ impurities, at least initially. In addition, our experience with extensive vacuum degassing of one cell ( $\mathrm{s} / \mathrm{n} 1202)$ did not lead to any significant difference in the melting plateau for that cell compared to other cells that were not subjected to degassing. This implies that the presence of volatile $\mathrm{N}_{2}$ impurities has a negligible influence on the observed plateaus, and/or the $\mathrm{N}_{2}$ is partially dissolved and or trapped in the solid $\mathrm{SF}_{6}$. While our melting curves are consistent with finite distribution coefficients in the range $0.2 \leq k_{\mathrm{s}, 1} \leq 0.4$, there are ambiguities associated with such interpretations of melting data [36]. We are unaware of any publications reporting on solid solutions of $\mathrm{SF}_{6}$ and $\mathrm{N}_{2}$.

Other less volatile impurities, such as $\mathrm{CF}_{4}$, are present in our samples, but at much lower concentrations (e.g., $0.3 \mu \mathrm{mol} \cdot \mathrm{mol}^{-1}$; Table 4 ). Any effect large enough to produce the melting ranges observed here, if due only to the $\mathrm{CF}_{4}$ impurities, would imply the existence of partial solid solutions and one or more eutectic or peritectic points. We are unaware of any publications reporting on solid solutions of $\mathrm{SF}_{6}$ and $\mathrm{CF}_{4}$.

Our source cylinder of $\mathrm{SF}_{6}$ is probably some of the highest purity commercial product available today, but some further improvement should be possible through the use of both active chemical getters and other differential degassing methods [45]. The chemical effects can be assessed via direct sample-to-sample thermometric comparisons of samples derived from different source gases of comparable purity. Cells with nominally identical source material, but with different vapor to liquid volume ratios, could also be compared and analyzed relative to the predictions of Eq. (7). Such comparisons will be presented in a later publication.

The dominant uncertainty in our experimental value for the $\mathrm{SF}_{6} \mathrm{TP}$ temperature is from the ITS-90 realization. This in turn is almost entirely due to uncertainty propagated from the $\mathrm{Hg} \mathrm{TP}$. While it is possible to achieve realizations of the $\mathrm{Hg} \mathrm{TP}$ with lower uncertainties [28] than those $(u(\mathrm{Hg} \mathrm{TP})=0.2 \mathrm{mK})$ assigned to our capsule SPRTs, such low-uncertainty calibration data were not available for these thermometers prior to this work.

The static pressure head correction is also a significant source of uncertainty. This is because the head correction coefficient is unusually large, which itself is a consequence of a relatively high mass density and a relatively low initial slope of the melting line in $\mathrm{SF}_{6}$. Our measurements of the pressure head coefficient 
are, to our knowledge, the first ever published for $\mathrm{SF}_{6}$. Despite a relatively poor statistical uncertainty (i.e., $15 \%)$ in the experimental value of the coefficient, the correction values as applied here to our immersiontype cells are likely correct to within $10 \%$. Moreover, there is no evidence of a systematic effect related to the head correction. This is due to the close agreement between the small adiabatic-type cells with no correction applied and the immersion-type cells where corrections of $1.55 \mathrm{mK}(\mathrm{s} / \mathrm{n} 1202)$ and $1.98 \mathrm{mK}(\mathrm{s} / \mathrm{n}$ $801)$ were applied. The largest disagreement between an adiabatic cell $(\mathrm{s} / \mathrm{n} 401)$ and an immersion cell $(\mathrm{s} / \mathrm{n}$ 801 ) was only $0.19 \mathrm{mK}$ (i.e., $9.6 \%$ of the head correction) as interpolated at $F=50 \%$, and only $-0.05 \mathrm{mK}$ in the case of $s / n 302$ and $s / n 1202$. The fact that we used a value for the coefficient calculated from a melting-line equation [20], itself derived from other melting data, is not a limitation in and of itself. It is worth noting that the pressure head coefficients as used in the ITS-90 are prescribed by the scale definitions, and therefore they are used universally without assigning an uncertainty. This is despite the fact that, in some cases, the ITS-90 values are not completely consistent with contemporary melting-line formulations. ${ }^{2}$

We relied on a calculated value for the static pressure head coefficient, assuming that Eq. (3) and Eq. (6) are valid. Our use of the liquid density in Eq. (3) is customary for fixed-point cell usage in the ITS-90, since it is the weight of the fluid column that creates the pressure head. However, the actual immersion depth $\Delta z_{\text {eff }}$ in Eq. (6) is calculated from the cell dimensions and in the liquidus limit where $F=1$. The correction of $h_{\mathrm{sol}} / h_{\text {iq }}=\left(\rho_{\text {liq }} / \rho_{\text {sol }}\right)^{1 / 3}=0.9315$ is an attempt to gauge the actual height of the liquid column as it is formed from the solid during the initial inner melt. This assumption may be too simplified, since the annular solid volume is unable to shrink the inner radius at the thermowell, which could in turn distort the axial (vertical) dimensions. Furthermore, at high melted fractions, the actual pressure head could become elevated beyond the initial height. In this case, the effective pressure head would start to increase with further increases in $F$, but our data lack the reproducibility at high $F$ to resolve the difference between $F^{-1}$ and $F$ dependence.

The lack of reproducibility for $F>80 \%$ requires some greater efforts to address. In the case of adiabatic cells, there are heat-leak errors, and improvements are required in the calorimetry. This in turn requires a greater degree of isolation to minimize the heat leaks. In the case of the immersion-type cells, the problems are subtler and are related to the conditions necessary for adequate immersion within the cell. These in turn depend on the spatial distribution of the solid-liquid interface remaining fully intact as a coaxial column in close contact with the outer side of the thermowell. Our observations of various melts under continuous melting are consistent with the disintegration of the solid mantle at high melted fractions. Presumably, the cohesion of the solid is insufficient to support its own weight under those conditions. To address this, we designed a second generation of immersion cells that contain horizonal baffles in the condensed region of the interior cell volume to serve as both radial heat shunts and structural reinforcement for the solid. We expect that these new designs will prevent portions of the solid from falling off of the mantle, allowing a higher heat-flux stability threshold under continuous melting and better reproducibility at high $F$ conditions. The results for those cells will be presented in a later publication.

Our main objective for this work was to demonstrate that the $\mathrm{SF}_{6} \mathrm{TP}$ can serve as a "drop-inreplacement" for $\mathrm{Hg}$ TP cells. This objective has been achieved, to a certain extent, using only these firstgeneration cells and their prototype design. It was achieved to the extent that our $\mathrm{SF}_{6} \mathrm{TP}$ realization uncertainty is mostly limited by realization of the $\mathrm{Hg} \mathrm{TP}$ itself. It is not yet achieved, however, to the extent that the ease of realization is comparable to that when using $\mathrm{Hg} \mathrm{TP}$ cells. The $\mathrm{Hg} \mathrm{TP}$ can be easily realized using a continuous melting mode, which is convenient and simple to set up in the laboratory. In contrast, our $\mathrm{SF}_{6}$ immersion-type cells require a more complicated experimental realization with step melting and quasi-adiabatic conditions. With future refinements in technique and some degree of automation, however,

\footnotetext{
${ }^{2}$ For example, the pressure head coefficient for the Ar TP is $3.3 \mathrm{mK} / \mathrm{m}$ according the ITS-90 [1], but it is $3.48 \mathrm{mK} / \mathrm{m}$ according to contemporary melting line and density EoS [46].
} 
a step melting approach should not present a significant limitation to adopting $\mathrm{SF}_{6}$ or some other nonmetal to replace the Hg TP. In addition, further work is needed to verify our results using the much more common long-stem-type SPRTs

\section{Conclusions}

We have presented our first results for the realization of the $\mathrm{SF}_{6} \mathrm{TP}$ using four TP cells of novel and varied design. Two immersion-type cells and two small adiabatic-type cells were used to test the reproducibility of the realizations subject to varied conditions and corrections. These first-generation cell designs yield TP temperatures that are both self-consistent and in agreement with the most recent and lowest uncertainty values reported in the literature. The maximum disagreement between any two cells is $0.19 \mathrm{mK}$ at $F=0.5$ and $0.17 \mathrm{mK}$ as extrapolated to the liquidus point $(F=1)$. Nitrogen impurities of less than $3 \mu \mathrm{mol} \cdot \mathrm{mol}^{-1}$ appear to be the dominant factor in determining the shape of the melting curves, with a possible argon contamination in one case. While the data are consistent with possible solid/liquid distribution coefficients in the range $0.2 \leq k_{\mathrm{s} .1} \leq 0.4$, the nature of melting curves does not permit a strict interpretation for impurity distributions. Our mean TP temperature is 223.55607 (35) K extrapolated to the liquidus point, and our uncertainty of $0.35 \mathrm{mK}$ is primarily limited by the realization of the ITS-90 itself.

We have made the first published experimental determination of the static pressure head coefficient for $\mathrm{SF}_{6}$, and our value of $-0.116(17) \mathrm{mK} / \mathrm{cm}$ agrees with the calculated value of $-0.116(2)$ as derived from the GW [7] density EoS and the melting line slope of 1.556(25) MPa/K from Harvey [20]. We have found that immersion-type cells must be operated using step melting in a quasi-adiabatic mode in order to obtain reproducible results that are comparable to the smaller adiabatic-type cells. This is in contrast to the continuous melting techniques commonly used for metal fixed-point immersion cells, and in particular those used for realization of the $\mathrm{Hg} \mathrm{TP}$. Our results have demonstrated that $\mathrm{SF}_{6}$ has the potential to replace the Hg TP as the fixed point for the calibration of SPRTs on the ITS-90, with some qualifications. Some further improvements to lower the $\mathrm{SF}_{6} \mathrm{TP}$ realization uncertainties are possible using immersion cells with horizontal baffles, which serve to support the solid mantle at higher melted fractions. Improvements in the adiabatic techniques would also allow better reproducibility at higher melted fractions. The uncertainty for the ITS-90 temperature, however, could only be further improved by lowering the realization uncertainty of the Hg TP.

\section{Acknowledgments}

We thank Allan Harvey of the NIST Applied Chemicals and Materials Division for helpful insights and many detailed discussions pertaining to the $\mathrm{SF}_{6} \mathrm{EoS}$ and for providing several important references. We thank Mike Moldover and Jon Hougen of the NIST Sensor Science Division for helpful discussions on various related subjects. Michal Chojnacky and Tobias Herman of the Sensor Science Division provided support via SPRT calibration data and use of an Hg triple-point cell. Jay Nanninga of the NIST Fabrication Technology Division provided vital engineering support. Wyatt Miller and Andrew Almeida provided assistance in the laboratory. We gratefully acknowledge helpful discussions with Patrick Rourke and Sergey Dedyulin of the National Research Council of Canada and Gabriel Sarmanho of Inmetro. We thank Jonathan Pearce of the National Physical Laboratory and Delores del Campo of the Centro Español de Metrologia for helpful comments on the manuscript. We also thank Greg Strouse of the NIST Physical Measurement Laboratory headquarters office for support for this project during its early stages of development. 


\section{References}

[1] Preston-Thomas H (1990) The International Temperature Scale of 1990. Metrologia 27(2):3-10. https://doi.org/10.1088/0026-1394/27/2/010

[2] Furukawa GT (1992) Realization of the mercury triple point. Temperature: Its Measurement and Control in Science and Industry, ed Schooley JF (American Institute of Physics, New York), Vol. 6, pp 281-285.

[3] Strouse GF, Lippiatt J (2002) New NIST mercury triple-point cells. Tempmeko 2001: 8th International Symposium on Temperature and Thermal Measurements in Industry and Science, ed Fellmuth B, Seidel J, Scholz G (VDE Verlag Gmbh, Berlin), pp 453-458. Available at https://www.nist.gov/publications/new-nist-mercury-triple-point-cells

[4] 110th Congress of the United States of America (2008) Mercury Export Ban Act of 2008. Public Law 110-414. Available at https://www.congress.gov/110/plaws/pub1414/PLAW-110publ414.pdf

[5] Minimata Convention on Mercury. Available at www.mercuryconvention.org/

[6] Ripple DC, Strouse GF (2005) Selection of alternatives to liquid-in-glass thermometers. Journal of ASTM International 2(9):1-9, https://doi.org/10.1520/JAI13404

[7] Guder C, Wagner W (2009) A reference equation of state for the thermodynamic properties of sulfur hexafluoride $\left(\mathrm{SF}_{6}\right)$ for temperatures from the melting line to $625 \mathrm{~K}$ and pressures up to $150 \mathrm{MPa}$. Journal of Physical and Chemical Reference Data 38(1):33-94. https://doi.org/10.1063/1.3037344

[8] Blanke W, Klingenberg G, Weiß R (1993) Thermische Zustandsgrößen von $\mathrm{SF}_{6}$ auf der Dampfdruckkurve zwishen dem Tripelpunkt und dem kritishen Punkt sowie im Einphasengebiet zwishen $225 \mathrm{~K}$ und $450 \mathrm{~K}$. PTB-Mitteilungen 103:27-35.

[9] Funke M, Kleinrahm R, Wagner W (2001) Measurement and correlation of the ( $\boldsymbol{p}, \boldsymbol{\rho}, \boldsymbol{T})$ relation of sulphur hexafluoride $\left(\mathrm{SF}_{6}\right)$. II. Saturated-liquid and saturated-vapour densities and vapour pressures along the entire coexistence curve. Journal of Chemical Thermodynamics 34(6):735-754. https://doi.org/10.1006/jcht.2001.0907

[10] Rourke PMC (2016) The triple point of sulfur hexafluoride. Metrologia 53(2):L1-L6. https://doi.org/10.1088/0026$1394 / 53 / 2 / 11$

[11] Mangum BW, Furukawa GT (1990) Guidelines for realizing the International Temperature Scale of 1990 (ITS-90). (National Institute of Standards and Technology, Gaithersburg, MD), NIST Technical Note (TN) 1265. https://doi.org/10.6028/nist.tn.1265

[12] Lemmon EW, Huber ML, McLinden MO (2013) NIST Standard Reference Database 23: Reference Fluid Thermodynamic and Transport Properties-REFPROP, Version 9.1 (Standard Reference Data Program, National Institute of Standards and Technology, Gaithersburg, MD). Available at https://www.nist.gov/srd/refprop

[13] Quiñones-Cisneros SE, Huber ML, Deiters UK (2012) Correlation for the viscosity of sulfur hexafluoride (SF6) from the triple point to $1000 \mathrm{~K}$ and pressures to $50 \mathrm{MPa}$. Journal of Physical and Chemical Reference Data 41(2):023102-023102023102-023111. https://doi.org/10.1063/1.3702441

[14] Assael MJ, Koini IA, Antoniadis KD, Huber ML, Abdulagatov IM, Perkins RA (2012) Reference correlation of the thermal conductivity of sulfur hexafluoride from the triple point to $1000 \mathrm{~K}$ and up to $150 \mathrm{MPa}$. Journal of Physical and Chemical Reference Data 41(2):023104-023104-023104-023109. https://doi.org/10.1063/1.4708620; Erratum (2014) Journal of Physical and Chemical Reference Data 43(3). https://doi.org/10.1063/1.4885454

[15] Busch G, Guntherodt H-J, Haller W, Wyssmann P (1974) Lorentz number and thermal conductivity of gallium, mercury, and mercury-indium alloys. Journal de Physique Colloques, 35(C4):C4-313-C4-316. https://doi.org/10.1051/jphyscol:1974460

[16] Turdukozhaeva AM (2013) Temperature dependence of the dynamic viscosity of liquid mercury. Russian Journal of Physical Chemistry A 87(9):1595-1597. https://doi.org/10.1134/S0036024413090252

[17] Michel J, Drifford M, Rigny P (1969) Structure and molecular motions of solid sulfur, selenium, and tellurium hexafluorides. Journal de Chimie Physique et de Physico-Chimie Biologique. 67:31.

[18] Kiefte H, Penney R, Clouter MJ (1988) Brillouin scattering studies of the $\mathrm{SF}_{6}$ crystal. Journal of Chemical Physics 88(9):5846-5849. https://doi.org/10.1063/1.454546

[19] Konstantinov VA, Manshelii VG, Smirnov SA (1992) Effect of rotation of molecules on heat transport in solid SF 6 . Soviet Journal of Low Temperature Physics 18:11.

[20] Harvey AH (2017) On the melting curve of sulfur hexafluoride. Journal of Physical and Chemical Reference Data 46(4):043102. https://doi.org/10.1063/1.5005537

[21] Tew WL (2016) Realizations of the triple point of sulfur hexafluoride using refillable pressurized cells. Tempmeko 2016, Oral Session O11.2, 30 June 2016, Zakopane, Poland.

[22] Miller HC, Verdelli LS, Gall JF (1951) Some physical properties of sulfur hexafluoride. Industrial and Engineering Chemistry 43(5):1126-1129. https://doi.org/10.1021/ie50497a037

[23] ASTM International (2015) ASTM A269/A269M-15a - Standard Specification for Seamless and Welded Austenitic Stainless Steel Tubing for General Service (ASTM International, West Conshohocken, PA). https://doi.org/10.1520/A0269_A0269M-15A

[24] ASTM International (2015) ASTM A270/A270M-15 - Standard Specification for Seamless and Welded Austenitic and Ferritic/Austenitic Stainless Steel Sanitary Tubing (ASTM International, West Conshohocken, PA). https://doi.org/10.1520/A0270_A0270M-15

[25] Paulsen SS (2009) Pressure Systems Stored-Energy Threshold Risk Analysis. Pacific Northwest National Laboratory, Richland, WA, PNNL-18696, August 2009.

[26] Concord Specialty Gases, Inc. (2014) Ultra High Purity Grade SF 6 , Batch Lb-12, 22-Aug-2014. Concord Specialty Gases, Inc., Eatontown, NJ, Report 1292/14.

[27] SAES Pure Gas, Inc. (2015) MicroTorr MC50-702FV. SAES Pure Gas, Inc., San Luis Obispo, CA. 
[28] Tew WL (2015) Calibration of cryogenic resistance thermometers between $0.65 \mathrm{~K}$ and $165 \mathrm{~K}$ on the International Temperature Scale of 1990. (National Institute of Standards and Technology, Gaithersburg, MD), NIST Special Publication (SP) 250-91. https://doi.org/10.6028/nist.sp.250-91

[29] Tew WL, Strouse GF (2001) Standard Reference Material 1750: Standard Platinum Resistance Thermometers, 13.8033 K to 429.7485 (National Institute of Standards and Technology, Gaithersburg, MD), NIST Special Publication (SP) 260-139. https://doi.org/10.6028/nist.sp.260-139

[30] Strouse GF (2008) Standard platinum resistance thermometer calibrations from the Ar TP to the Ag FP (National Institute of Standards and Technology, Gaithersburg, MD), NIST Special Publication (SP) 250-81. https://doi.org/10.6028/nist.sp.250-81

[31] Meyer CW, Tew WL (2006) ITS-90 non-uniqueness from PRT subrange inconsistencies over the range $24.56 \mathrm{~K}$ to 273.16 K. Metrologia 43(5):341-352. https://doi.org/10.1088/0026-1394/43/5/002

[32] Bramley P, Pickering J (2006) Better accuracy in temperature calibration and measurement through a new type of analogto-digital converter. Cal Lab Magazine Oct-Nov-Dec 2006:21-26.

[33] Dedyulin SN (2017) Sulfur hexafluoride: A novel fixed point for contact thermometry. International Journal of Thermophysics 38(5):79. https://doi.org/10.1007/s10765-017-2216-8

[34] Pavese F, Molinar Min Beciet G (2013) Modern Gas-Based Temperature and Pressure Measurements (Springer Science + Business Media, New York), 2nd Ed.

[35] Fellmuth B, Hill KD, Pearce JV, Peruzzi A, Steur PPM, Zhang J (2015) Guide to the Realization of the ITS-90 Fixed Points: Influence of Impurities (Bureau International de Poids et Mesures, Paris, France). Available at www.bipm.org/en/committees/cc/cct/publications-cc.html\#thermometry-guides

[36] Joint Committee for Guides in Metrology, Working Group 1 (2008) Evaluation of Measurement Data-Guide to the Expression of Uncertainty in Measurement (Bureau International de Poids et Mesures, Paris, France), Joint Committee for Guides in Metrology Publication 100:2008. Available at https://www.bipm.org/utils/common/documents/jcgm/JCGM_100_2008_E.pdf

[37] Campestrini M, Stringari P, Arpentinier $\mathrm{P}$ (2014) Solid-liquid equilibrium prediction for binary mixtures of $\mathrm{Ar}, \mathrm{O}_{2}, \mathrm{~N}_{2}, \mathrm{Kr}$, $\mathrm{Xe}$, and $\mathrm{CH}_{4}$ using the LJ-SLV-EoS. Fluid Phase Equilibria 379:139-147. https://doi.org/10.1016/j.fluid.2014.07.020

[38] Fellmuth B, Mendez-Lango E, Nakano T, Sparasci F (2017) Guide to the Realization of the ITS-90: Cryogenic Fixed Points (Bureau International de Poids et Mesures, Paris, France). Available at www.bipm.org/en/committees/cc/cct/publications-cc.html\#thermometry-guides

[39] White DR (2008) Uncertainties in the realisation of the SPRT subranges of the ITS-90 CCT 24e Session, Doc. CCT/08-19rev2. CCT Working Documents: 24th Meeting (Bureau International de Poids et Mesures, Paris, France). Available at www.bipm.org/cc/CCT/Allowed/24/Uncert_CCT-08-19-rev-2014-01-24.pdf

[40] Meyer CW, Ripple DC (2006) Determination of the uncertainties for ITS-90 realization by SPRTs between fixed points. Metrologia 43:327. https://doi.org/10.1088/0026-1394/43/5/001

[41] Tew WL, Meyer CW (2013) Normal and anomalous self-heating in capsule-type resistance thermometers in the range $1 \mathrm{~K}$ to 273 K. Temperature, Its Measurement and Control in Science and Industry, ed Meyer CW (American Institute of Physics, College Park, MD), Vol. 8, AIP Conference Proceedings 1552, pp 451. https://doi.org/10.1063/1.4819583

[42] Chojnacky M (2016) unpublished data. U.S. Department of Commerce, National Institute of Stands and Technology, Gaithersburg, MD.

[43] White DR, Jones K, Williams JM, Ramsey IE (1997) A simple resistance network for the calibration of resistance bridges. IEEE Transactions on Instrumentation and Measurement IM-46(5):1068-1074. https://doi.org/10.1109/19.676712

[44] Sparasci F (2017) LNE-CNAM, private communication, October 2017.

[45] Ancsin J (1992) Development of cryogenic sealed cells as temperature standards: Their filling system and the purification of $\mathrm{CO}_{2}$. Metrologia 29:71-78. https://doi.org/10.1088/0026-1394/29/1/009

[46] Tegeler Ch, Span R, Wagner W (1999) A new equation of state for argon covering the fluid region for temperatures from the melting line to $700 \mathrm{~K}$ at pressures up to $1000 \mathrm{MPa}$. Journal of Physical and Chemical Reference Data 28(3):779-850. https://doi.org/10.1063/1.556037

About the authors: Weston L. Tew is a physicist in the Thermodynamic Metrology Group of the Sensor Science Division of the Physical Measurement Laboratory at NIST. He carries out research in lowtemperature thermometry, nonmetal fixed points, noise thermometry, and special temperature measurement applications.

Klaus N. Quelhas is an electrical engineer and team leader in the Thermometry Laboratory of the National Institute of Metrology, Quality and Technology (INMETRO) in Rio de Janeiro, Brazil. His research involves fixed-point cells for contact thermometry, pure-metal thermocouples, and industrial thermometry.

The National Institute of Standards and Technology is an agency of the U.S. Department of Commerce. 